\title{
Development of Detailed Distributed Urban Drainage Models Using Remote Sensing and GIS Data
}

\author{
by \\ Moh Moh Lin Khin \\ BEng, Ryerson University, Canada, 2012 \\ A thesis \\ presented to Ryerson University \\ in partial fulfillment of the \\ requirements for the degree of \\ Master of Applied Science \\ in the Program of Civil Engineering
}

Toronto, Ontario, Canada, 2015

C)Moh Moh Lin Khin 2015 


\section{AUTHOR'S DECLARATION FOR ELECTRONIC SUBMISSION OF A THESIS}

I hereby declare that I am the sole author of this thesis. This is a true copy of the thesis, including any required final revisions, as accepted by my examiners.

I authorize Ryerson University to lend this thesis to other institutions or individuals for the purpose of scholarly research.

I further authorize Ryerson University to reproduce this thesis by photocopying or by other means, in total or in part, at the request of other institutions or individuals for the purpose of scholarly research.

I understand that my thesis may be made electronically available to the public. 


\title{
Development of Detailed Distributed Urban Drainage Models \\ Using Remote Sensing and GIS Data
}

\author{
Master of Applied Science 2015
}

Moh Moh Lin Khin

Civil Engineering Ryerson University

\begin{abstract}
Surface runoff source control such as Low Impact Development (LID) techniques are being used as retrofit options for older developed areas that lack available land to implement conventional practices such as stormwater management ponds. The complexity of the catchment area requires detailed distributed urban drainage models, which need high resolution land cover information, to accurately estimate the benefits that LIDs provide. This thesis explores the use of high resolution WorldView-2 satellite image in urban drainage modelling. A proposed two-stage image classification method achieved $83 \%$ in image classification accuracy. The classified image was then used to model streets, where the drainage is provided by curb and gutter, roadside ditches and LID. The developed urban drainage models gave comparable but mixed results for different drainage systems compared to the observed runoff data and Geographic Information System (GIS)-developed models. This research findings provide guidance to modellers in developing detailed distributed urban drainage models.
\end{abstract}




\section{Acknowledgements}

Firstly, I would like to thank my two supervisors, Dr. Ahmed Shaker and Dr. Darko Joksimovic. Their collaborative project made this thesis complete. With your knowledge, experience and expertise, both of you guided not only on this thesis, also to my personal and professional development as well. Thank you very much for being available to have long meetings over this two and a half years.

This project has also involved image processing, and this would never have been possible without Dr. Wai Yeung Yan's help from selecting the most suitable image from the archive and suggesting to try out several trials in the first round of doing image classification. I also like to acknowledge Credit Valley Conservation (CVC) for providing data for this research. Particularly, Amna Tariq and Lana Durham from CVC for taking time to answer my questions.

I would like to express the gratitude to my examining committee: Dr. James Li and Dr. Songnian Li for reviewing my thesis and providing constructive feedback, and Dr. Joseph Chow for chairing my oral exam.

I like to say thank you to my friends (none mentioned, but you know who you are). Any job would be unbearable without friends, who are always ready to celebrate every milestone I made.

Lastly, I would like to specially thank my family and relatives for their assistance and support during my studies. This thesis is dedicated to them. 


\section{Table of Contents}

AUTHOR'S DECLARATION FOR ELECTRONIC SUBMISSION OF A THESIS .......................................... ii

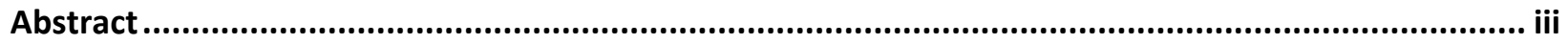

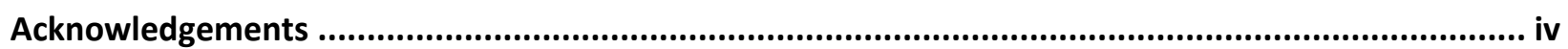

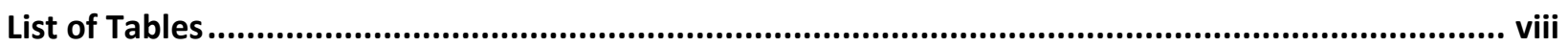

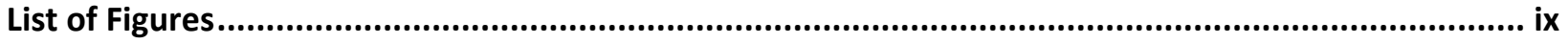

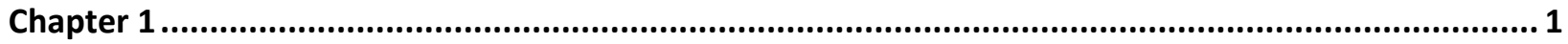

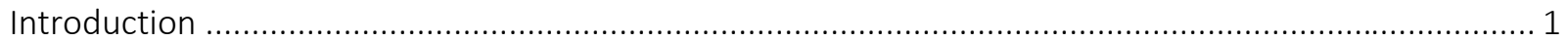

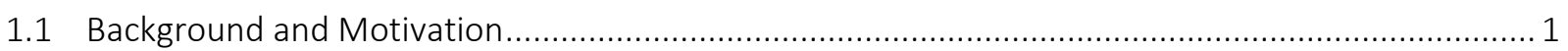

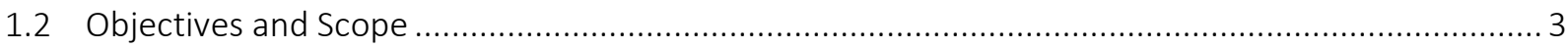

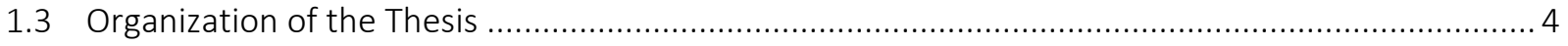

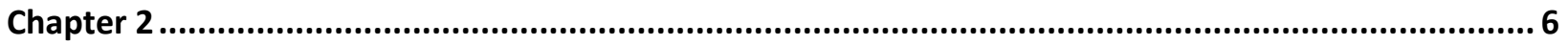

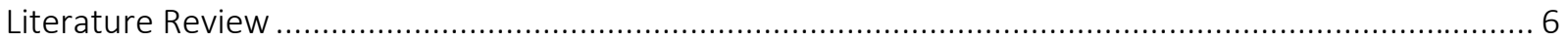

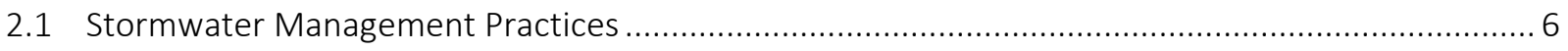

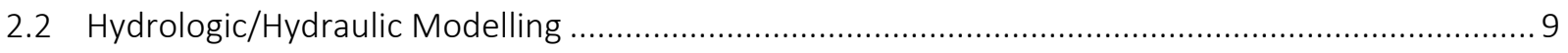

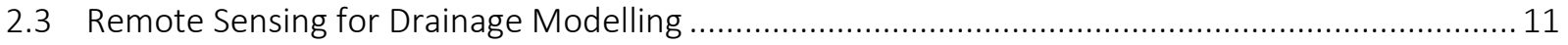

2.4 Developments to Satellite Sensors and Image Classification Methods ....................................... 13

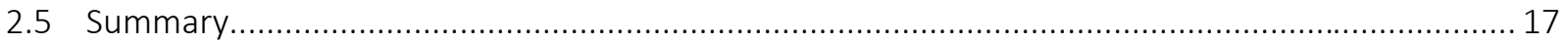

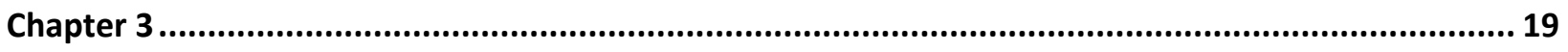

Utilization of Remote Sensing Technique in Urban Drainage Modelling ............................................ 19

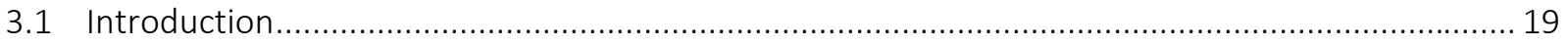

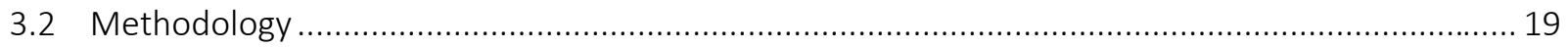

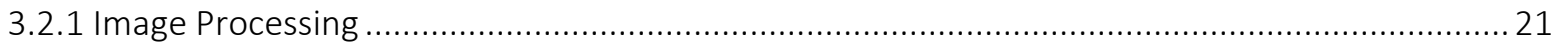

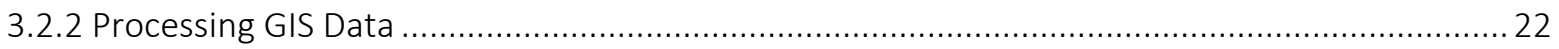

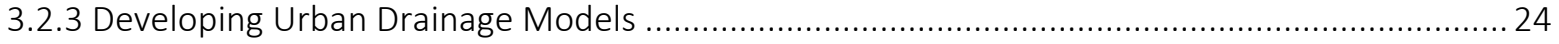

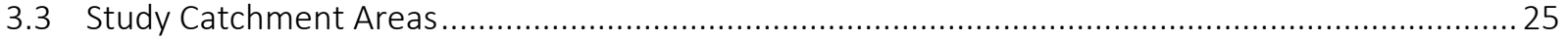

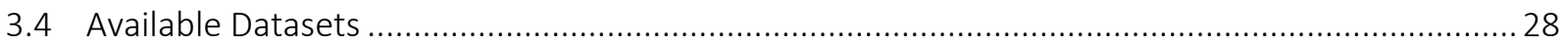

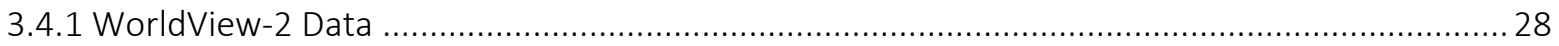




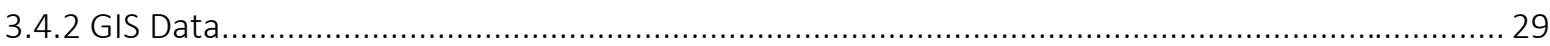

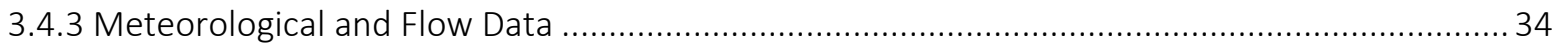

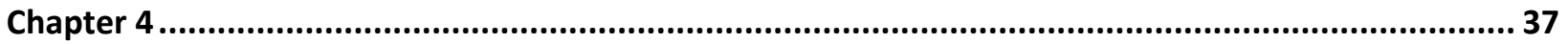

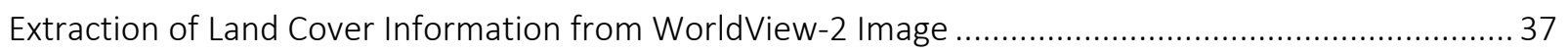

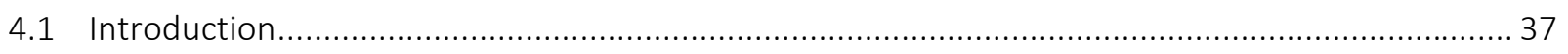

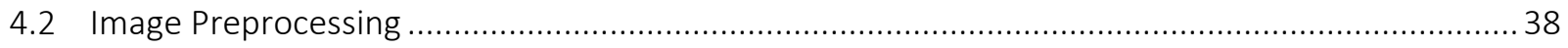

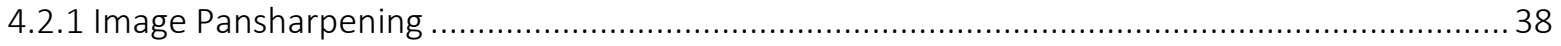

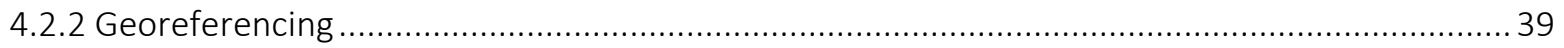

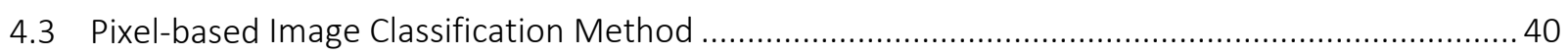

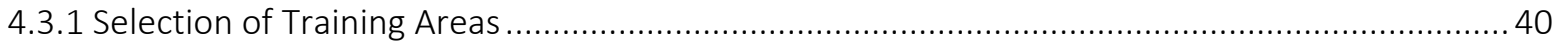

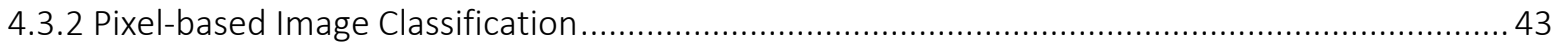

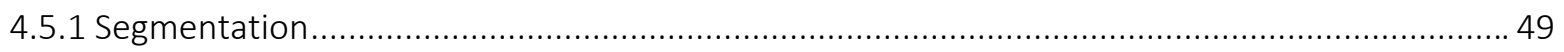

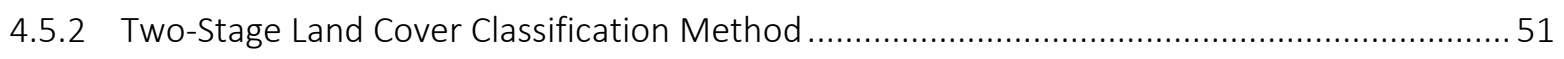

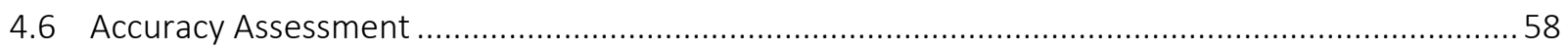

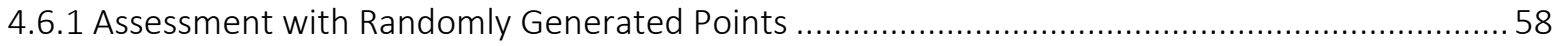

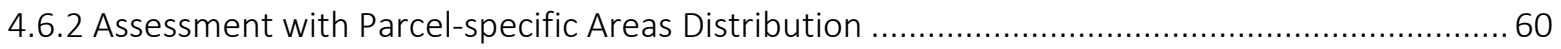

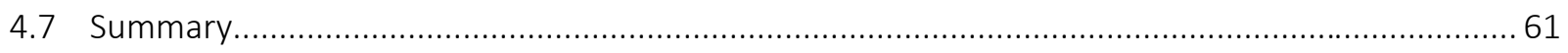

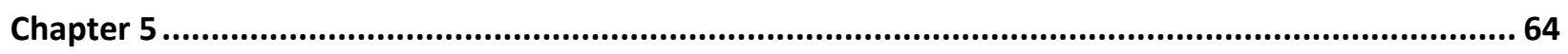

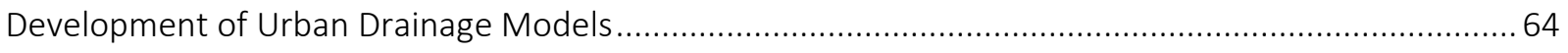

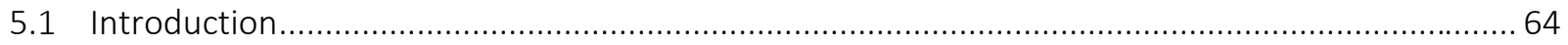

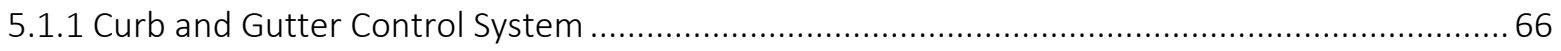

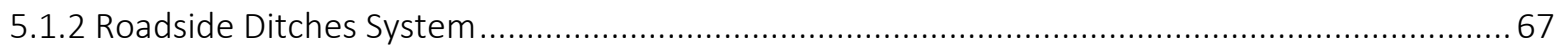

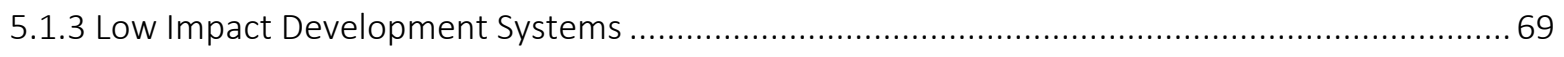

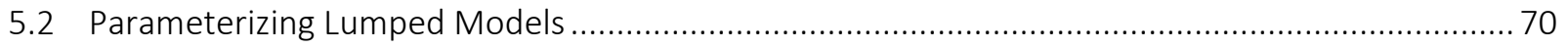

5.3 Constructing Detailed Distributed Homogeneous-area Models ............................................... 72

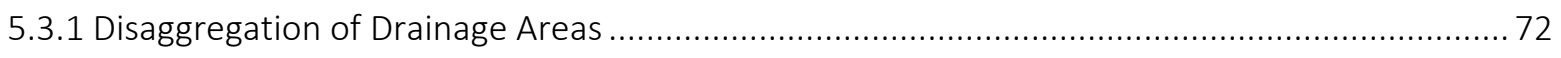

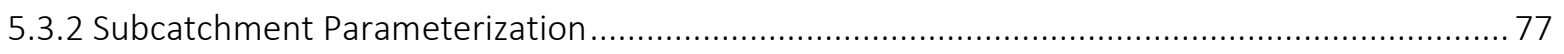

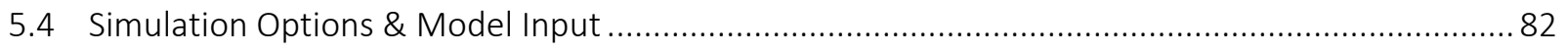

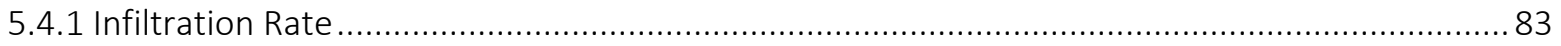

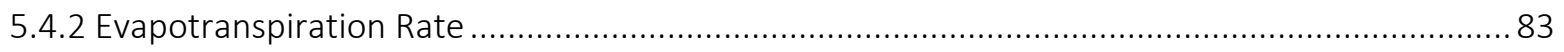

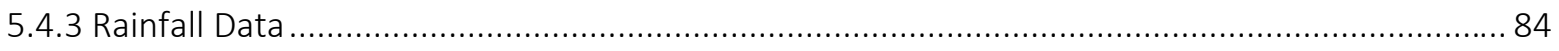




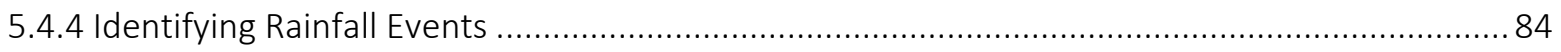

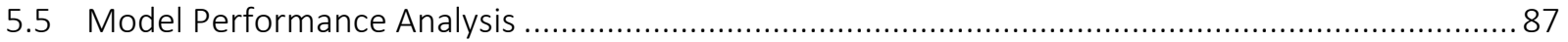

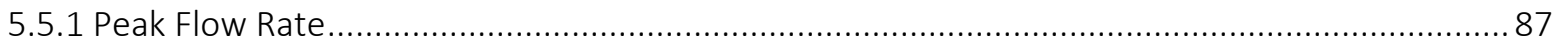

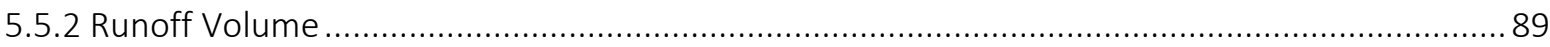

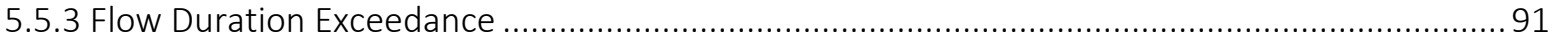

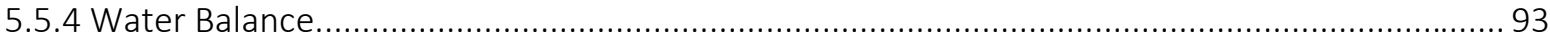

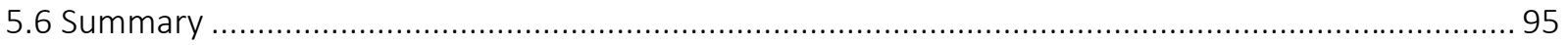

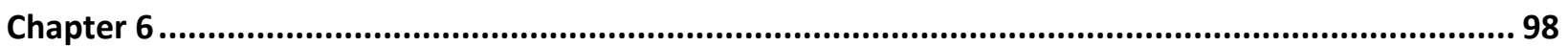

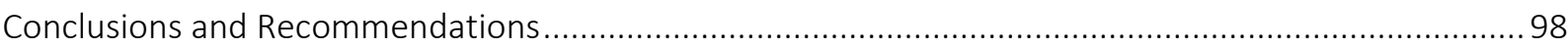

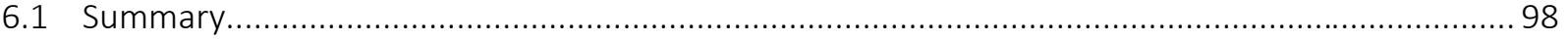

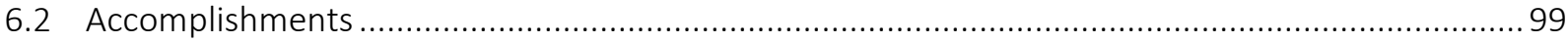

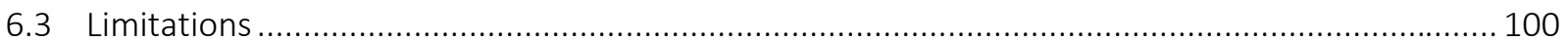

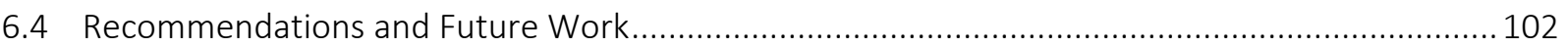

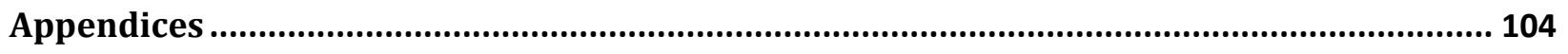

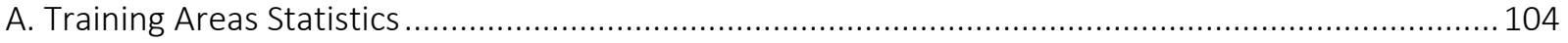

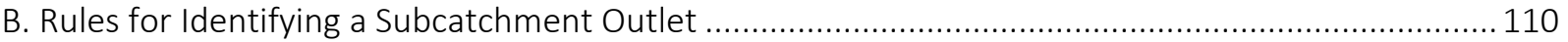

C. Summary of Monitored Rainfall Events in Excess of 30mm....................................................... 115

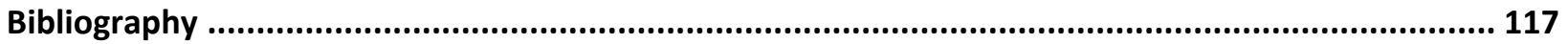




\section{List of Tables}

Table 3-1 Attributes of Available GIS data

Table 4-1 Error Matrix of the Maximum Likelihood Classification Result for Image1 …...........................44

Table 4-2 Error Matrix of the Maximum Likelihood Classification Result for Image2 .............................. 44

Table 4-3Error Matrix of the Two-stage Classification Result for Image1 ...............................................59

Table 4-4 Error Matrix of the Two-stage Classification Result for Image2 ….........................................60

Table 4-5 Total Area Distribution of Study Catchments .......................................................................... 62

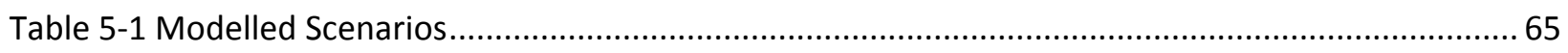

Table 5-2 Properties of the Subcatchments Used in Lumped Models ................................................... 72

Table 5-3 Hydrologic/hydraulic Parameters Assigned for Each Land Cover Type .................................... 77

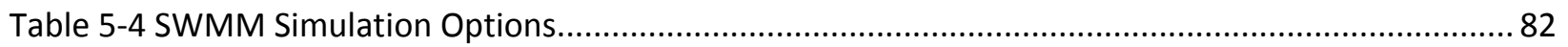

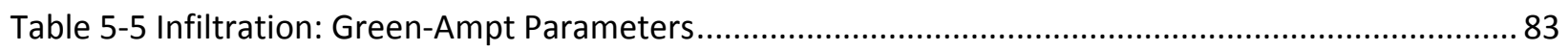

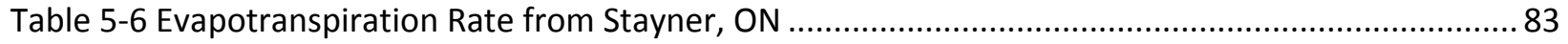

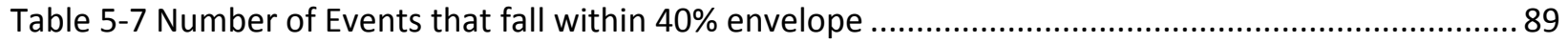

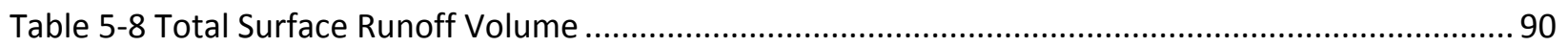

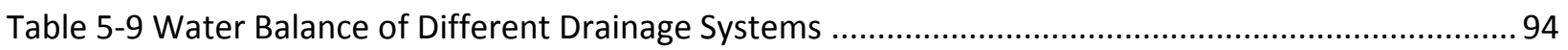




\section{List of Figures}

Figure 2-1 Example of LIDs (a) Porous Pavement and (b) Bioretention ............................................... 8

Figure 2-2 A Comparison of Information Contained on (a) 10m and 0.5m Images................................ 15

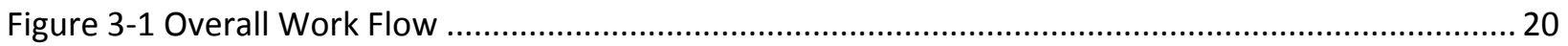

Figure 3-2 Conveyance System: (a) Roadside Ditch with Culvert and (b) LIDs .......................................26

Figure 3-3 A Series of LID - Road Retrofit Project ............................................................................ 26

Figure 3-4 Locations of Study Catchment Areas .................................................................................... 27

Figure 3-5 Graphical Presentation of Bands and their Wavelength of WorldView-2 Image ....................29

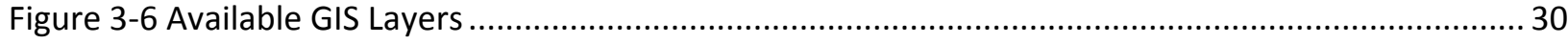

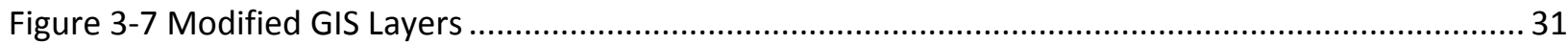

Figure 3-8 Digital Elevation Model for Study Catchment Areas ............................................................. 34

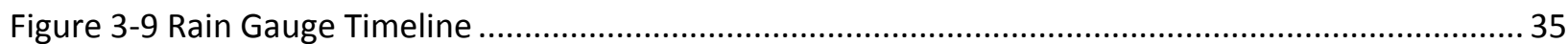

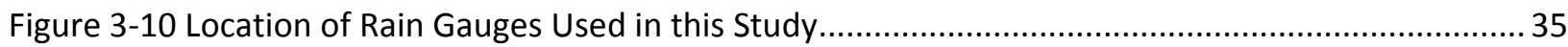

Figure 3-11 Location of the Three Study Catchments and Flow Monitoring Locations ............................36

Figure 4-1 WorldView-2: (a) Multispectral, (b) Panchromatic, (c) Pansharpened images ....................... 39

Figure 4-2 GIS Land Cover Data Laid Over: (a) WorldView-2 Image (b) Orthoimage ............................. 40

Figure 4-3 (a) Same Colour of Road, Driveway and Parking Lot (b) Different Colours of Rooftops ........... 41

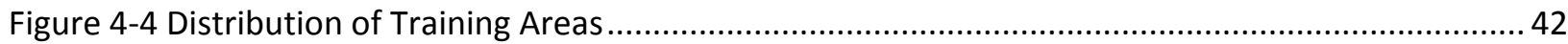

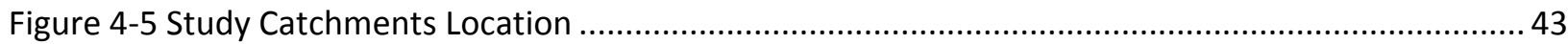

Figure 4-6 Pixel-based Maximum Likelihood Classification Result (a) Image1 (b) Image 2...................... 44

Figure 4-7 Brightness Values of Training Areas at Each Band............................................................. 45

Figure 4-8 Separability of vegetation and non-vegetation at different NDVIs ....................................... 47

Figure 4-9 Subset of WorldView-2: (a) SUM 732 band (b) SUM753 band................................................48

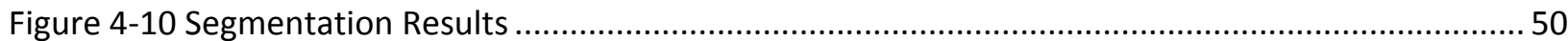

Figure 4-11 (a) Brightness Values of Vegetation vs. NonVegetation ........................................................ 52

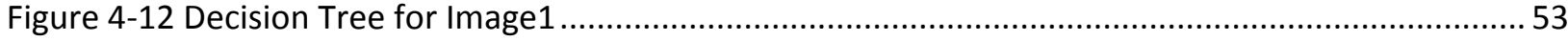

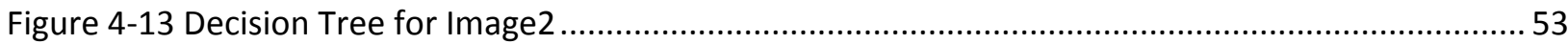

Figure 4-14 A Topological Rule Applied in the Second-stage of the Image Classification .........................55

Figure 4-15 First-stage Classification Result -Image1 .............................................................................. 56

Figure 4-16 Two-stage Classification Result -Image1 …..................................................................... 56 
Figure 4-17 First-stage Classification Result -Image2

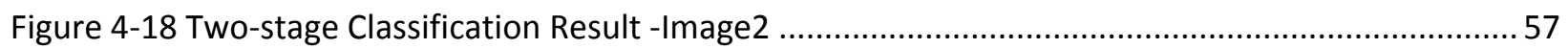

Figure 4-19 Percent Imperviousness Differences between Two Sources of Data.

Figure 5-1 A Conceptual Representation of Roadside Ditches as Swales .............................................. 68

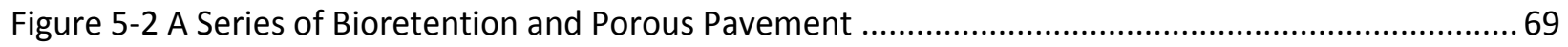

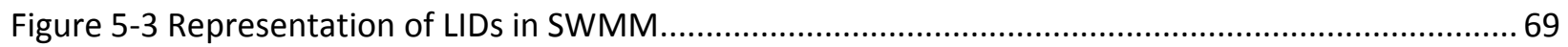

Figure 5-4 Detailed Distributed Homogeneous-area Models of Curb \& Gutter System ........................... 74

Figure 5-5 Detailed Distributed Homogeneous-area Models of Roadside Ditches and Curb \& Gutter ..... 75

Figure 5-6 Detailed Distributed Homogeneous-area Models of LID Systems ........................................ 76

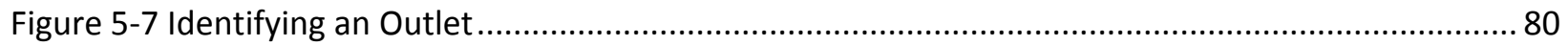

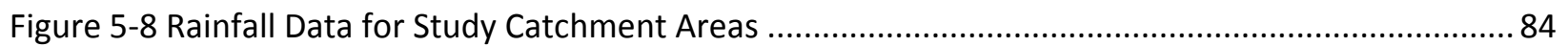

Figure 5-9 Observed Rainfall vs Runoff Depth of a Curb \& Gutter System ............................................. 85

Figure 5-10 Observed Rainfall vs Runoff Depth of a Combined System .................................................. 86

Figure 5-11 Observed Rainfall vs Runoff Depth of a LID System .......................................................... 86

Figure 5-12 Simulated vs. Observed Peak Flow Rate- Curb and Gutter Control (LV1) ............................. 88

Figure 5-13 Simulated vs. Observed Peak Flow Rate- Combined System (LV2) .................................... 88

Figure 5-14 Simulated vs. Observed Peak Flow Rate- LID System (LV4) ................................................. 89

Figure 5-15 Flow Duration Curve for Curb \& Gutter System ................................................................ 91

Figure 5-16 Flow Duration Curve for a Combined System................................................................... 92

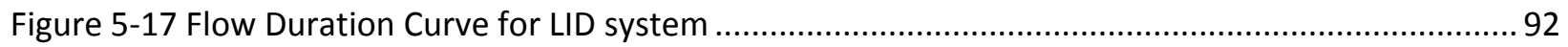

Figure A-1 Training Statistics of Vegetation and NonVegetation ........................................................ 104

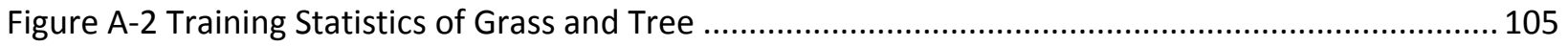

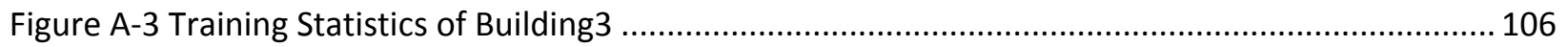

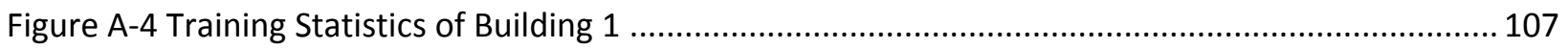

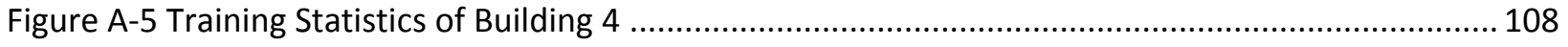

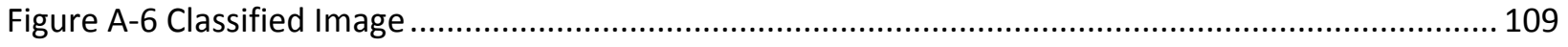




\section{Chapter 1}

\section{Introduction}

\subsection{Background and Motivation}

Globally, the increase of population and urbanization leads to the gradual replacement of naturally pervious areas with man-made impervious materials (Foley et al., 2005). Urbanization reduces the amount of infiltration and evapotranspiration, and results in an increase of stormwater runoff, downstream flooding, erosion and degradation of receiving water bodies (Hatt et al., 2004). To mitigate the negative effects of urbanization, there has been an increasing interest in stormwater source control measures in recent years. Source controls such as Low Impact Development (LID) techniques are potentially attractive as retrofit options for older developed areas that lack available land to implement conventional measures such as stormwater management ponds. Some of the municipalities in Canada already have implemented different forms of LID with a goal of maintaining the predevelopment hydrologic conditions (Dietz, 2007). Examples of LID include porous pavements, bioretention, rain gardens, green roofs and bioswales. LID manages stormwater as close to its source as possible by modifying small areas located within the public right-ofway and/or on private properties throughout the watershed. Moreover, LIDs can 1) create more aesthetically pleasing neighbourhoods, 2) decrease stormwater runoff by having a storage medium underneath, 3) improve groundwater recharges and evapotranspiration, 
and 4) improve water quality since pollutants are removed as runoff passes through the filtering medium.

Before implementing any LID projects, running a simulation model is a way to predict the benefits that LIDs may provide. Simulation results from a validated model could be used in making decision for LID techniques implementation in future developments instead of doing a costly long-term monitoring support analysis. Since the goal of LID projects is to mitigate the adverse hydrologic and water quality effects of urbanization, the LID performance is assessed in terms of the achieved reduction in runoff volume and peak flow rate, as well as water balance restoration. Elliott and Trowsdale (2007) reviewed the existing stormwater models, and reported Storm Water Management Model (SWMM) as one of the applicable models to assess the LIDs performance. SWMM is widely used to develop detailed models for planning and designing purpose. In SWMM, catchments are spatially distributed and overland flow can be routed between catchments. That is specifically beneficial to represent LIDs explicitly. By explicitly representing LID areas occupying $100 \%$ of a catchment, it makes easier for novice modellers to assign required hydrologic/hydraulic parameters. To represent spatially distributed catchments in detailed, field-surveying, Geographic Information System (GIS) data and remote sensing techniques are considered as viable sources to obtain land cover information in detail.

Field surveying is labour intensive and time consuming. Therefore, it is not a feasible method to collect detailed information for a large study area. Similarly, GIS datasets can be developed through digitization of aerial photographs that is a time-consuming process. Therefore, GIS data is not available for every urbanized area but satellite imageries can be 
obtained for any part of the world. Satellite images capture the most recent information accurately with frequent update. This has been demonstrated initially on coarse resolution imageries since the launch of first satellite sensor, Landsat, in 1972. With the advancement of satellite sensors, satellite derived topographic information is becoming more detailed, where very high resolution images provide information in sub-metre. However, traditionally used pixel-based classification methods do not produce the detailed information at high accuracy. Therefore, different classification methods such as object-based classifiers, rulebased classifiers etc., have been replacing pixel-based classification method in classifying very high resolution satellite images (Sugumaran et al., 2003; Walter, 2004; Guo et al., 2007; Liu et al., 2008; Blaschke, 2010).

As resources required to collect and update GIS and remote sensing data differ, three scenarios were presented by developing the following models in SWMM: 1) detailed distributed models using the information derived from satellite images and 2) detailed distributed models using sufficient GIS data. In contrast to the detailed distributed models, the third scenario, 3) lumped models were also developed to make a model performance comparison between lumped and detailed distributed urban drainage models.

\subsection{Objectives and Scope}

Spatially varying distributed drainage model development has been driven by technology advancement, which was difficult or even impossible to develop due to the restriction of finescale data acquisition and computation resources in the past. The goal of this study is to 
develop detailed distributed urban drainage models by utilizing the land cover information from remote sensing data. In particular, the objectives of this thesis are:

1) to develop and evaluate a two-stage image classification technique using WorldView-2 image in order to automatically extract land cover information,

2) to develop methodologies for parameterization of detailed distributed urban drainage models using the information from objective 1 ,

3) to assess the performance of the developed models by comparing their results against the observed data from monitored catchments that have different drainage systems.

The scope of the thesis includes the development of detailed distributed urban drainage models for three drainage systems 1) curb and gutter control, 2) roadside ditches and 3) LIDs (porous pavement and bioretention) systems using the land cover information from two sources. The first one being the GIS land cover information from the City of Mississauga, which was collected through Ryerson University's Library. However, GIS data is not always available or the available GIS data might be collected for other purposes; so, they are not readily available to develop SWMM. Therefore, an alternative approach to extract land cover information was demonstrated by using remote sensing data, WorldView2 image. The developed models performance were analyzed by comparing with the monitored runoff quantity data, which were available from 2010 -2013 through Credit Valley Conservation (CVC).

\subsection{Organization of the Thesis}

This thesis is organized into six Chapters. Chapter 1 presents the background of stormwater management issues, introduces LIDs and their benefits, and advantages of modelling LID 
areas explicitly. A viable source to extract detailed land cover information is also introduced. The chapter is summarized with the objectives and scope of the thesis.

Chapter 2 provides the background knowledge linking the research area of remote sensing and urban drainage modelling. More specifically, it discusses the trends of the scale of hydrologic models being introduced, and the complexity of data required for different scales of models. The viable sources to retrieve such detailed information, remote sensing data, are also introduced. Then problems associated with classifying urban areas to extract land cover information are discussed by providing the results of a literature review of the existing methods.

Chapter 3 introduces the study catchment areas and presents the methodologies to achieve the objectives set in Chapter 1. Available datasets for the development of urban drainage models are also described. A rationale behind the modification of existing GIS layers is discussed, and the procedures carried out to produce modified GIS layers are illustrated.

Chapter 4 proposes a two-stage classification method for image processing. The results of the proposed method and traditionally used pixel-based method are compared to emphasize the improved accuracy of a proposed method. The imperviousness area distribution at lot-level derived from the classification results is compared against the modified GIS layer.

Chapter 5 utilizes the outputs of Chapter 4 and the modified GIS layer, and presents methodologies for the development of SWMM for three drainage systems. The developed models performance are compared against the observed runoff data. Chapter 6 specifies the key research findings, limitations, recommendations and future work. 


\section{Chapter 2}

\section{Literature Review}

\subsection{Stormwater Management Practices}

Water quality and quantity issues associated with urbanization have been well documented since the rise of urban land cover. For example, Owens and Walling (2002) reported that urban sources of pollution and total phosphorous content degrade the water quality at lakes or streams. The studies of White and Greer (2006) and Jacobson (2011) showed that decreases of natural pervious land covers (wetlands, forests) results in less groundwater recharges and more runoff. White and Greer (2006) studied the streamflow characteristics with reference to the land covers over the period of 1966 -2000 using historic aerial photographs. They concluded that generation of runoff volume increases proportionally with the increases of built-up areas, and high frequency floods occurrences with the greater impervious areas. Such studies promoted stormwater management practices to adapt for ongoing needs since stormwater management has been focused to convey stormwater runoff offsite quickly using piped networks and end-of-pipe control at the outfall, historically. 
Stormwater management practice has been evolved with the awareness of water quality issues in early 1990's. In Ontario, Canada, Ministries of Environment (MOE) and Natural Resources (NMR) mandate water quality to protect and enhance surface and ground water resources (MOE-MNR, 1991). Traditionally used curb and gutter controls are being replaced by ditches, which enhance infiltration and runoff quality, to achieve water quality and quantity control targets (Li et al., 1998; D’Arcy and Frost, 2001). End of pipe controls such as dry ponds, wet ponds, infiltration drains etc., were constructed mostly in early 1990's. These controls are commonly termed as urban Best Management Practices (BMPs). The purposes of BMPs are: to detain water during the wet weathers, remove pollutants by settling, and subsequently release relatively clean rainwater to the outlet (Montalto et al., 2007; Davis, 2008).

Researchers predict that urbanization is continue to grow over the next 25 years. It is projected that already developed areas, for example California, are to increase by $98 \%$ (Alig et al., 2004). The shortage of available land in urban areas has restricted the implementation of BMPs. The regulatory requirements also pertain to treating the stormwater quality. For example, MOE (2003) requires that total suspended solid (TSS) loads be reduced $80 \%$ at the source by using green infrastructures, where the degree of subwatershed urbanization is high. Some practices of source control include downspouts disconnection, implementing LID, etc. Unlike traditional drainage systems, LID has the potential to address water quality and quantity issues without transferring problems further downstream. LIDs are being incorporated with a goal of maintaining the pre-development hydrologic conditions by utilizing infiltration method (Dietz, 2007). Example of LID includes porous pavements (Fig.2-1(a)) and bioretention (Fig. 2-1(b)). LIDs manage runoff volume 
at the source, and they promote evapotranspiration and infiltration rate. Infiltrated water can be temporarily stored, treated, and discharged through perforated pipes to water conveyance system. Therefore, three main benefits of LIDs can be summarized as they are able to 1) filtrate sediments and pollutants, 2) delay runoff peak, and 3) reduce runoff volume.

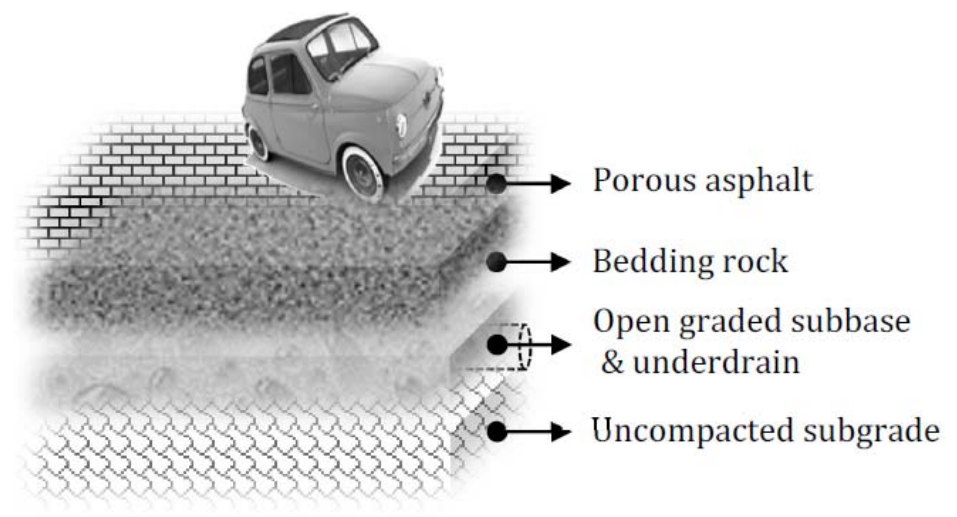

(a)

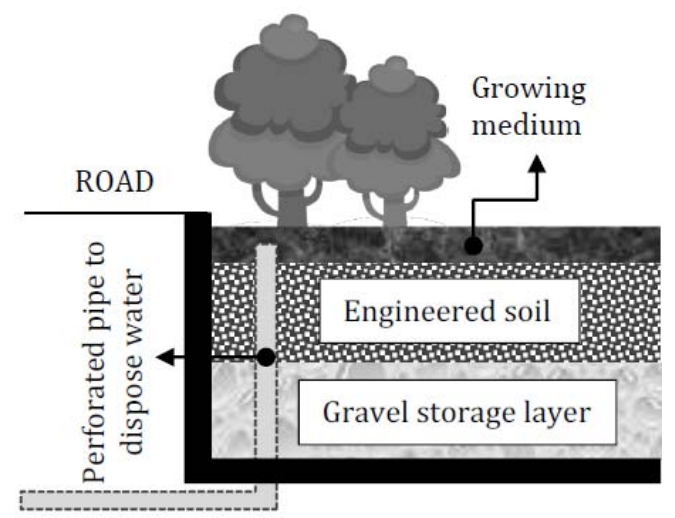

(b)

Figure 2-1 Example of LIDs (a) Porous Pavement and (b) Bioretention

The design of LIDs is subject to the native soil types. The system may be designed with or without underdrain pipes. In the case of having saturated soil types, partial infiltration and underdrain is included. Otherwise, LIDs may be designed without an underdrain for full infiltration. An alternative to traditional concrete or asphalt pavement, porous pavements are used for driveways and parking lots, where there is light traffic. Due to the fact that porous pavements have void areas between interlocking, it allows water to infiltrate through bedding then water is conveyed to the stormwater pipes.

Bioretention utilizes surface areas for planting, where plants help to remove pollutants from runoff. Runoff from road is conveyed as sheet flow to the growing medium 
of bioretention. Then, engineered soil consists of sand bed, organic layer etc., treats the runoff which gradually infiltrates. Existing studies reported that LIDs are the most effective retrofit strategy for stormwater management in urban areas (Rushton, 2001; Hood et al., 2007). As the practices evolved from implementing end-of-pipe dry and wet ponds, infiltration drains and swales to clustered LID, modelling scale of urban drainage models has also been transformed from watershed level to small scale at lot-level to predict the performance of individual stormwater control systems.

\subsection{Hydrologic/Hydraulic Modelling}

The impact of impervious surfaces on the hydrological cycle is well studied, and the Rational method has been widely used to calculate peak runoff volume since the late $19^{\text {th }}$ century (Canters et al., 2011). The Rational method does account for different types of land cover; however, the simplified method has a lot of limitations including a constant distribution of rainfall and the calculated runoff is directly proportional to the rainfall (Canters et al., 2011). In larger catchments, these simple "linear" models have been shown to work (Beven, 2011). In reality, hydrological processes are non-linear and these parameters should not be simply averaged. Hence, spatial and temporal resolution were considered in further studies.

Research conducted by Wilson et al. (1979), Abbott et al. (1986) and Refsgaard (1997) also found that a variation of catchments' hydrologic response impacts on the simulation results such as runoff volume and peak flow rate at a watershed level. With the increasing awareness of the problem of nonlinearity, a feasible disaggregation of the drainage area has been done with the data and computational resources available over the 
last four decades (Canters et al., 2011). Therefore, study catchments have been disaggregated into individual subcatchments based on the spatial variability in land features. To fulfill the needs of spatially varying data in accurate digital representations, GIS was used as a valuable tool to generate spatial information in hydrologic modelling (Pullar and Springer, 2000). The primary GIS data integrated in hydrologic modelling is the digital elevation model (DEM) to describe topography of catchments in the late 1980s (Moore et al., 1991; Sui and Maggio, 1999). Depending on the grid size of DEM, early attempts of spatially distributed models were mostly grid-based models (Montgomery and Foufoula-Georgiou, 1993; Zhang and Montgomery, 1994; Turcotte et al., 2001). These studies developed processes to delineate catchments and flow routing towards the steepest direction based on DEM at watershed scale.

Beven (2001) discussed the problem of uniqueness in defining catchments; he pointed out that a model should account the effects of local heterogeneity. As more than one land cover types fall within a defined catchment area in grid-based models, hydrologic parameters were averaged. Therefore, it is useful to implicitly consider the effect of heterogeneity and non-linearity of catchments characteristics. Hence, to address the uniqueness of the subcatchment, homogeneous-area models have been disaggregated based on physiographic and climatic characteristics (Abida and Ellouze, 2006). In an effort to take account of the specific characteristics of the subcatchment areas, the development of distributed homogeneous-area models have been studied extensively. However, such coarse-scale homogeneous-area models are still not appropriate for urban settings, since in any typical urban areas it is common to see many patches of heterogeneous land cover types. 
In the past, the impediment of developing detailed urban drainage model can be regarded by lacking the automatic data acquisition of high resolution data to feed in hydrologic modelling (Bellal et al., 1996). That thus paves a way to use remote sensing data to serve such needs. Since very high resolution satellite images capture smaller ground features accurately, high resolution data to feed in hydrologic modelling can be produced by executing image classification techniques on satellite images. With the cost of requiring detailed land cover information and computational power, more "realistic" models have been developed than ever.

\subsection{Remote Sensing for Drainage Modelling}

Remotely sensed earth observation data has been used widely in urban environmental studies and some of the applications include: monitoring the biophysical environment using the digital change detection techniques (Coppin and Bauer, 1996); assessing urban heat island effect due to urban expansion (Weng, 2009); and land cover mapping to extract topographic information (Yang et al., 2003).

In particular for urban drainage modelling, satellite remote sensing has been demonstrated as a viable approach for acquiring topographic information in a large spatial extent with the development of different image classification approaches. Detailed methodology of image classification processes and their application in urban drainage modelling will be discussed in the next section. In general, the merits of using remote sensing data in hydrology studies can be summarized as: 1) data captured by airborne or satellite sensors usually have high spatial resolution, which can provide precise location of specific 
land features for urban drainage modelling, e.g. surface water changes, urban growth, snow cover, and impervious surface extraction (Lu and Weng, 2009); 2) remote sensing data provides multi/hyperspectral information that can be used for land cover characterization (Nosetto et al., 2012) and soil moisture determination (Ahmad et al., 2010); and 3) specific remote sensors can offer additional information apart from general mapping purpose, such as determination of surface heat fluxes from thermal sensors (Song et al., 2012). Extraction of land cover patterns and impervious surface extent are of particular importance to the development of detailed drainage models in a complex urban environment. Thus, high resolution satellite data are being acquired to serve in land cover classification. Particularly in water quality and quantity modelling, some of the studies demonstrated the use of remote sensing data to retrieve land cover information. For example, Elgy (2001) used airborne data to classify land cover types which was aimed to be used in urban drainage modelling; Thanapura et al. (2007) extracted the runoff coefficient from QuickBird and GIS vector layers; water quality models were developed by Ha et al. (2003) from Landsat TM multispectral bands and Korea Multi-Purpose Satellite (KOMPSAT) panchromatic data, and Lee et al. (2010) from QuickBird satellite imagery.

However, there is a lack of study on utilizing remote sensing data to develop detailed distributed urban drainage models to assess LIDs performance. A study that used Light Detection and Ranging (LiDAR) data to identify the optimum location of LID implementation was carried out by Jensen et al. (2010). Apart from this study, remote sensing data was not utilized to model LID-implemented area and assess the performance of LIDs. Evaluation of LID performance was demonstrated in Xiao et al. (2007), where in-situ measurement was conducted to obtain physical parameters of a site. Another LID assessment study conducted 
by Smith et al. (2005) used GIS data to determine land cover types. In-situ measurement gives almost the true representation of the study catchments; however, it is time consuming and not a practical approach for a large extent. An alternative to doing field surveying is using GIS data; yet, not every municipality has sufficiently complete GIS data. To overcome these issues, utilizing remote sensing data in urban drainage modelling is a practical approach that requires less resources. The advancements in satellite sensors make the automatic acquisition of high resolution data possible and bring the disaggregation of hydrologic models to the next stage.

\subsection{Developments to Satellite Sensors and Image Classification Methods}

The developments of satellite sensors can be commonly introduced in terms of spatial resolution and spectral resolution. Spatial resolution can be described as the size of a pixel, which dictates the smallest size of objects that can be seen on an image - in other words, how much detail is captured and what is visible to human eyes is reported as spatial resolution. Spectral resolution characterizes the type and nature of targets that are recorded by sensors in a variety of bands.

The first generation of satellite sensor, Landsat, was launched in 1972, and the users for the first-time had the opportunity to classify 30 -metre spatial resolution imageries in different bands. The advantages of image classification over visual interpretation are being able to automate the processes and get the less subjective classification results. In image classification, land cover types of interest that exist in the study areas have to be identified as training areas. A comprehensive discussion on the effect of training areas on classification can be found in Chen and Stow (2002). In general, the training areas should be well- 
distributed throughout the study area. Sources of reference to select the training areas could be a priori knowledge of the study area or purely relying on the user's recognition skills. A rule of thumb on the pixel size of the training area is defined as 10 times "the number of bands used in the classification". This process is training software to match the rest of the similar pixel to the predefined land cover types. Again, there are several parametric rules to match pixel-by-pixel, such as maximum likelihood, minimum distance, parallelepiped classification techniques, etc.

The satellite data collection has improved in moderate resolution satellites such as Landsat 7 ETM+ and SPOT 5. Improvement in this satellite generation includes the enhancement in spatial resolution, which is the ability to capture more detail of the earth's surface. Moreover, on top of having visible bands (i.e. red, green, blue), near infrared band(s) and thermal band are included in remote sensors to provide more spectral information. The development of high resolution satellite imagery has bloomed since 1999, when the first one-metre spatial resolution satellite image became available. Stow et al., (2004) and Lu and Weng (2009) used one-metre resolution IKONOS to extract urban impervious surfaces. Subsequently, QuickBird, WorldView-1 and Geoeye-1 satellite payloads were launched to provide image data with pixel size of $0.61 \mathrm{~m}, 0.50 \mathrm{~m}$ and $0.41 \mathrm{~m}$, respectively, at nadir mode.

Nowadays, users have a lot of options to choose from a variety of satellite images. User requirements and the goal to achieve from utilization of satellite image dictate which satellite image should be employed. Fig. 2-2 illustrates the rationale behind of requiring high resolution images especially in urban settings, where small heterogeneous areas are presented. As shown in Fig. 2-2 (a) if a 10-m resolution image is used, one pixel captures 
both grass, driveway, road, and car; however, Fig. 2-2 (b) shows that a 0.5-m resolution image has 400 pixels, which capture different land cover types separately. Hence, in order to improve the image classification accuracy, high resolution images seem to be more applicable. Everitt et al., (2008) conducted a comparison of image classification accuracy on QuickBird (2.4 m resolution) and SPOT 5 (10 m resolution), and reported that QuickBird gives a higher accuracy. The use of highest available resolution of satellite images supports the aims of this research, which include the accuracy assessment of the satellite derived urban drainage models intended for use without model calibration.
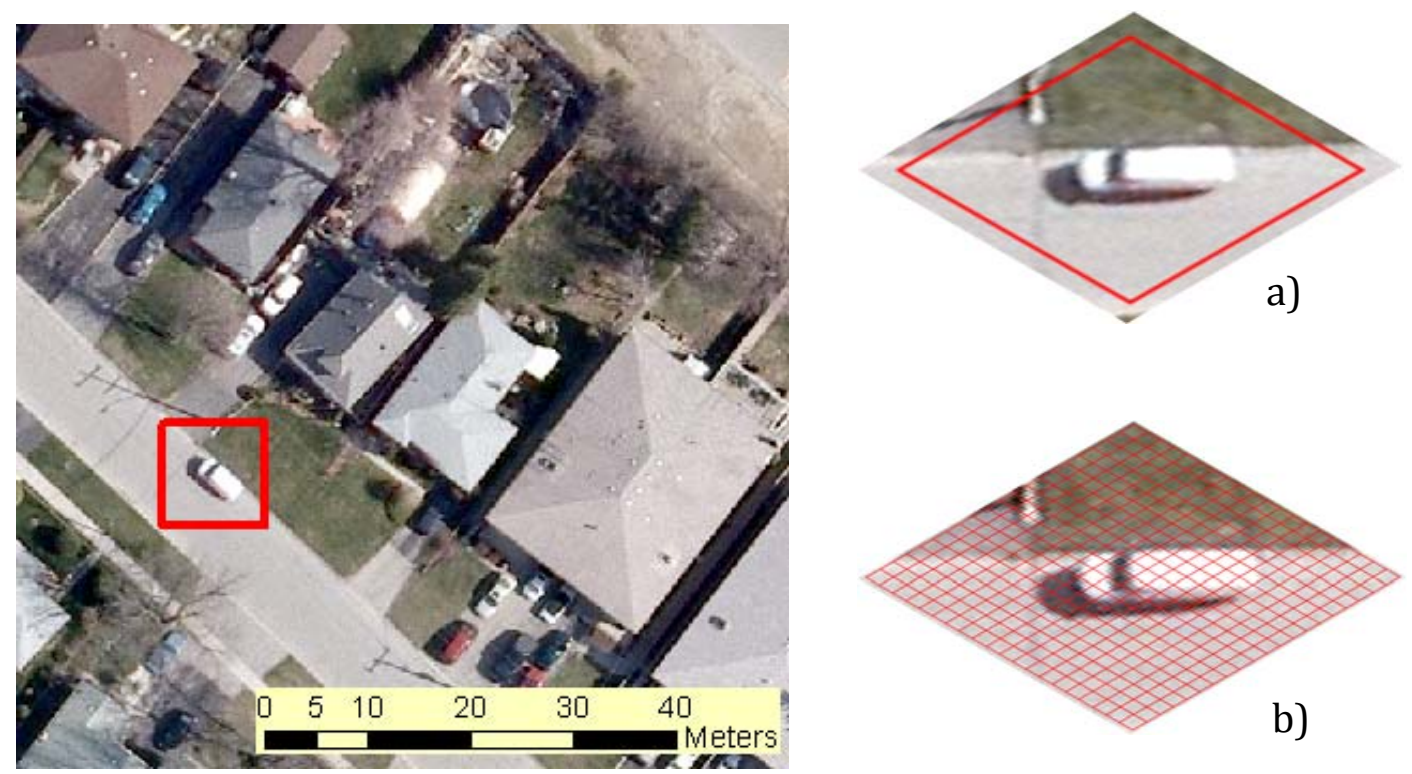

Figure 2-2 A Comparison of Information Contained on (a) 10m and 0.5m Images

One thing to note about a finer resolution of satellite images is many small objects including shadows caused by tall buildings and trees become more visible, which leads to the confusion with dark impervious surface and water bodies. Yan and Shaker (2011) reported that high resolution image may lead to the increase between-class spectral 
confusion and within-class spectral variation. Hence, traditional pixel-based classification techniques, which classify the image based on pixel by pixel, may not perform well with very high resolution satellite imagery. Also the studies of Walter (2004) and Blaschke (2010) concluded that instead of pixel-based analysis of the spectral values, spatially and spectrally similar pixels should be considered as an "object" in high spatial resolution satellite image classification. The increasing availability of very high spatial resolution imagery drove many researches to develop new classification methods such as object-based classifiers (Walter, 2004; Guo et al., 2007; Liu et al., 2008; Blaschke, 2010), rule-based classifiers (Sugumaran et al., 2003), fuzzy logic classifiers (Shackelford and Davis, 2003), support vector machines (Huang et al., 2002), and other algorithms to improve the classification accuracy.

Indeed, various factors influence the classification accuracy including the orientation of the sun, shadowing effect and the nature of the study area. Dare (2005) discussed in details the orientation of the sun and the shadow problems caused in high resolution satellite image in urban areas. The nature of the study area can be described as the type and size of the land covers. Land cover classification in urban areas particularly hinders the process due to the existence of heterogeneous land cover types in smaller scale. To aid in identifying specific features, auxiliary bands are generated by taking the correlation or proportion of the original bands of the sensor. Some of the commonly used auxiliary bands in land cover classification are Normalized Difference Built-up Index (NDBI) (Zhang et al., 2009), Normalized Difference Vegetation Index (NDVI) (Carlson and Ripley, 1997), Normalized Difference Water Index (NDWI) (Jawak and Luis, 2013) and Principal Component Analysis (PCA) (Jia and Richards, 1999). These well-established bands were derived based on the bands available from the first-generation satellite sensors. Therefore, only red, green, blue and near-infrared (NIR) 
bands were used. Since the new generation of the satellite sensors comes with more than four bands, some trial runs need to be conducted to determine the best possible combination for the specific site.

In October 2009, DigitalGlobe, Inc. launched its second generation of WorldView satellite sensor, which offers the first-ever 8-band multispectral image in $1.84 \mathrm{~m}$ pixel size, and panchromatic image with pixel size of $0.46 \mathrm{~m}$. Having the extra four spectral bands (coastal blue, yellow, red-edge, and near infra-red 2 (NIR2)) in addition to the red, green, blue and NIR bands have brought researchers' attention to employ WorldView-2 imagery in a diversity of applications. Applications of WorldView-2 imagery have been reported in mapping of urban tree species (Pu and Landry, 2012), forest biomass and carbon assessment (Eckert, 2012), and estimation of moving objects velocity (Salehi et al., 2012). In spite of the abovementioned attempts of using WorldView-2 imagery, there is a lack of evaluation on how applicable it is to use the very high spatial resolution images in urban drainage modelling, particularly in assessing LID's performance. That thus motivates us to use WorldView-2 imagery, and automate the process of retrieving land cover patterns to overcome the problem of land cover types unavailability everywhere.

\subsection{Summary}

To mitigate the negative effects of urbanization on stormwater runoff generation, source control LIDs have been implemented in several cities. Evaluating the LID-implemented areas using lumped model is challenging in parameterizing since it lumps together pervious areas, impervious areas and LIDs areas. By assuming that the whole study catchment has a uniform characteristic, all the required parameters are averaged to reflect the heterogeneity of the 
catchment area. Hence, some subcatchment parameters, such as depression storage, slope, width, etc., are estimated by the modeller and the models require calibration against monitored data.

Detailed distributed models explicitly represent a catchment as being entirely occupied by a LID, which allow a less subjective way to parameterize the models, leading to performing a model calibration becoming discretionary. Even though many studies (Paudel, 2010; Goldstein, 2011; Krebs et al., 2013; Alam, 2014) showed promising results from detailed distributed models, a transition from lumped models to detailed distributed models is not fast-moving. One of the reasons could be due to data availability of detailed land cover information since developing detailed distributed models requires the land cover information in fine resolution. Generally, land cover information is retrieved from field surveying, GIS and remote sensing data. The first two methods of data collection are not always feasible or accessible. Therefore, remote sensing data could be regarded as a potential data source that can be utilized in the development of detailed distributed urban drainage models. To overcome the usual shadow problems that are presented in very high resolution satellite images, an experimental image classification method needs to be examined for specific study areas. Therefore, in this thesis, object-based classification method that incorporates brightness values, area values and topological rules will be examined to produce land cover layers, which will subsequently be used in urban drainage modelling. Then an urban drainage model developed by using the satellite-derived information should be validated to investigate how feasible it is to use very high resolution satellite image in urban drainage modelling. 


\section{Chapter 3}

\section{Utilization of Remote Sensing Technique in Urban Drainage Modelling}

\subsection{Introduction}

This chapter introduces a road retrofit pilot project in the Lakeview neighbourhood, City of Mississauga, Ontario, Canada. To explicitly represent LID areas and to avoid having to estimate average values for hydrologic/hydraulic parameters of catchments that have different hydrologic responses, detailed distributed homogeneous-area drainage models are to be developed. These detailed models are not widely used due to the cost of requiring detailed land cover information. Hence, Section 3.2 presents a methodology to utilize remote sensing and GIS data (if available) to obtain detailed land cover information, which will then be used in developing detailed urban drainage models. Sections 3.3 describes the case study, where the methodology will be tested. Section 3.4 provides the available datasets for the case study.

\subsection{Methodology}

The methodology illustrated in Fig. 3-1 was designed to achieve the three objectives of this thesis defined in Chapter 1 . WorldView-2 image was executed by a proposed two-stage image classification method. GIS land cover data is processed for accuracy assessment of 
image classification and to complement the information extracted from the WorldView-2 image in developing SWMM. The details of how the methodology is implemented will be discussed in Chapter 4 and Chapter 5. Chapter 4 covers all the image processing details to produce land cover types that can be used in developing urban drainage models, and Chapter 5 presents the development of drainage models at different resolution (lumped and detailed distributed models) using two sources of land cover data derived from Chapter 4, and the assessment of developed models.

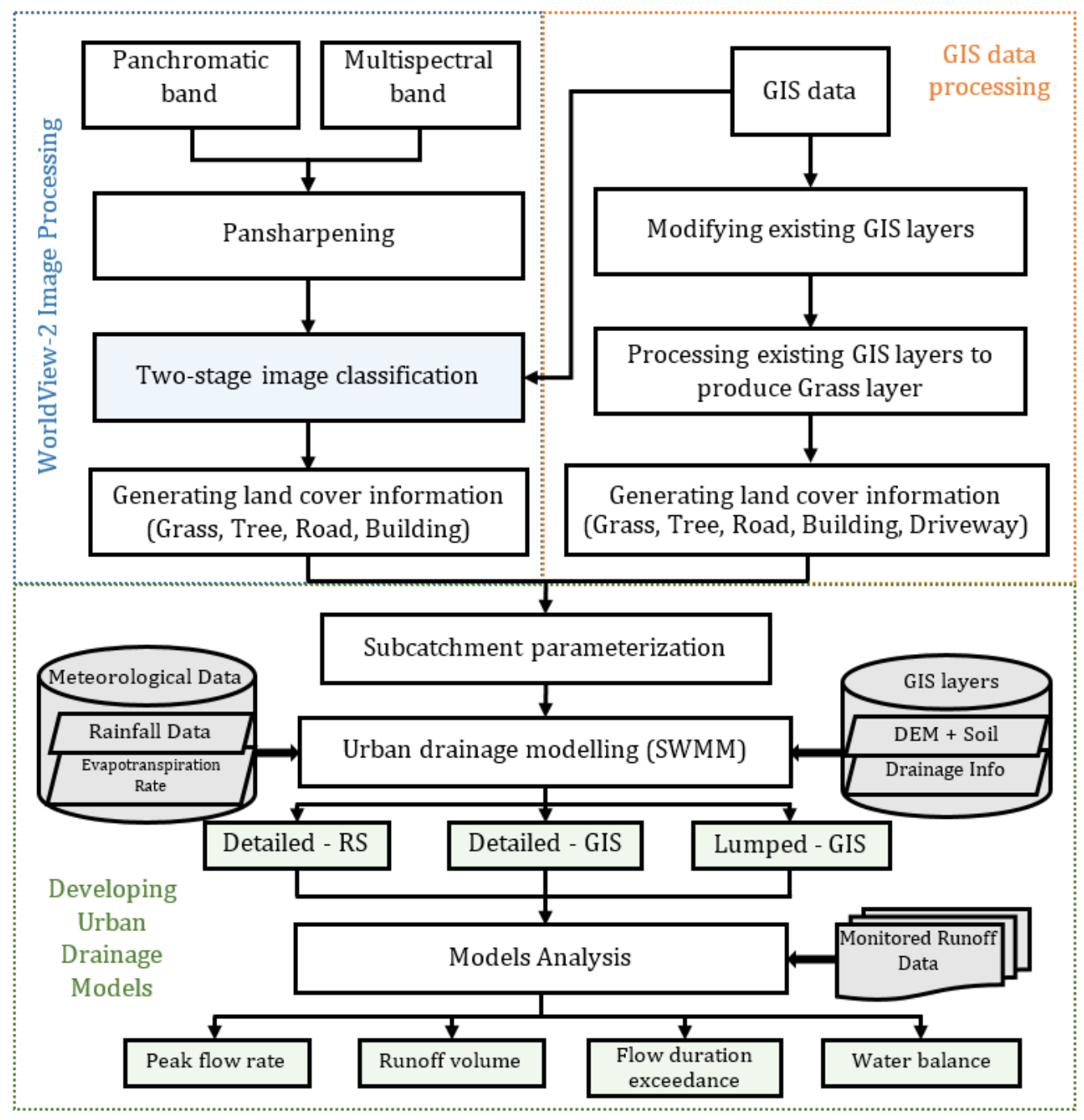

Figure 3-1 Overall Work Flow 


\subsubsection{Image Processing}

\section{- Pansharpening}

Image pansharpening is a process that uses a panchromatic image to sharpen multispectral images. For example, a WorldView- 2 satellite image comes with the panchromatic $(0.5 \mathrm{~m}$ spatial resolution) and 8-band multispectral ( $2 \mathrm{~m}$ spatial resolution) bands. To get the best possible spectral and spatial resolutions of WorldView-2 image, panchromatic image and multispectral image needed to be fused together. The pansharpened reaps the benefits of having high spectral resolution of its multispectral bands, as well as fine spatial resolution of its panchromatic band.

\section{- Two-stage Image Classification Method}

A two-stage classification method based on object-based image classification is proposed. Prior to image classification, very high resolution image was segmented as objects. Then, in the first stage of the classification, rules based on brightness values and areas were defined to form a decision tree to classify the segmented polygons into different land cover types. Auxiliary bands, which had a good separability to differentiate different land cover types, were generated since the original bands may have similar brightness values for interested land cover types. Rules were developed by analyzing the statistics of the brightness values of interested land cover types at different bands. In the second stage of the classification, following the framework as found in Liu et al., (2008) and Guo et al., (2007), topographic rules were incorporated to post-classify the initial classification result. In this study, lot boundary derived from available GIS data was utilized to define the topographic rule. 


\section{- Generating land cover information}

Typical land cover types that exist in a residential area such as grass, tree, road and buildings are to be extracted from a high resolution image. Then, the accuracy of the classified images are to be assessed in two ways. Firstly, a check was performed to determine the number of the randomly generated 500 checkpoints that were correctly classified. Using the same checkpoints, accuracy of pixel-based classification is also reported. The comparison between these two results is made to emphasize the improvement of a two-stage classification method. Secondly, percent imperviousness at lot-level was calculated using both GIS data and remote sensing data. Since one of the research objectives was to determine how applicable it is to use remote sensing data in urban drainage modelling, the parameter that has been shown to govern the generation of runoff the most: the percent imperviousness, is compared.

\subsubsection{Processing GIS Data}

\section{- Modifying existing GIS layers}

Converting Polylines to Polygons: Since the land cover GIS data were not collected solely for the stormwater management purposes (catchments need to be represented by closed polygons), some of the layers, for example: driveway layer, was represented by polylines in original GIS layer. Such layers were converted to polygons. 
Removing Overlapped Areas: Moreover, some of the overlapping areas, for instance: between sidewalk and driveway layers, was removed in one of the layers in order to avoid double counting impervious areas.

Adding Missing Topographic Features: To reduce the impact of data being collected a couple of years ago, some of the GIS layers need to be modified. For example, a few buildings may be built any time after collecting GIS data or due to human errors, some omission errors could happen in GIS data. Therefore, some missing topographic features were updated by on-screen digitization.

\section{- Processing existing GIS layers to produce Grass layer}

The original GIS data did not have a layer that represents grass. Hence, all the existing GIS layers were merged into one layer. Then, grass area within each parcel was defined by using Erase function in ArcGIS, where Input Features = parcel boundary; Erase Features = merged layer; Output feature $=$ grass.

\section{- Generating land cover information}

After processing GIS layers, land cover types were presented by the following five layers: 1 ) wooded area (tree), 2) building, 3) road, 4) driveway, and 5) grass. After producing these five land cover types in order to improve data quality, firstly, polygons were integrated if the area is smaller than $0.15 \mathrm{~m}$, which removed smaller gaps between land cover types. Secondly, as a result of Erase function to produce grass layer, more than one grass polygons within one lot were assigned same IDs in GIS. By definition, catchment in SWMM should have a unique ID if they are not connected. Hence, Multipart to single part process was executed in ArcGIS to have a unique ID for every catchment. 


\subsubsection{Developing Urban Drainage Models}

\section{- Subcatchment Parameterization}

Once subcatchments were created from GIS data and WorldView-2 data, hydrologic and hydraulic parameters are to be assigned based on the resultant of the land cover information. With reference to Rossman (2010), \% Imperviousness, Manning's n, depression storage, \%Zero-imperv parameters were assigned accordingly. Then, a set of rules was developed to identify an outlet for each subcatchment.

\section{- Urban drainage modelling using SWMM}

The primary data requirement of urban drainage models, land cover information to parameterize specific Manning's n and depression storage values, was collected from two sources: GIS data and the classification results of the WorldView-2 images. The other data required to input in SWMM include: 1) soil type to determine the infiltration rate, 2) average monthly evapotranspiration rate, 3) storm drainage infrastructure information that convey runoff, 4) digital elevation model (DEM) to identify the elevation values of all hydraulic elements in SWMM, 5) rainfall data for the period of analyses, and 6) monitored runoff data to validate the models performance.

With all these described data, two detailed distributed homogeneous-area models using land cover information from two different sources, but the same model structure and subcatchment parameterization, were developed to simulate the rainfall - runoff process. Using the GIS data, lumped models were also developed. This comparison was made to examine how the land cover variation, as determined from the two approaches, influences the hydrologic simulation results. 


\section{- Models Analysis}

The developed models were analyzed by comparing total simulated vs. observed surface runoff volume, simulated vs. observed peak flow rate, flow duration exceedance and water balance for three different drainage system. This comparison highlighted the benefits of implementing LIDs.

\subsection{Study Catchment Areas}

The Lakeview neighbourhood has drainage network comprised of curb and gutter controls, as well as roadside ditches with culvert systems that discharge directly to the Lake Ontario. Residents were concerned about ditches having ponding water after rain in this older neighbourhood. As LID projects target older residential neighbourhoods to improve their drainage systems, the City of Mississauga's Transportation and Works Department initiated a road retrofit pilot project in the Lakeview neighbourhood. Existing ditch and culvert systems (Fig. 3-2(a)) were replaced with a series of boulevard bioretention and porous pavement driveways (Fig. 3-2(b)) within the public right-of-way (ROW). Porous pavement allows water to infiltrate in small rainfall events; so, runoff may not occur. In the events of having heavy rainfall, road captures the runoff from porous pavement, conveying it through curb cuts into bioretentions as shown in Fig. 3-3. This project ensured that the neighbourhood has a proper drainage system, a reduction in runoff and an improved quality of water discharged into the Lake Ontario. This project was completed in fall 2012. Since then, CVC has monitored the performance of the LIDs by observing rainfall/runoff data at a monitoring well for LID-implemented catchment, as well as two other (control) sites, where roadside ditches with culverts system, and curb and gutter controls are still being used. 


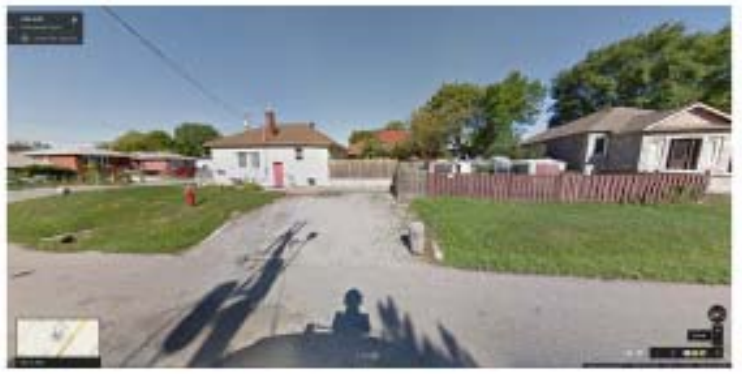

(a)

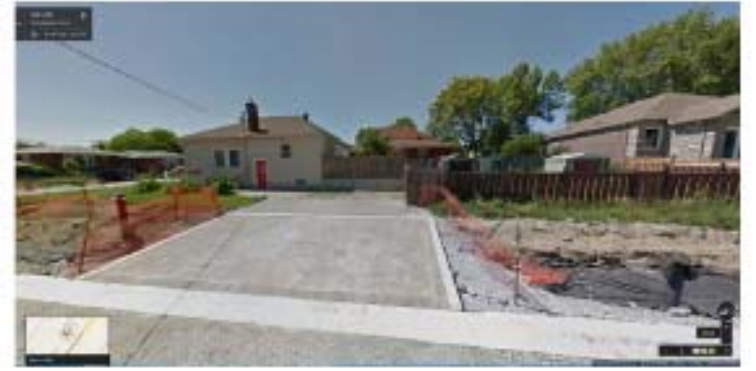

(b)

Figure 3-2 Conveyance System: (a) Roadside Ditch with Culvert and (b) LIDs

(Source: Google Streetview)

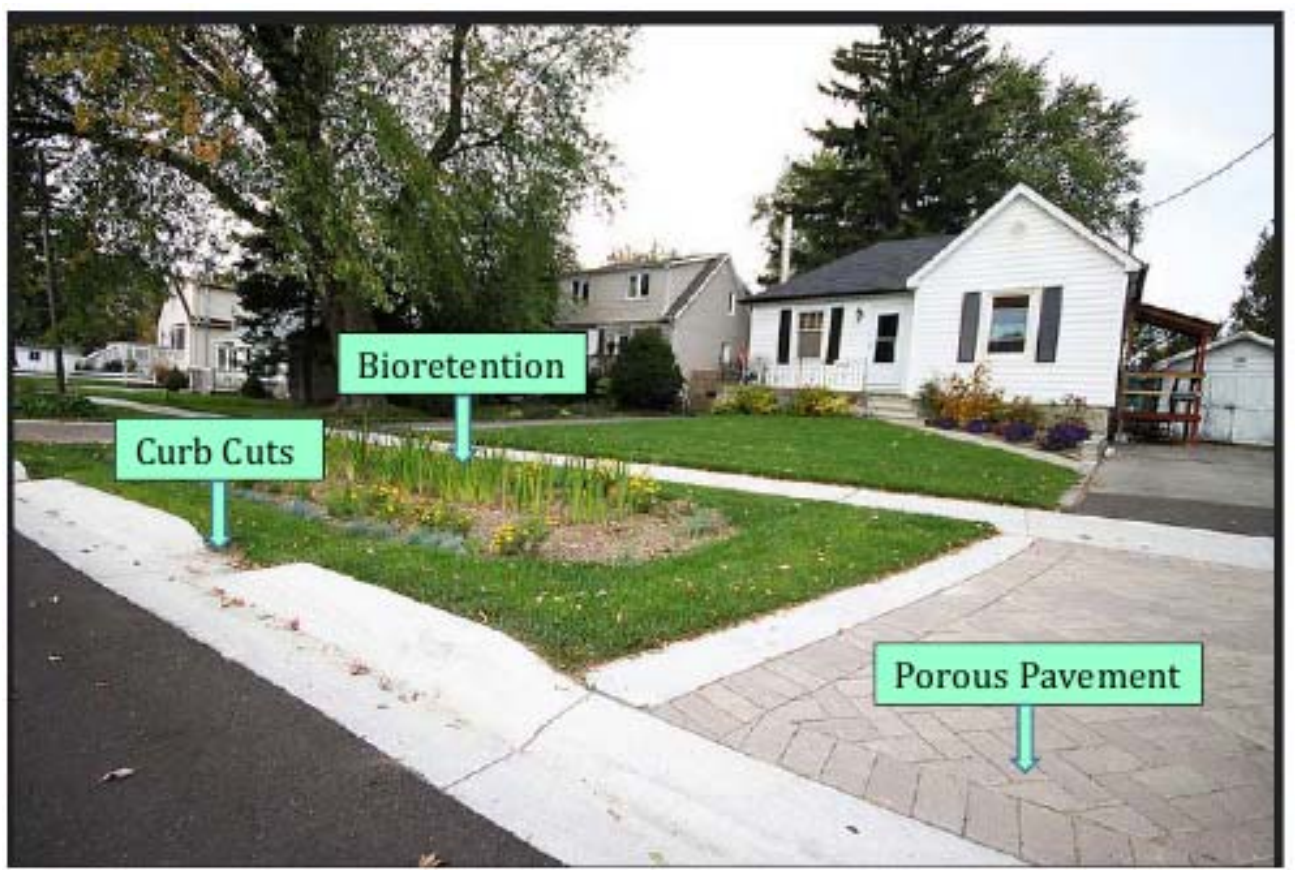

Figure 3-3 A Series of LID - Road Retrofit Project

(Source: $C V C$ )

The study catchment areas are in low-density residential area with sandy loam soil type. Fig 3-4 shows the location of the catchment areas denoted as LV1, LV2 and LV4. CVC provided the monitored rainfall -runoff records at the specified monitoring wells from July 2010 to December 2013. With reference to the City of Mississauga's GIS data, the size and 
imperviousness of each catchment area are as follows.

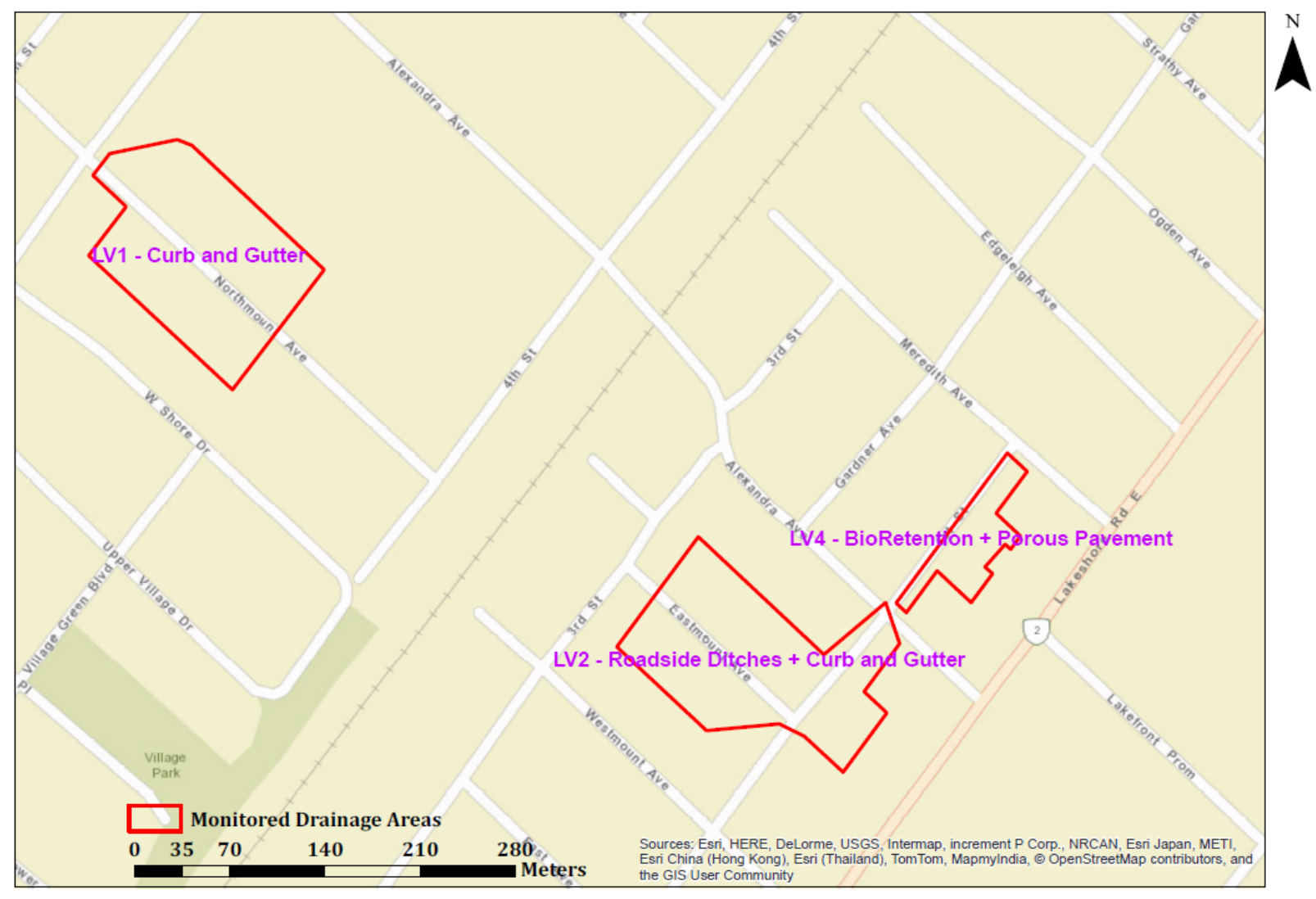

Figure 3-4 Locations of Study Catchment Areas

The first catchment area is situated along Northmount Avenue bounded by Atwater Avenue and Fourth Street, which will be referred to as LakeView-1 (LV1) in the following sections. LV1 is 1.7 ha in size and with an imperviousness of 52\%. LV1 is serviced using a curb and gutter system with storm sewers running beneath the street.

The second catchment, referred to as LakeView-2 (LV2), is situated just $350 \mathrm{~m}$ southwest of LV1. It is 1.7 ha in size and has an imperviousness of $48 \%$. The drainage area contained is the Eastmount Avenue and a section of the First Street. The drainage system provided along the Eastmount Avenue consists of roadside ditches and culvert beneath driveways, and curb and gutter system along the First Street. 
The third catchment is the pilot road retrofit project that was completed along the First Street between the Alexandra Avenue and Meredith Avenue. This area, referred to as LakeView-4 (LV4), is 0.3 ha with an imperviousness of 44\%. Before LIDs were implemented, LV4 had roadside ditches. As a part of the Lakeview road revitalization project, the drainage infrastructure of LV4 was reconstructed with a series of bioretention cells and porous pavement within the municipal right-of-way.

CVC conducted a detailed survey to identify the disconnected downspouts within these study catchment areas. The total areas of identified Roof Directly Connected Area (RDCA) were $700 \mathrm{~m}^{2}, 1813 \mathrm{~m}^{2}, 292 \mathrm{~m}^{2}$ in LV1, LV2 and LV4, respectively.

\subsection{Available Datasets}

\subsubsection{WorldView-2 Data}

A WorldView-2 satellite image covers the City of Mississauga. Both the panchromatic $(0.5 \mathrm{~m}$ spatial resolution) and 8-band multispectral (2m spatial resolution) bands in 11-bit radiometric resolution were captured on April 30th 2011. Radiometric resolution describes its ability to detect small differences in reflected energy.

Panchromatic band records wavelengths extending from $450 \mathrm{~nm}$ to $800 \mathrm{~nm}$. Its spectral resolution is fairly coarse compared to the multispectral bands. In multispectral bands, the wavelength from $400-1040 \mathrm{~nm}$ has been separated into eight bands to define much finer wavelength. Individual band is sensitive to the reflected energy at distinguished wavelengths of the spectrum. 
The 8-band multispectral data includes band 1 -coastal blue ( $400 \mathrm{~nm}-450 \mathrm{~nm})$, band 2 -blue ( $450 \mathrm{~nm}-510 \mathrm{~nm})$, band 3 -green $(510 \mathrm{~nm}-580 \mathrm{~nm})$, band 4 -yellow (585 nm - 625 $\mathrm{nm})$, band 5 -red $(630 \mathrm{~nm}-690 \mathrm{~nm})$, band 6 -red edge $(705 \mathrm{~nm}-745 \mathrm{~nm})$, band 7 -near infrared $1(770 \mathrm{~nm}-895 \mathrm{~nm})$, and band 8 -near infrared $2(860 \mathrm{~nm}-1040 \mathrm{~nm})$ as displayed in Fig. 3-5.

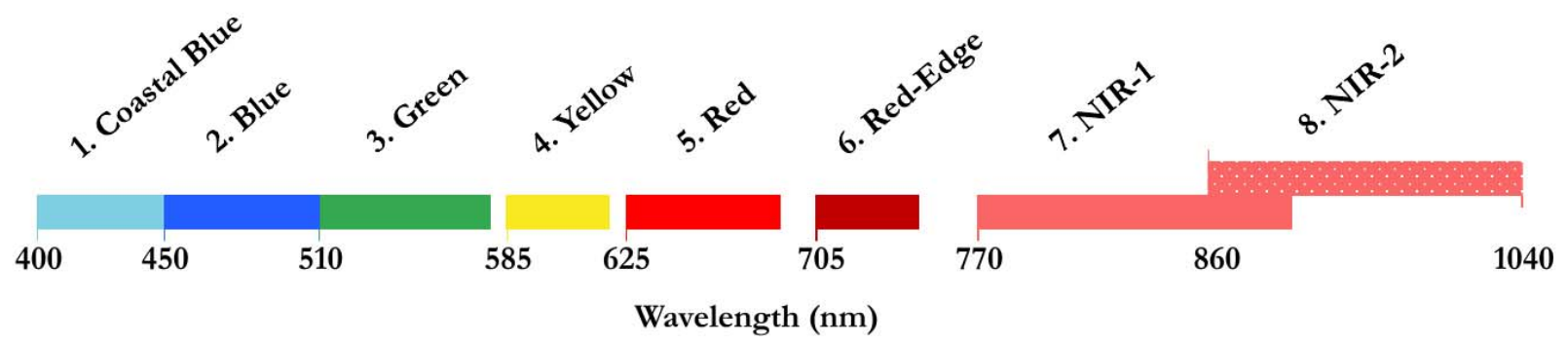

Figure 3-5 Graphical Presentation of Bands and their Wavelength of WorldView-2 Image

In brief, panchromatic band can detect objects as small as $0.5 \mathrm{~m}$ in black and white only. Due to its coarse spectral resolution, panchromatic band alone cannot be used for land cover classification purpose. On the other hand, multispectral eight bands represent objects of various colours based on their reflectance in each of the narrow bands, and the smallest objects being able to capture is $2 \mathrm{~m}$.

\subsubsection{GIS Data}

The available GIS land cover data: 1) STM Node, 2) STM Main, 3) Wooded Area, 4) Driveway, 5) Lot Boundary, 6) Road, and 7) Building layers are shown in Fig. 3-6. Some of the GIS layers had to be processed as outlined in Section3.2.2 to get ready to use in developing SWMM. Since the available GIS data were not collected solely for the stormwater management purposes, some of the polyline layers needed to be converted to polygons layers as SWMM represents catchments as closed polygons. Moreover, some areas for 
instance, lawns and all the paved areas, are not identified in the GIS layer. Therefore, a layer that represents lawns called Grass layer was generated. Before generating Grass layer, it is important to take a closer look on existing Building layer to ensure that all the types of buildings including sheds, patios, etc., are included. In Fig. 3-6, as indicated with white arrows, existing GIS layers did not include some sheds and paved areas. Therefore, manual on-screen digitization was done to update the existing Building and Driveway layers. When digitizing missing features, WorldView-2 image collected on April $30^{\text {th }} 2010$ was used as a base map; since, the GIS layer will be used as a reference to check the accuracy of image classification method. The modified GIS layer, as shown in Fig. 3-7, will be used instead of existing GIS layers in the subsequent processes.

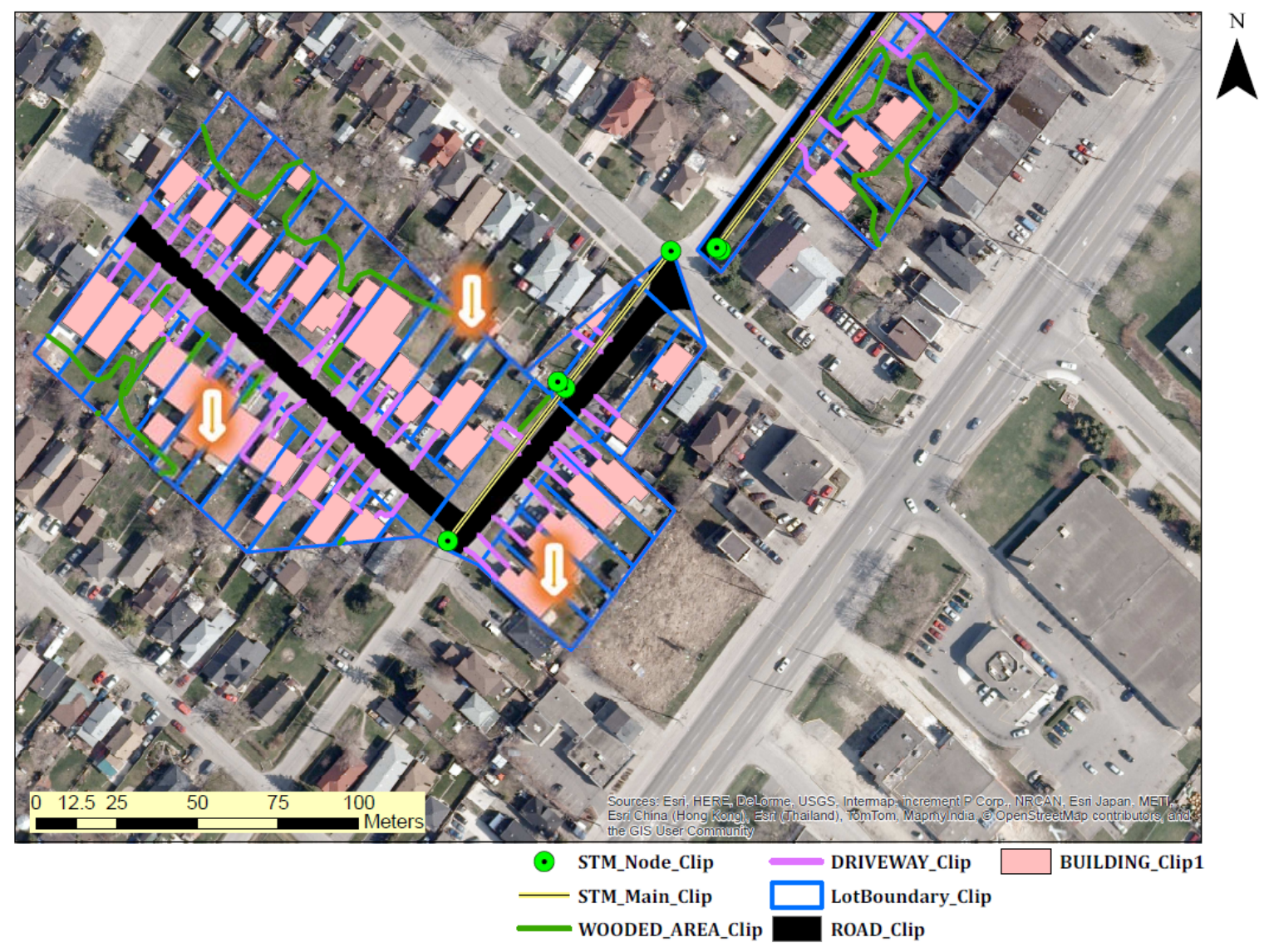

Figure 3-6 Available GIS Layers 


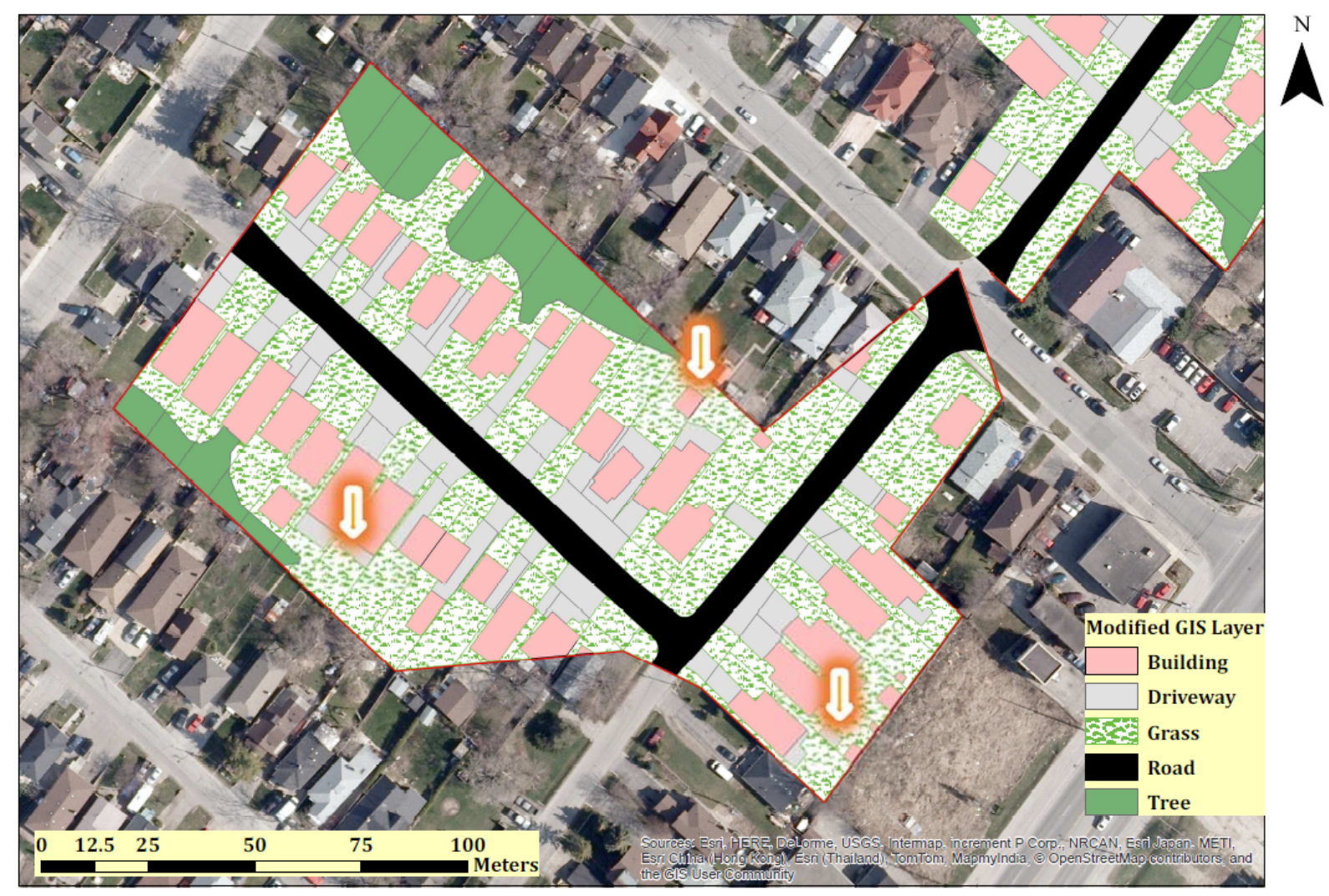

Figure 3-7 Modified GIS Layers

Table 3-1 provides the information that contain in each layer. Table 3-1 (a) STM Node contained information such as the X,Y coordinates of the junction/node, type; (b) STM_Main contained the length of the pipe, upstream node and its invert elevation, downstream node and its invert elevation, diameter, pipe/conduit materials, etc; (c) Wooded Area and (d) Driveway described the length of the polylines; (e) Lot Boundary, (f) Building and (g) Road contained the total area of the polygons. The other GIS data made available was a raster type 5metre resolution DEM (Fig. 3-8), which is colour coded based on the elevation values at a two-metre interval. This fairly coarse DEM was used in identifying the general flow direction within the study catchments. Fig 3-8 suggested that the overland flow should be from Northwest to South-East, North-west to South-east then North-east, towards South-west, respectively, for LV1, LV2 and LV4. 


\section{Table 3-1 Attributes of Available GIS data}

\begin{tabular}{|c|c|}
\hline \multicolumn{2}{|l|}{ Identify } \\
\hline \multicolumn{2}{|r|}{$\therefore$ STM_Node_Clip } \\
\hline \multicolumn{2}{|c|}{$\begin{array}{c}\square \text { STM_Node_Clip } \\
\qquad \text { LG01 }\end{array}$} \\
\hline \multicolumn{2}{|r|}{ 图 } \\
\hline Location: & ${ }_{616,102.9664,825,699.909 \text { Meters }}=$ \\
\hline Field & Value \\
\hline OBJECTID & 1 \\
\hline Shape & Multipoint \\
\hline TYPE_FK & $\mathrm{MH}$ \\
\hline CELLNAME & LG01 \\
\hline NODE_ID & 1919 \\
\hline LOC_FK & MISS \\
\hline OWNER_FK & MISS \\
\hline CENT_X & 616103.05 \\
\hline CENT_Y & 4825699.84 \\
\hline MSLINK & 1919 \\
\hline GMRotation & 0 \\
\hline \multicolumn{2}{|c|}{1} \\
\hline Identified $1 \mathrm{fe}$ & eature \\
\hline
\end{tabular}

\section{(a) STM_Node}

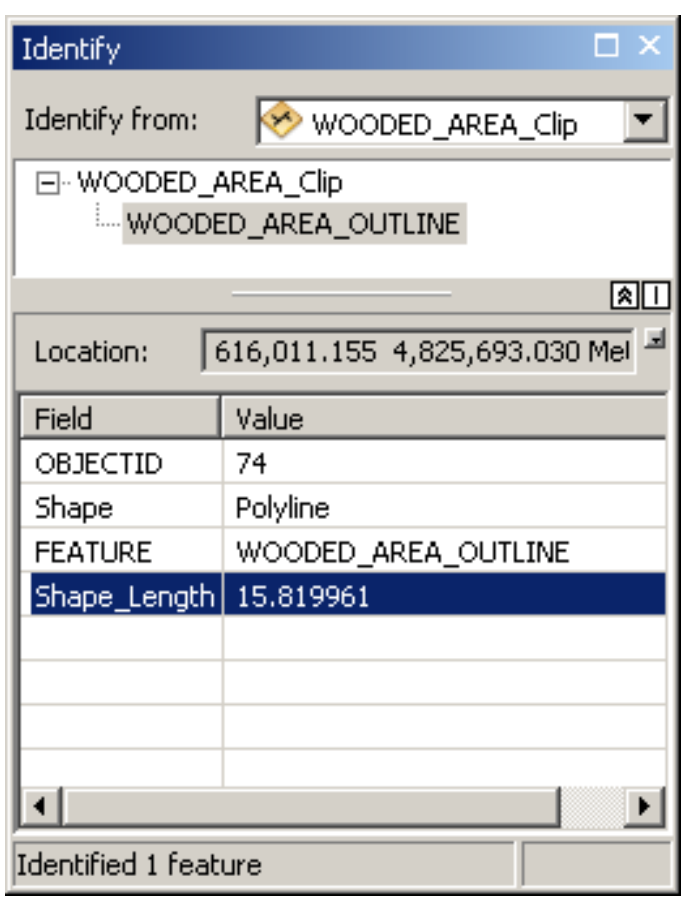

(c) Wooded Area

\begin{tabular}{|c|c|c|}
\hline \multicolumn{2}{|l|}{ Identify } & $\square \times$ \\
\hline Identify from: & • STM_Main_Clip & 7 \\
\hline \multicolumn{3}{|c|}{$\begin{array}{c}\square . \text { STM_Main_Clip } \\
\text { CC04951 }\end{array}$} \\
\hline & & 图回 \\
\hline \multicolumn{3}{|c|}{ Location: $\quad 616,083.9164,825,675.038$ Mete } \\
\hline Field & Value & $\Delta$ \\
\hline OBJECTID & 2 & \\
\hline Shape & Polyline & \\
\hline PLAN_NUM & C04951 & \\
\hline UP_INV_ELE & 84.45 & \\
\hline DN_INV_ELE & 84.33 & \\
\hline PIPE_MAT & CON & \\
\hline \multicolumn{3}{|l|}{ PLAN_UNITS } \\
\hline TYPE_FK & MAIN & - \\
\hline STR_LENGTH & 53.56 & \\
\hline PIPE_SIZE & 525 & \\
\hline NODE_FROM_ & 1940 & \\
\hline NODE_TO_FK & 1919 & - \\
\hline Identified $1 \mathrm{fec}$ & & \\
\hline
\end{tabular}

(b) STM_Main

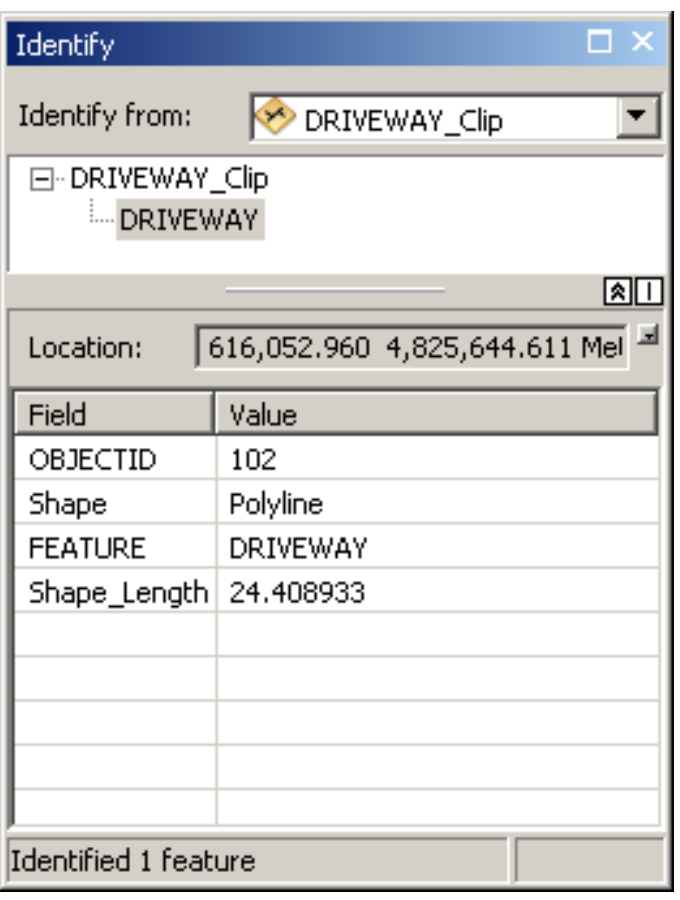

(d) Driveway 


\begin{tabular}{|c|c|c|}
\hline \multicolumn{2}{|l|}{ Identify } & $\square \times$ \\
\hline Identify from: & 8 LotBoundary_Clip & $\nabla$ \\
\hline \multicolumn{3}{|c|}{$\begin{array}{c}\square . \text { LotBoundary_Clip } \\
\ldots .3792\end{array}$} \\
\hline \multicolumn{3}{|r|}{ 因口 } \\
\hline Location: $\quad \sqrt{6}$ & $616,161.704 \quad 4,825,704.9$ & \\
\hline Field & Value & $\Delta$ \\
\hline OBJECTID & 30 & \\
\hline Shape & Polygon & \\
\hline CITY_PIN & 12808700 & \\
\hline CENT_ $X$ & 616152.8773 & \\
\hline CENT_Y & 4825720.2995 & \\
\hline AREA & 413.06 & \\
\hline TxtID & 3792 & \\
\hline Shape_Length & 92.61976 & \\
\hline Shape_Area & 413.067093 & \pm \\
\hline \multicolumn{3}{|c|}{ Identified 1 feature } \\
\hline
\end{tabular}

(e) Lot Boundary

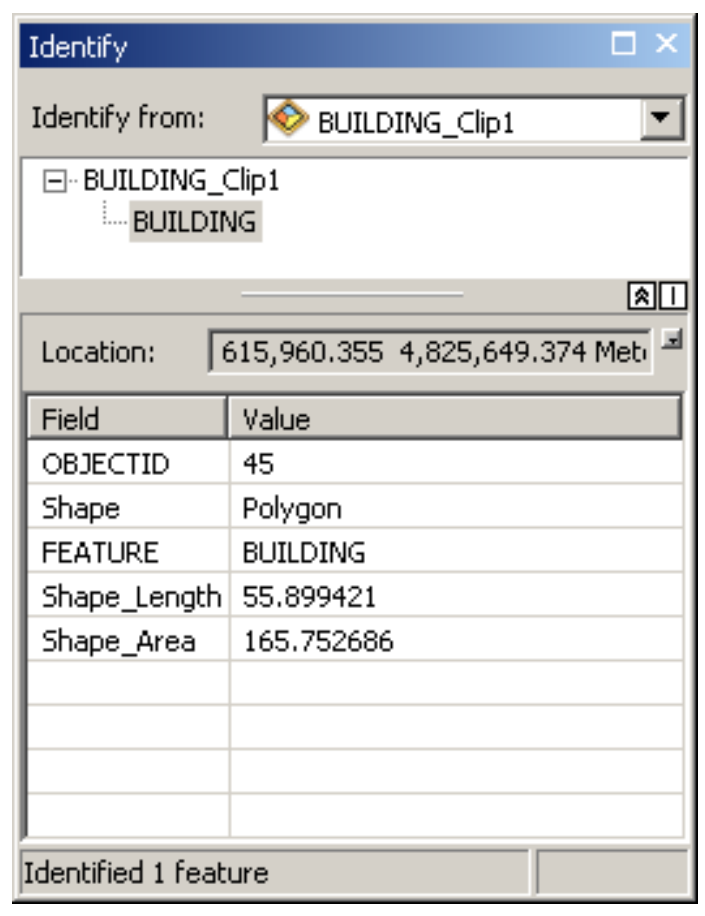

(g) Building

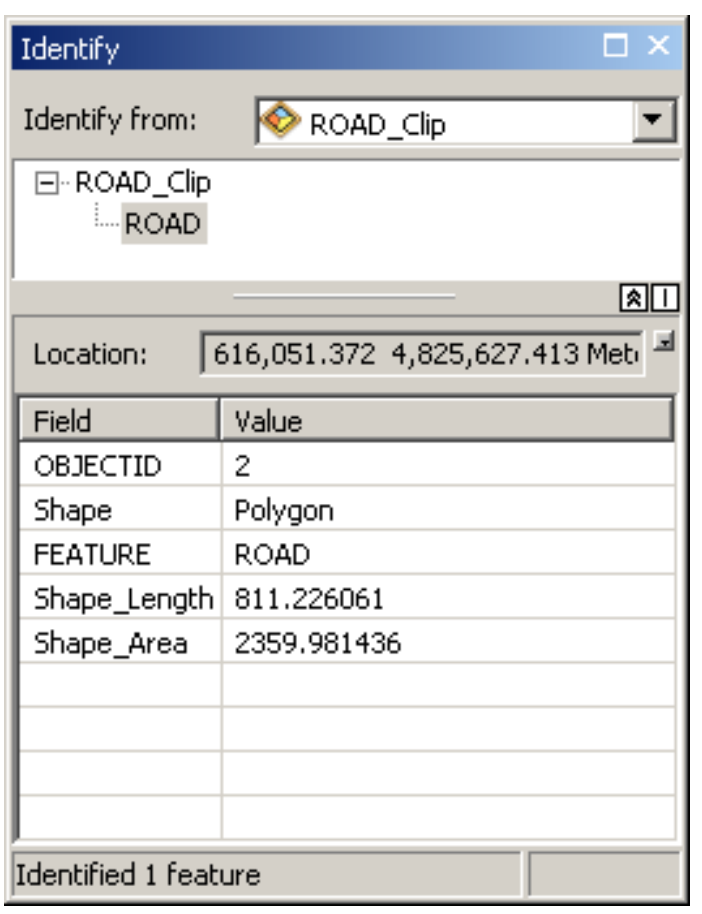

(f) Road 


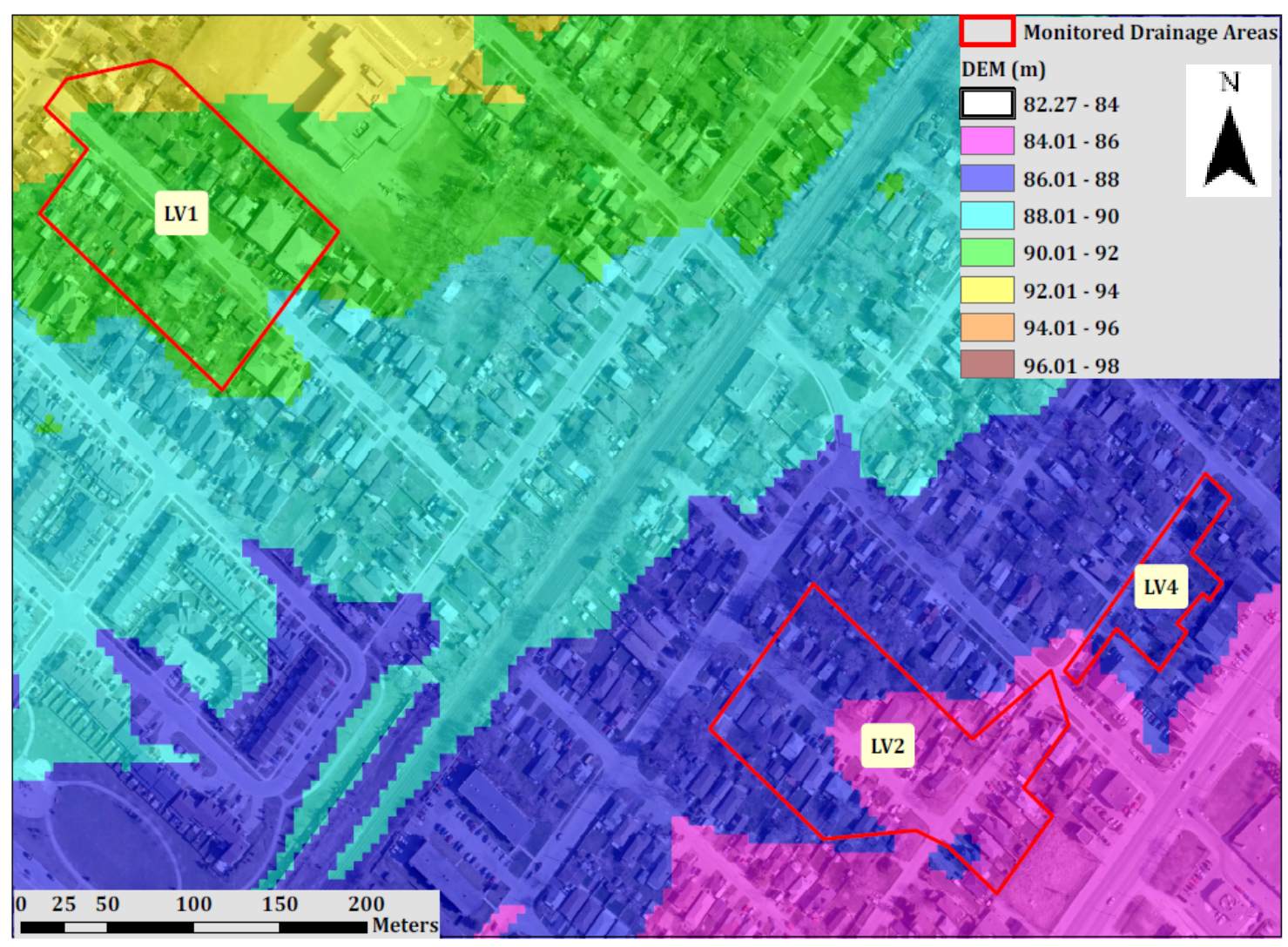

Figure 3-8 Digital Elevation Model for Study Catchment Areas

\subsubsection{Meteorological and Flow Data}

Throughout the monitoring period from July 5, 2010 to December 31, 2013, rainfall data were recorded by different rain gauges (MississaugaS01, Cawthra and CVC Cawthra, located within $1 \mathrm{~km}$, Wolfdale, within $6.5 \mathrm{~km}$, and Riverwood, within $8 \mathrm{~km}$ radius of the study areas) in five-minute interval. The timeline of the rain gauges used is shown in Fig. 3-9, and the locations of the rain gauges are shown in Fig. 3-10. Monthly average evapotranspiration rate was obtained from the Stayner, ON, weather station, which is situated $100 \mathrm{~km}$ north of the study sites. Monitored runoff data were recorded at the specified monitoring locations as displayed in Fig. 3-11. 


\begin{tabular}{|c|c|c|c|c|c|c|c|}
\hline Year & & 2010 & 2011 & & 2012 & & 2013 \\
\hline Month & \begin{tabular}{|l|l|}
7 & 8 \\
\end{tabular} & \begin{tabular}{|l|l|l|l|}
9 & 10 & 11 & 12 \\
\end{tabular} & \begin{tabular}{|l|l|l|l|l|l|l|l|l|l}
2 & 3 & 4 & 5 & 6 & 7 & 8 & 9 & 10 & 11 \\
\end{tabular} & 2 & \begin{tabular}{|l|l|l|l|l|}
3 & 4 & 5 & 6 & 7 \\
\end{tabular} & \begin{tabular}{|l|l|l|l|l|}
8 & 9 & 10 & 11 & 12 \\
\end{tabular} & \begin{tabular}{|l|l|l|l|l|l|l|l|l|l|l|l|}
1 & 2 & 3 & 4 & 5 & 6 & 7 & 8 & 9 & 10 & 11 & 12 \\
\end{tabular} \\
\hline Raingauge & $\mathrm{RW}$ & \begin{tabular}{|l|l|}
$S 1$ & RW \\
\end{tabular} & CAW & \begin{tabular}{l|l} 
S3 & cvC \\
\end{tabular} & 53 & & $S 1$ \\
\hline
\end{tabular}

\begin{tabular}{|l|c|}
\hline 1) Riverwood & RW \\
\hline 2) Mississauga Station 01 & S1 \\
\hline 3) Cawthra & CAW \\
\hline 4) Mississauga Station 03 & S3 \\
\hline 5) CVC Cawthra Station & CVC \\
\hline
\end{tabular}

Figure 3-9 Rain Gauge Timeline

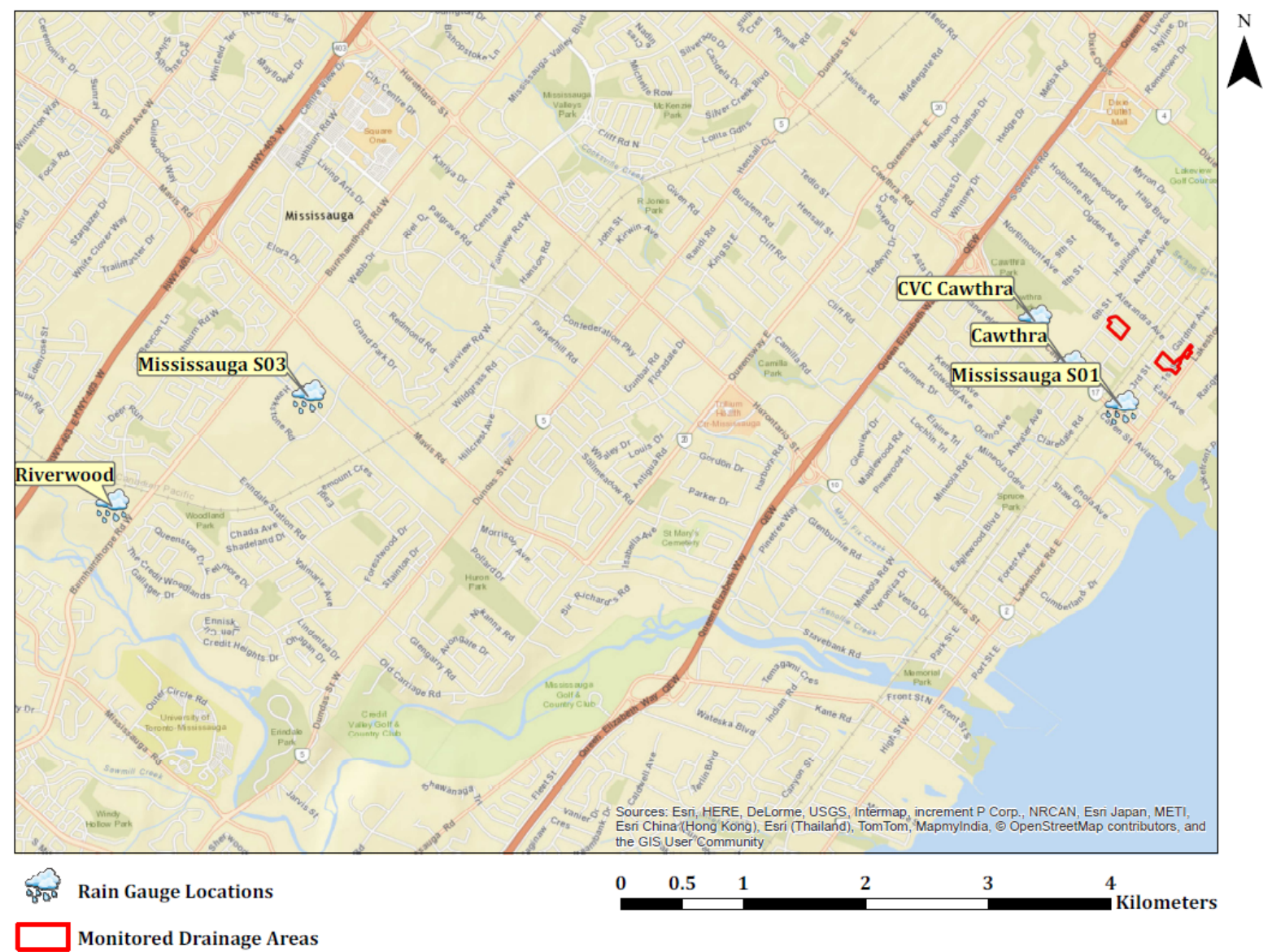

Figure 3-10 Location of Rain Gauges Used in this Study 


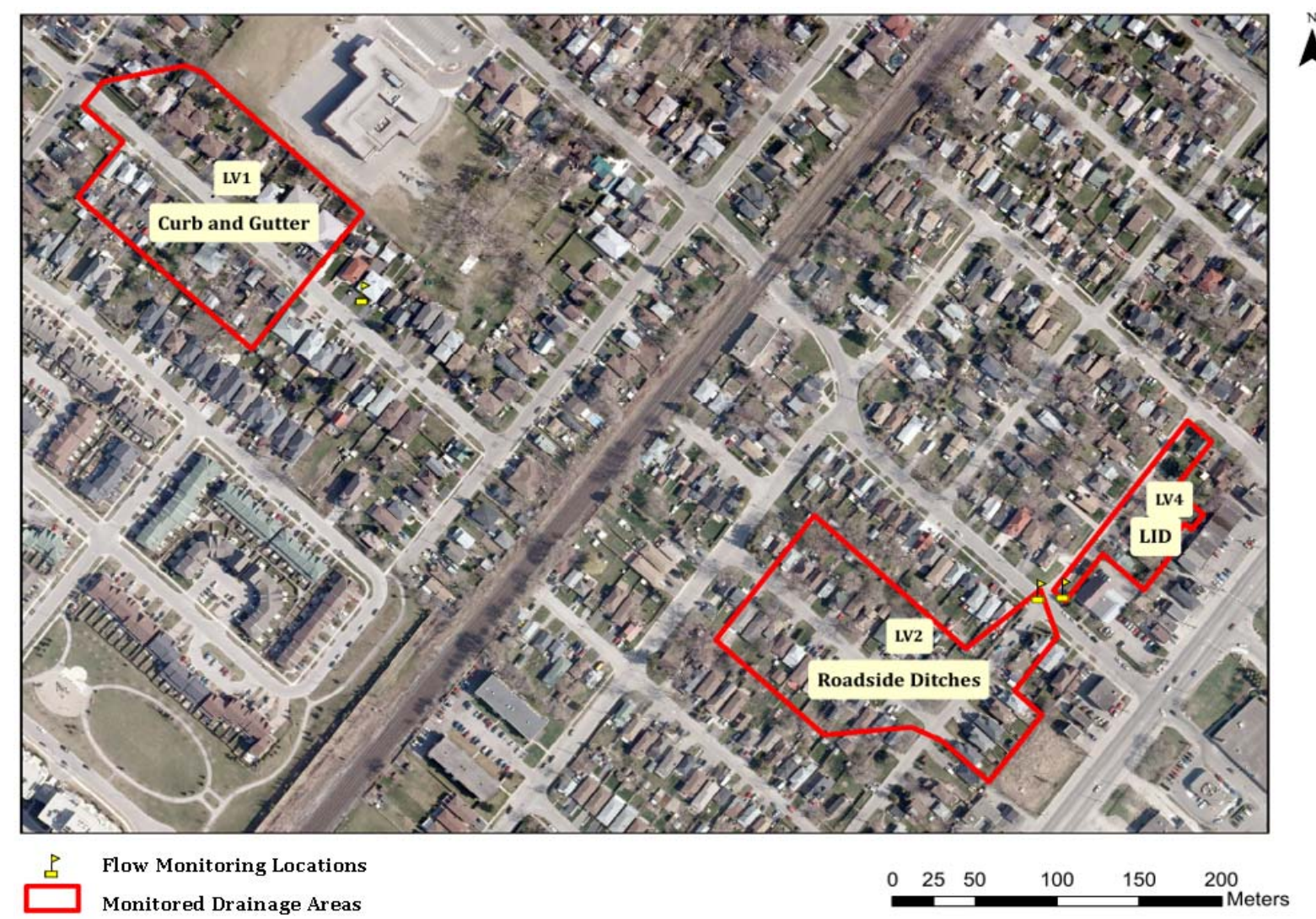

Figure 3-11 Location of the Three Study Catchments and Flow Monitoring Locations 


\section{Chapter 4}

\section{Extraction of Land Cover Information from WorldView-2 Image}

\subsection{Introduction}

This chapter focuses on the processing of WorldView-2 image to generate different land cover types. To achieve the best possible spectral and spatial resolution of WorldView-2 image, Pansharpening was carried out in Section 4.2. Section 4.3 discusses the land cover types presented in the study area, defines the training areas of each land cover type, and demonstrates the pixel-based image classification method applied on WorldView-2 image. Underperforming of pixel-based method leads to the generating of auxiliary bands in Section 4.4, and the development of a two-stage image classification in Section 4.5. Section 4.6 assesses the accuracy of the two-stage image classification method in two ways. Firstly, by determining how many of the randomly generated 500 points being correctly classified. Secondly, by comparing the pervious and impervious areas distribution at lot-level from a classified image and the modified GIS data. Section 4.7 comments on the classification accuracy achieved, and summarizes the findings on image processing. 


\subsection{Image Preprocessing}

\subsubsection{Image Pansharpening}

Image pansharpening is a process that uses a panchromatic image to sharpen multispectral images. The pansharpened reaps the benefits of having high spectral resolution of its multispectral bands, as well as fine spatial resolution of its panchromatic band.

In 2004, Zhang reviewed the existing methods of remote sensing image fusion, such as Intensity, Hue and Saturation (IHS), Principal Component Analysis (PCA), Brovey transform, Wavelet-based fusion, etc (Zhang, 2004). These methods may produce an unsatisfactory result, which may not reflect the true colour of the image scene, particularly on very high resolution satellite imagery. Subsequently, Padwick et al. (2010) proposed the Hyperspherical Color Sharpening (HCS) method, which is a tailor-made for WorldView-2 imagery. This method was proven to outperform visually and quantitatively than all the other methods.

Hence, to achieve the best possible of spatial and spectral resolution, HCS method was executed on WorldView-2 image in the ERDAS IMAGINE 2013. By fusing the multispectral bands (1.84 $\mathrm{m}$ spatial resolution) with the panchromatic band (0.46 m resolution), the resultant pansharpened image was produced with eight spectral bands at a half-metre spatial resolution image. Fig 4-1 shows a small subset of multispectral, panchromatic and pansharpened images to illustrate the visual and quantitative enhancement of pansharpening. 


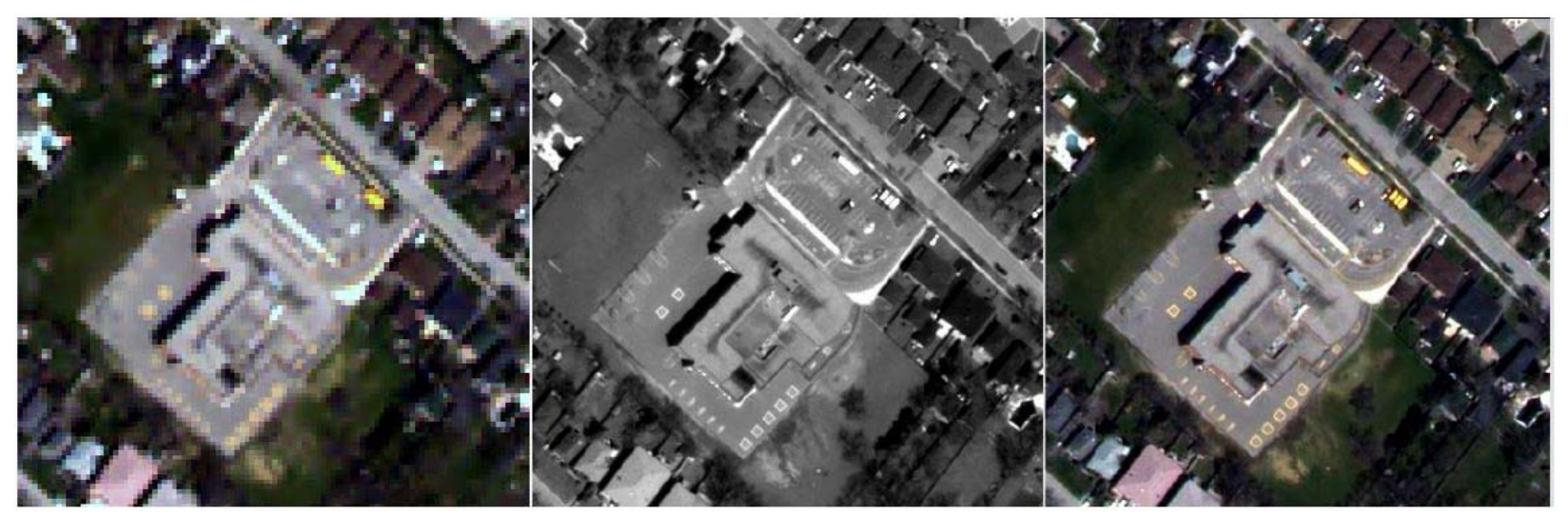

(a)

(b)

(c)

Figure 4-1 WorldView-2: (a) Multispectral, (b) Panchromatic, (c) Pansharpened images

\subsubsection{Georeferencing}

Pansharpened images need to be georeferenced depending on the geographic location of the study area. Image georeferencing is needed due to the bias generated by the use of the rational polynomial coefficient models (Tong et al., 2010) that lead to the image may not be in the correct position with reference to spatial locations of structures (buildings, streets, places). Below Fig. 4-2(a) presents the GIS land cover layer overlaid on WorldView-2 image. Misalignment of the edge of road, building etc., indicated that georeferencing should be undertaken. Ground control points' $(\mathrm{x}, \mathrm{y}, \mathrm{z})$ coordinates can be collected from field data or the georeferenced map for image georeferencing. For georeferencing, 13 ground control points were generated on both WorldView-2 image and orthoimage. Then, six points were used as control points and the remaining seven points were used as checkpoints. The accuracy of the georeferencing is reported by the root mean square error (RMSE) of the checkpoints. RMSE for the georeferencing was 0.35 metre as reported in ERDAS Imagine. 


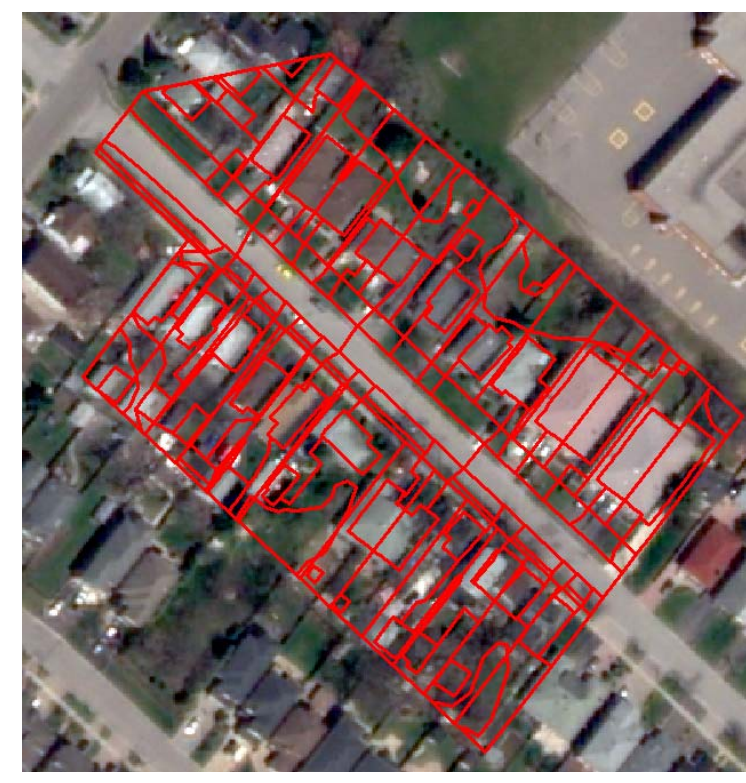

(a)

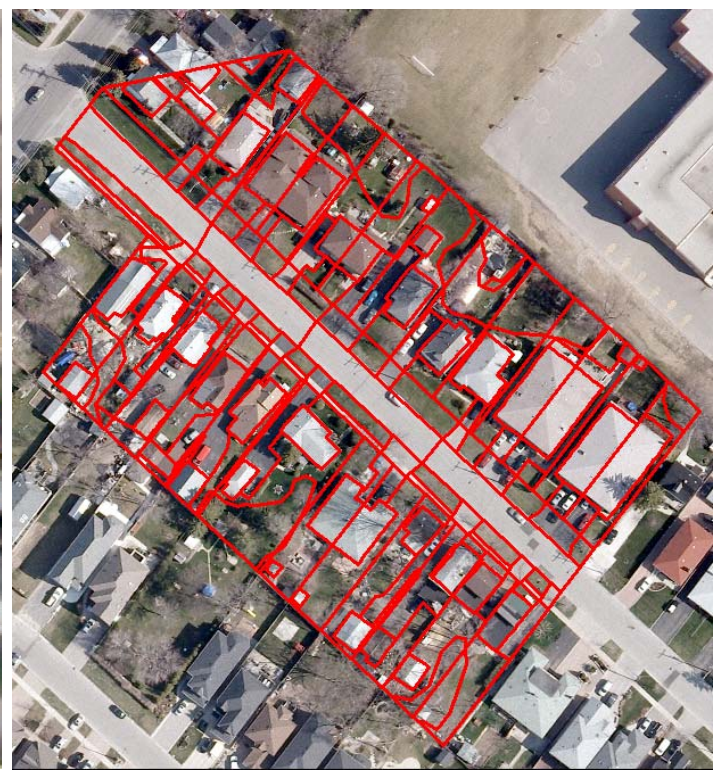

(b)

Figure 4-2 GIS Land Cover Data Laid Over: (a) WorldView-2 Image (b) Orthoimage

Since the study areas are located in Mississauga, Ontario, Canada, the WorldView-2 image was re-projected to NAD 1983 UTM Zone 17N. Then, the image was clipped to $900 \mathrm{~m}$ $\times 650 \mathrm{~m}$ just to cover the study catchment areas of LakeView study sites as illustrated in Fig 4.3. Then, the WorldView-2 image was geo-referenced to an orthoimage downloaded from the Scholars Geoportal. When GIS data was laid on top of the orthoimage as shown in Fig. 42. (b), the edge of the building and road, etc., were properly aligned; therefore, orthoimage was chosen as a reference source.

\subsection{Pixel-based Image Classification Method}

\subsubsection{Selection of Training Areas}

The first step to do in feature selection is identifying the types of interested land cover types that exist in the catchment areas. As all the study catchments were in residential land cover zone, the following four land cover types were identified: 1) grass, 2) tree, 3) road and 4) 
building. By looking at the aerial photos and Google imagery, this neighbourhood seemed to use the same material for road, sidewalk and driveway. By having the same material/colour, reflectance values of road, sidewalk and driveway are in a similar brightness value range (Fig. 4-3 (a)). Therefore, these three land cover types were not possible to be identified from satellite imagery since the image classification process relies on the reflectance value of the land cover types. Another thing to note about the nature of these study areas is that rooftops can be found in a variety of colours. In this case, the rooftops having quite similar colour were grouped together (Fig. 4-3 (b)). Hence, three groups of buildings were treated separately in the intermediate stages of the image classification decision tress, but all the buildings were combined at the end of the classification result. The distribution of training areas is shown in Fig. 4-4.

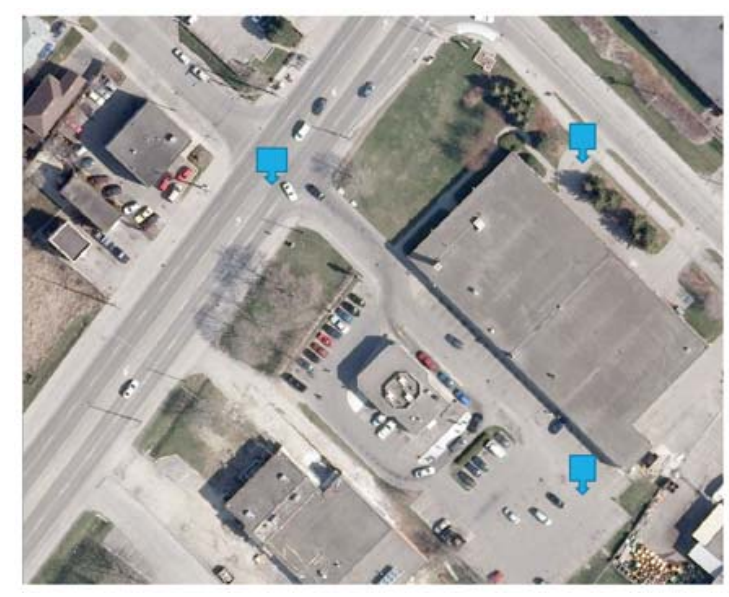

(a)

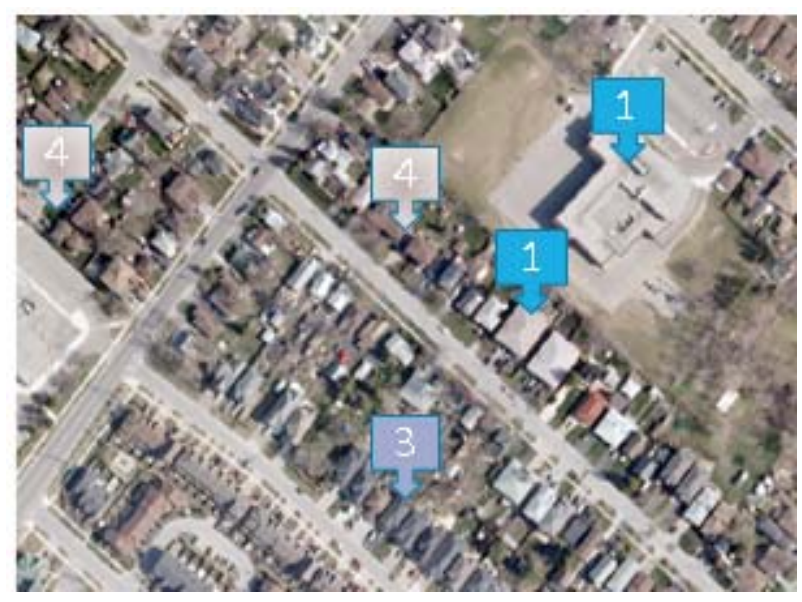

(b)

Figure 4-3 (a) Same Colour of Road, Driveway and Parking Lot (b) Different Colours of Rooftops 


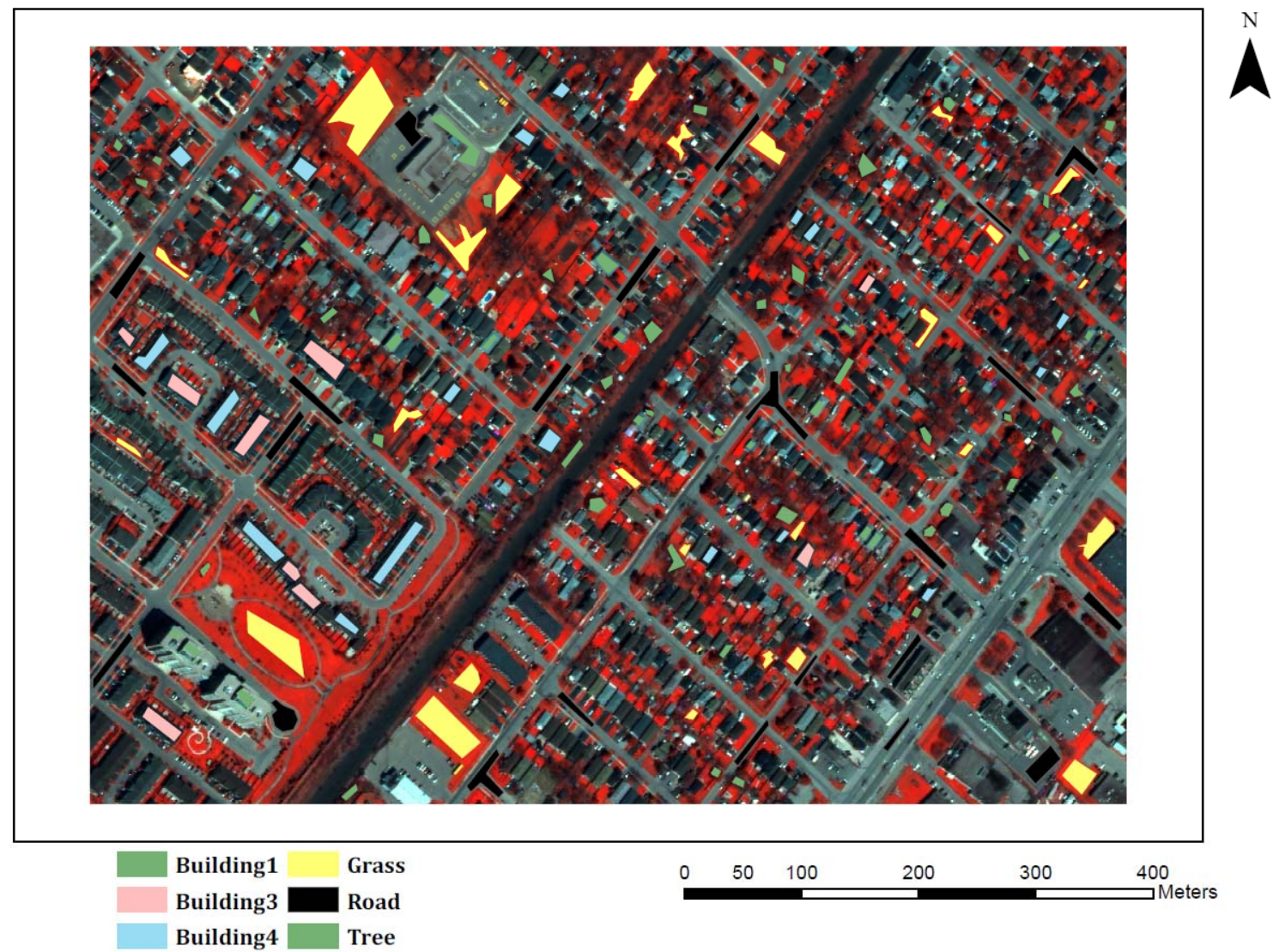

Figure 4-4 Distribution of Training Areas

In the image classification process, various factors influence the classification accuracy including the orientation of the sun and the nature of the study area. The nature of the study area can be described as the homogeneity of the land cover types and the smallest size of the land cover type that exist. The satellite image that captured all three study catchment areas was split due to the fact that the area between LV1 and LV2 was a mixedland cover. Since the purpose of this study is to model urban drainage areas, the drainage areas that have been monitored were isolated and used in the study. Hence, the WorldView2 image was cut into two separate images for image classification. Fig 4-5 shows the two images, consisting of LV1 in Image 1 and LV2 and LV4 in Image2. 


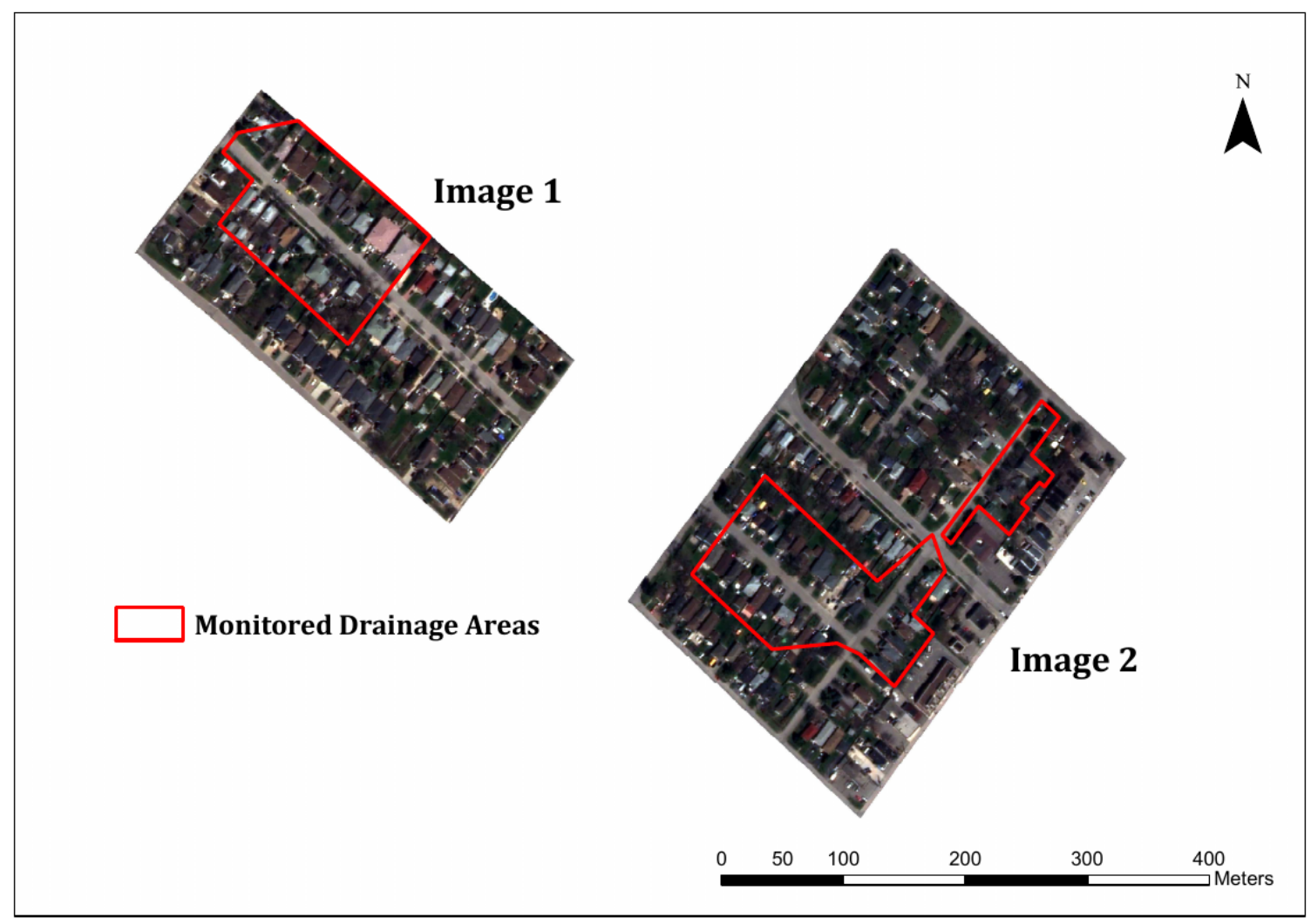

Figure 4-5 Study Catchments Location

\subsubsection{Pixel-based Image Classification}

Traditionally used pixel-based classification method using the maximum likelihood algorithm was executed on a WorldView-2 image to classify the image into the four land cover types (Building, Grass, Road, Tree) using the abovementioned training areas. Maximum likelihood achieved the overall accuracy of $63.6 \%$ in Image1 and $73.00 \%$ in Image2. The classified images of Image1 and Image 2 are as displayed below in Fig.4-6(a) and (b), respectively. The error matrices are as illustrated in Tables 4-1 and 4-2. 


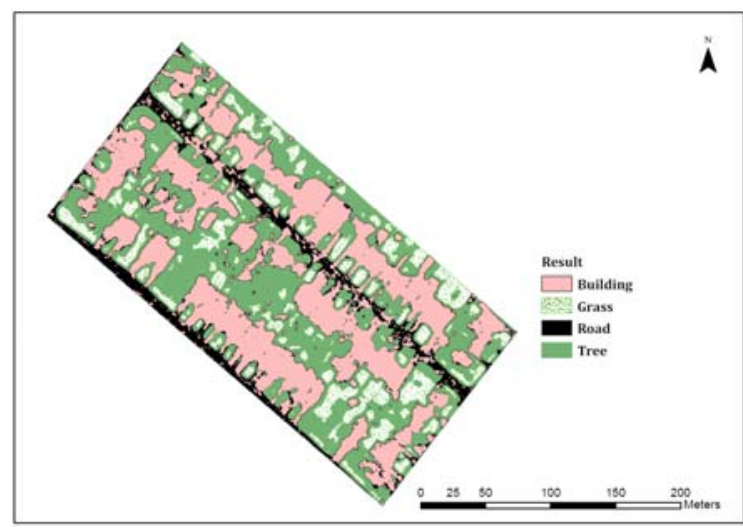

(a)

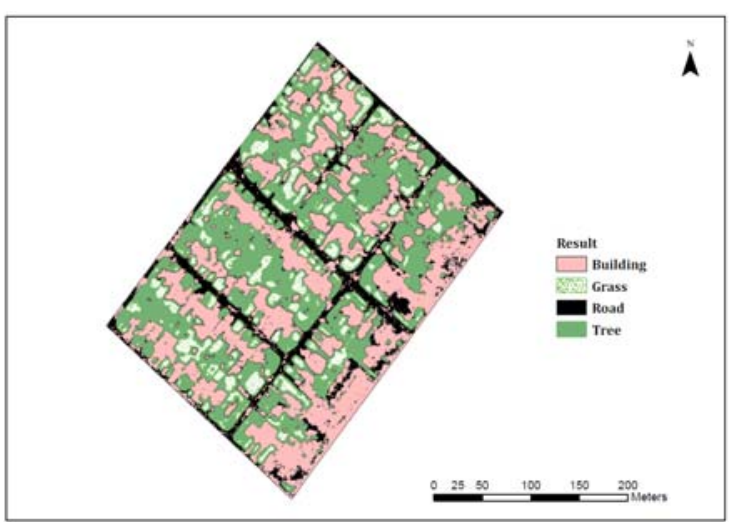

(b)

Figure 4-6 Pixel-based Maximum Likelihood Classification Result (a) Image1 (b) Image 2

Table 4-1 Error Matrix of the Maximum Likelihood Classification Result for Image1

\begin{tabular}{lcccccc}
\hline \hline & \multicolumn{7}{c}{ Known Cover Types } \\
\cline { 2 - 7 } Classified & Grass & Tree & Building & Road & Total & User's \\
\hline Grass & $\mathbf{6 7}$ & 1 & 0 & 3 & 71 & $94.37 \%$ \\
Tree & 59 & $\mathbf{6 9}$ & 23 & 42 & 193 & $35.75 \%$ \\
Building & 0 & 2 & $\mathbf{1 4 4}$ & 49 & 195 & $73.85 \%$ \\
Road & 1 & 1 & 1 & $\mathbf{3 8}$ & 41 & $92.68 \%$ \\
\hline Total & 127 & 73 & 168 & 132 & 500 & \\
\hline \hline Producer's & $52.76 \%$ & $94.52 \%$ & $85.71 \%$ & $28.79 \%$ & & $\mathbf{6 3 . 6 0 \%}$
\end{tabular}

Table 4-2 Error Matrix of the Maximum Likelihood Classification Result for Image2

\begin{tabular}{lcccccc}
\hline \hline & \multicolumn{7}{c}{ Known Cover Types } \\
\cline { 2 - 7 } Classified & Grass & Tree & Building & Road & Total & User's \\
\hline Grass & $\mathbf{7 4}$ & 0 & 0 & 0 & 74 & $100.00 \%$ \\
Tree & 59 & $\mathbf{1 0 9}$ & 14 & 14 & 196 & $55.61 \%$ \\
Building & 0 & 0 & $\mathbf{1 3 3}$ & 47 & 180 & $73.89 \%$ \\
Road & 0 & 0 & 1 & $\mathbf{4 9}$ & 50 & $98.00 \%$ \\
\hline Total & 133 & 109 & 148 & 110 & 500 & \\
\hline \hline Producer's & $55.64 \%$ & $100.00 \%$ & $89.86 \%$ & $44.55 \%$ & & $\mathbf{7 3 . 0 0 \%}$
\end{tabular}




\subsection{Auxiliary Bands Generation}

As illustrated in Section 4.3 pixel-based image classification did not perform well on WorldView-2 image since pixel-basessssd classification is based on the spectral values only. Hence, in this study, object-based image classification that incorporates both spectral and spatial patterns, which has been proven to be appropriate for very high resolution remote sensing imagery (Myint et al., 2011). Therefore, a two-stage image classification method was developed to produce more accurate classified images. As shown in Fig. 4-7, the brightness values of the interested land cover types in an urban area do not vary significantly on the original eight bands of WorldView-2. Therefore, some of the auxiliary bands were generated to aid in classification.

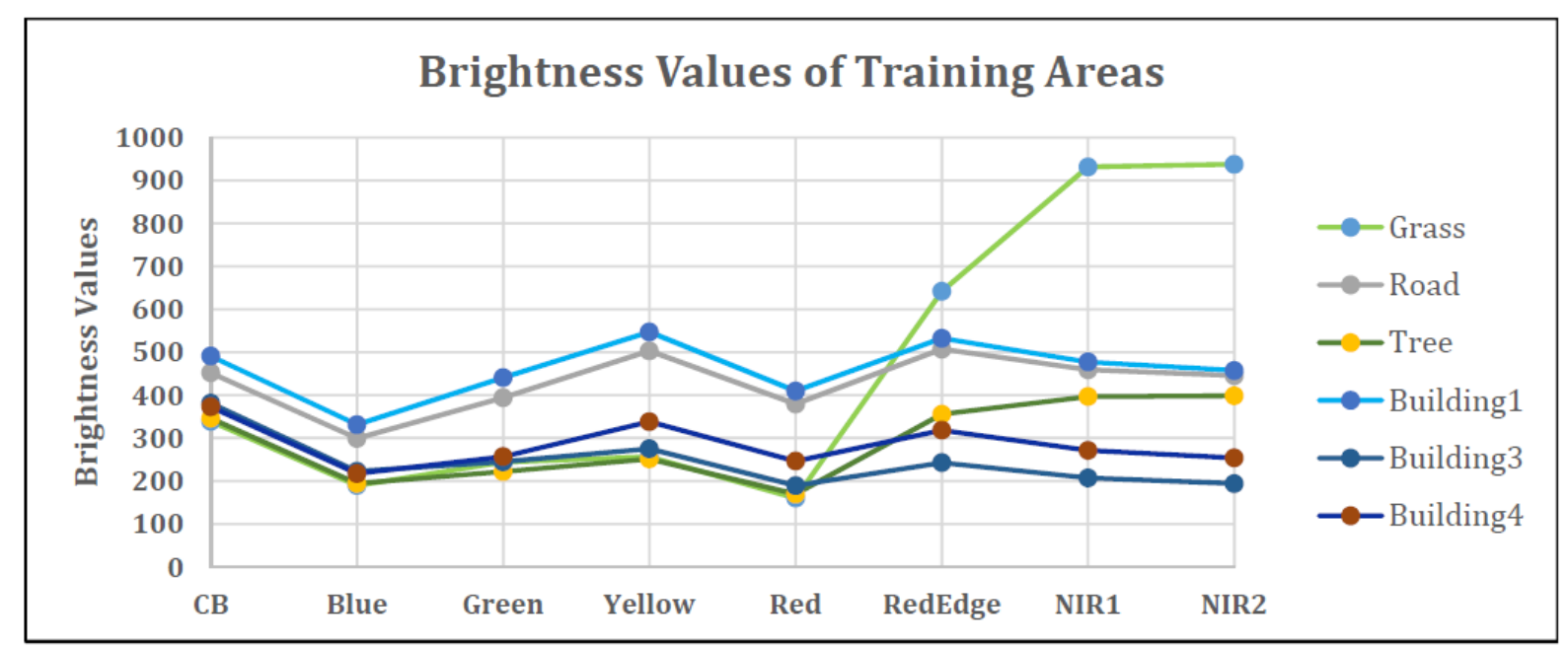

Figure 4-7 Brightness Values of Training Areas at Each Band

Due to the lack of having a good separability to classify the heterogeneous land cover types that present in the study catchment areas, auxiliary bands were generated to increase the separability among different land covers. WorldView-2 provides a high spectral resolution data; however, it is expected that information extracted from the original eight 
bands might be redundant. Hence, the Principal Component Analysis (PCA) was applied to reduce the correlation of the pan-sharpened multispectral bands by creating a new set of bands containing most of the unrelated spatial structure (Jensen, 2005). Thus, the first three PCA bands, which contain larger amount of variance from the original dataset, were taken into consideration.

Since the original and PCA derived feature spaces may not be able to distinguish all land cover features with high accuracy, several studies included the correlations or quantification between the ratio of the difference of certain bands to physical characteristics. Therefore, in order to aid in spectral analysis, Normalized Difference Vegetation Index (NDVIs) were also generated. As precedent sensors of WorldView-2 has only four common bands (i.e. red, green, blue, NIR), NDVI was derived by using the red and NIR bands. However, WorldView-2 has a high spectral resolution, it comes with two NIR bands (bands 7 and 8), and two red bands, namely, red (band 5) and red-edge (band 6). Therefore, there are four possible combinations to derive NDVI (Jawak and Luis, 2013; Belgiu et al., 2014). With reference to Fig. 4-8, the experimental testing revealed that the NDVI1 and NDVI3 outperformed than other possible combinations in separating the features in these study areas. Fig. 4-8 illustrates the statistics of the brightness values of vegetation and nonvegetation land cover types. Brightness values at NDVI1 and NDVI3bands for vegetation were about 0.4 while non-vegetation were about 0.1 ; that resulting 0.3 differences between two features. However, brightness values at NDVI2 and NDVI4 bands for vegetation were about 0.05 and non-vegetation were about - -0.05 . Hence, NDVIs generated by Eqs. 4.1 and 4.2 were taken into account in further image processing. 


$$
\begin{aligned}
& N D V I 1=\frac{(N I R 1-R e d)}{(N I R 1+R e d)} \\
& N D V I 3=\frac{(N I R 2-R e d)}{(N I R 2+R e d)}
\end{aligned}
$$

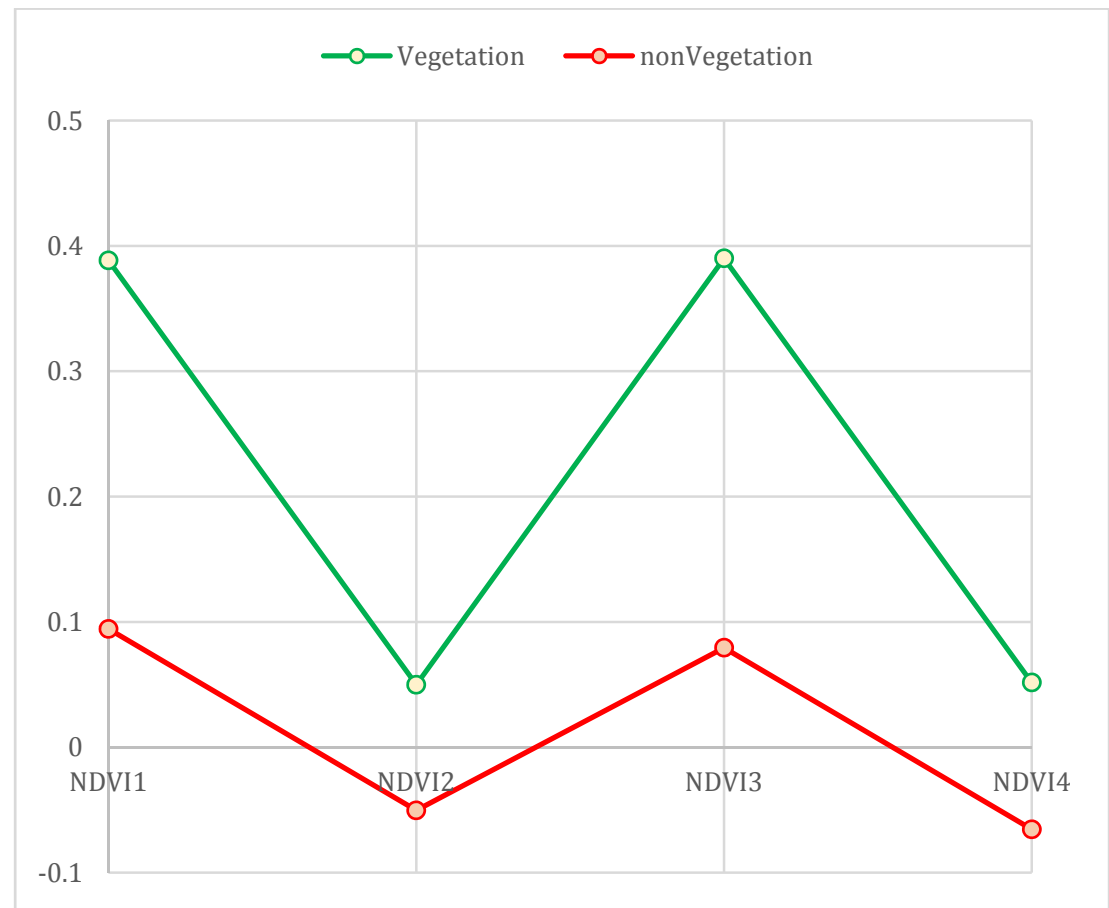

Figure 4-8 Separability of vegetation and non-vegetation at different NDVIS

On top of PCA bands and NDVIs, extra two bands were generated, which were specifically useful in detecting different colours of rooftops. When the image was toggled between displaying at true colours and false colours, certain rooftops were apparent at the specific band combinations of false colours. Therefore, a summation of the brightness of all the pixels of 1) NIR1 (band7), green (band3) and blue (band2), and 2) NIR1 (band7), red (band5) and green (band3) bands were generated by using Eqs. (4.3) and (4.4), respectively. The resultants of the new bands are as shown in Fig. 4-9, which are particularly useful in extracting rooftops from the other land cover types. As a result of the aforementioned steps, 
the image dataset has now fifteen bands in total (eight original bands, three PCA bands, two NDVIs and two SUM bands).

$$
\begin{aligned}
& \text { SUM732 }=\text { NIR } 1+\text { Green }+ \text { Blue } \\
& \text { SUM753 }=\text { NIR } 1+\text { Red }+ \text { Green }
\end{aligned}
$$

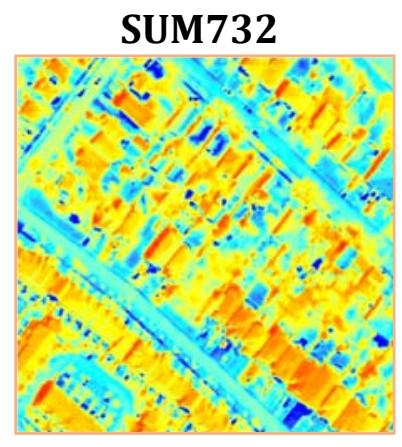

(a)

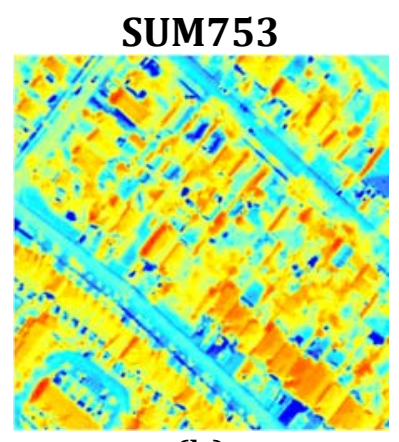

(b)
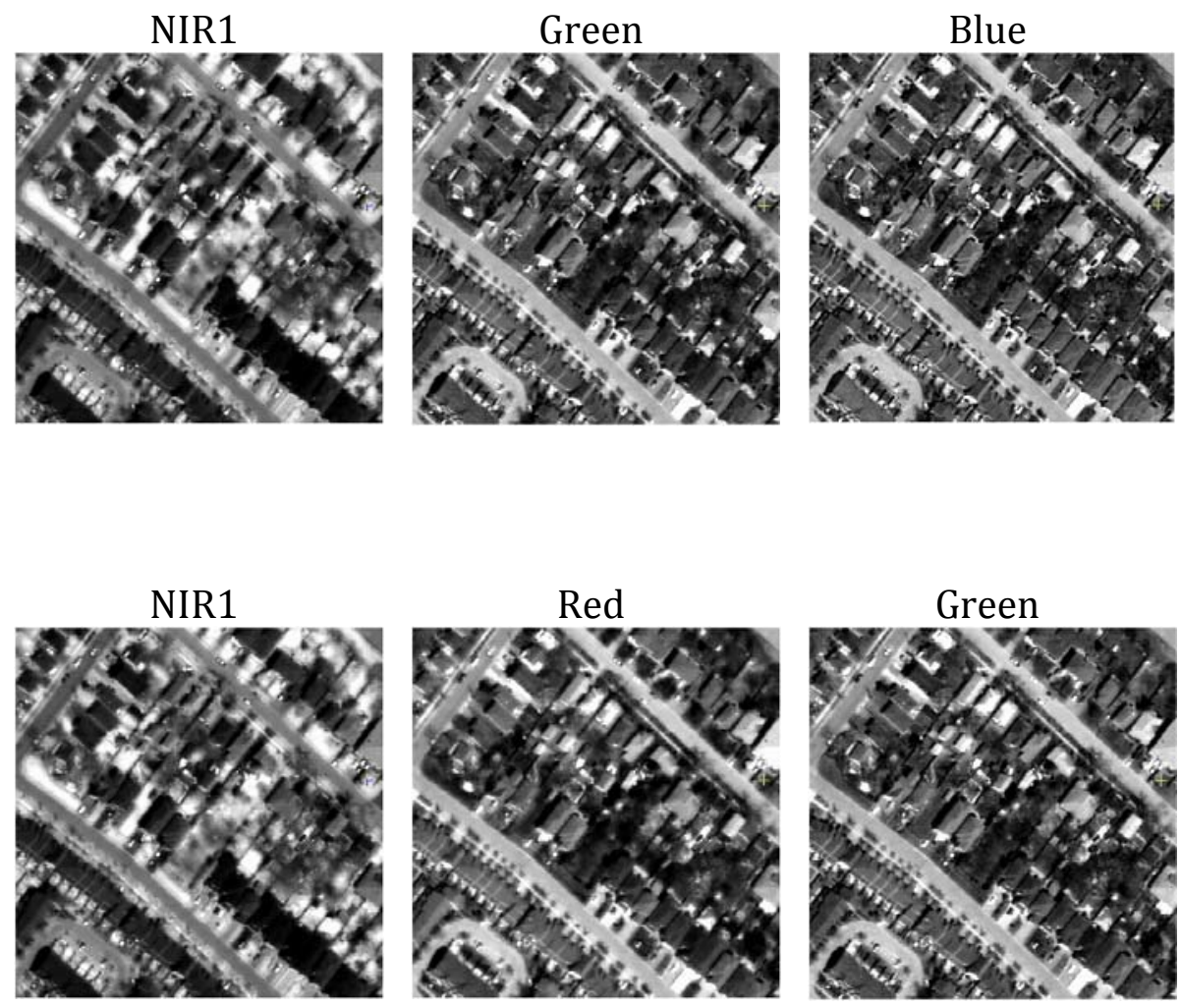

Figure 4-9 Subset of WorldView-2: (a) SUM 732 band (b) SUM753 band 


\subsection{Object-based Image Classification Method}

Object-based image classification method composes of two major phases: segmentation and classification. Segmentation aims to group neighbouring pixels into "objects" at multiple scale levels, where the grouped pixels are relatively homogeneous in terms of the brightness values of the image bands (Blaschke, 2010). In second part, a two-stage image classification method was developed that utilizes spatial, spectral and topological information.

\subsubsection{Segmentation}

The image was broken down into object segments using eCognition 8.1. The problems associated with segmentation process are either the image could be over-segmented (when the real world object is segmented into smaller objects) or under-segmented (when more than one of the real world objects are merged together). The first stage of object-based image classification, segmentation, significantly affects the classification result. Hence, several trials were executed to avoid over-segmentation or under-segmentation.

Multi-resolution segmentation was used to group homogeneous pixels with the following settings in the eCognition 8.1. The advantages of multi-resolution segmentation is being able to segment an image into "homogenous areas to the different scales of interest". In general, residential land cover types are composed of small heterogeneous regions; hence, scale parameter was set at 20. A visual inspection of the segmented polygons pointed out that there were still some of the objects being over-segmented. However, when scale parameter was increased over 20, many objects were under-segmented. Hence, scale parameter was set at 20 , and the over-segmented will be rectified by spatial merging, combining more than one objects, in the classification process. Then, segments homogeneity 
parameters: shape and compactness of interested land cover type were customized for a given study area. To capture as much shaded areas in the form of long and narrow polygons between two houses, compactness criteria (compactness of a square being 1) was set 0.2 . Then, the weight of shape (in the range of $0.1-1$ ) was set as 0.8 . Another parameter was defining the weight of bands to be used in segmentation. Since auxiliary bands contain additional useful information, band combination was assigned as the auxiliary bands weigh double than the original eight bands. These parameters were selected based on trial-runs for this specific study area; therefore, one may not obtain the optimum result using these parameters on other imageries. The outcome of the segmentation process is as shown below in Fig. 4-10.

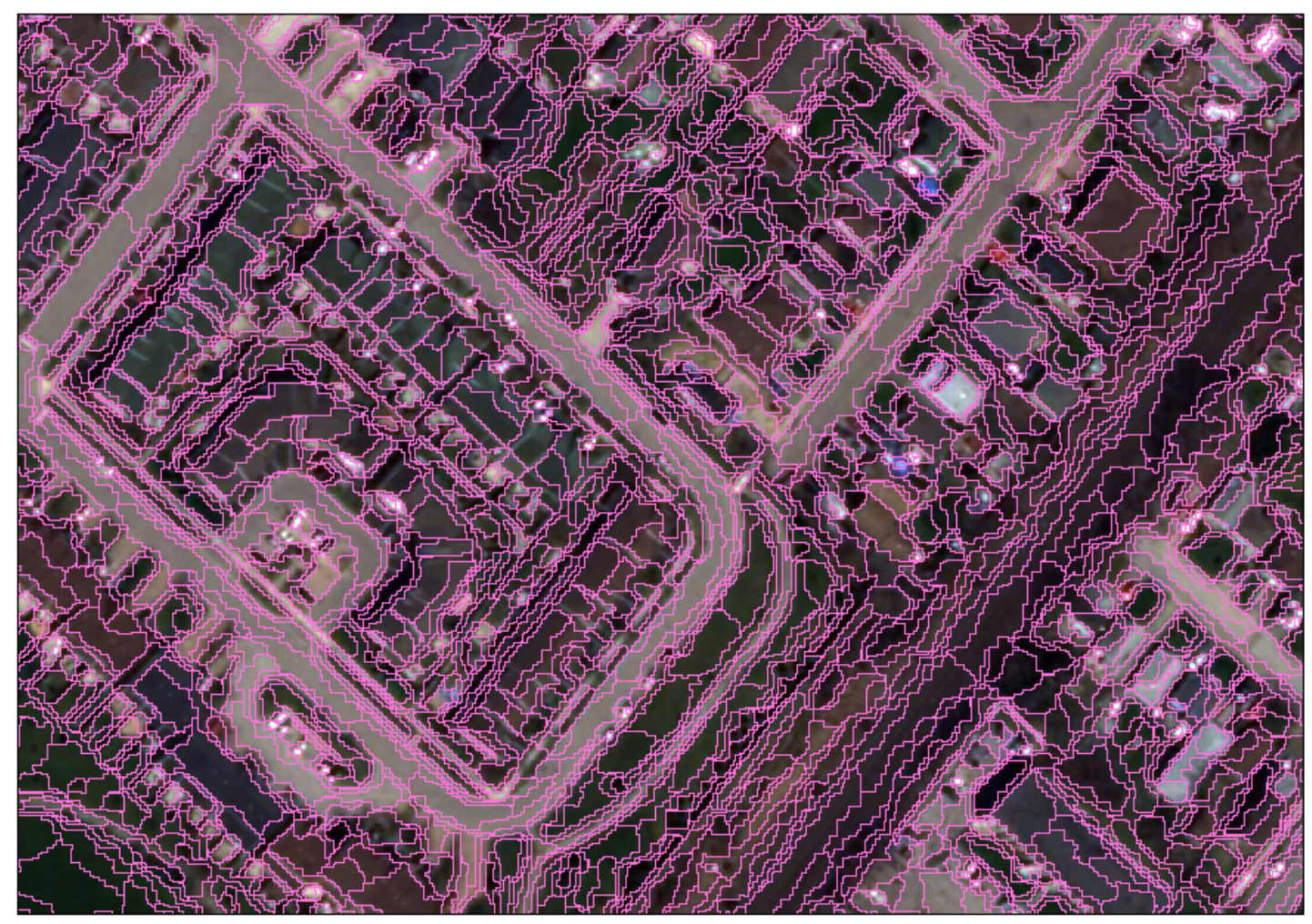

Figure 4-10 Segmentation Results 


\subsubsection{Two-Stage Land Cover Classification Method}

The following proposed image classification method involved two stages. In the first stage, brightness values and area parameters were used to develop decision rules to classify the image into four different land cover types. In the second stage, the topological rules were applied to rectify some mis-classified results of the first stage.

\section{- First Stage: Rule-based Decision Tree Classification}

The result of segmentation process, segmented polygons, were then processed in ArcMap 10.2. To extract the brightness values of all the generated bands and area parameters for each polygon, the zonal statistics as table tool was used. Then, the polygons were classified into one of the land cover types as defined previously in Sec.4.3.1.

By analyzing the brightness values of each land cover type, a general to specific rulebased decision tree, composed of a condition(s) and an action was developed. The bands with the highest separability were selected as the conditions for each segmented polygon to be classified as the certain land cover type. Firstly, polygons were classified as either vegetation or non-vegetation, while considering both grass and tree as vegetation, and building and road as non-vegetation. Fig. 4-11 shows the brightness values of vegetation and non-vegetation groups at different bands. By analyzing the brightness values of mean, mean+std deviation, mean-std deviation of interested land cover types, and a preview of the tentative classification results (Fig. 4-11(b)) led to the development of decision trees as shown in Figs. 4-12 and 4-13 for Image1 and Image2, respectively. The remaining stages of brightness values plots, which led to the conclusion of selecting specific condition(s) at each step, are provided in Appendix. A. 


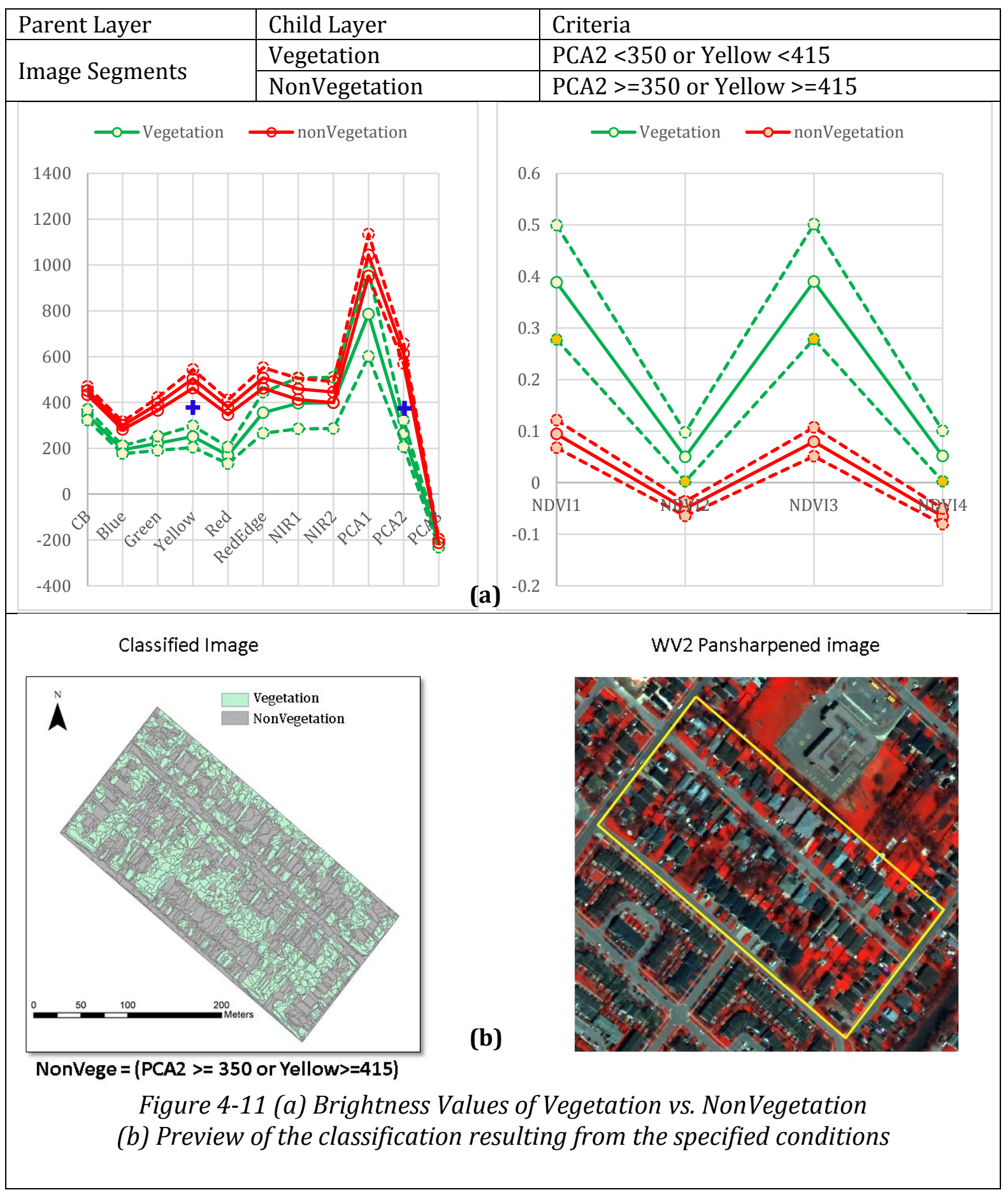




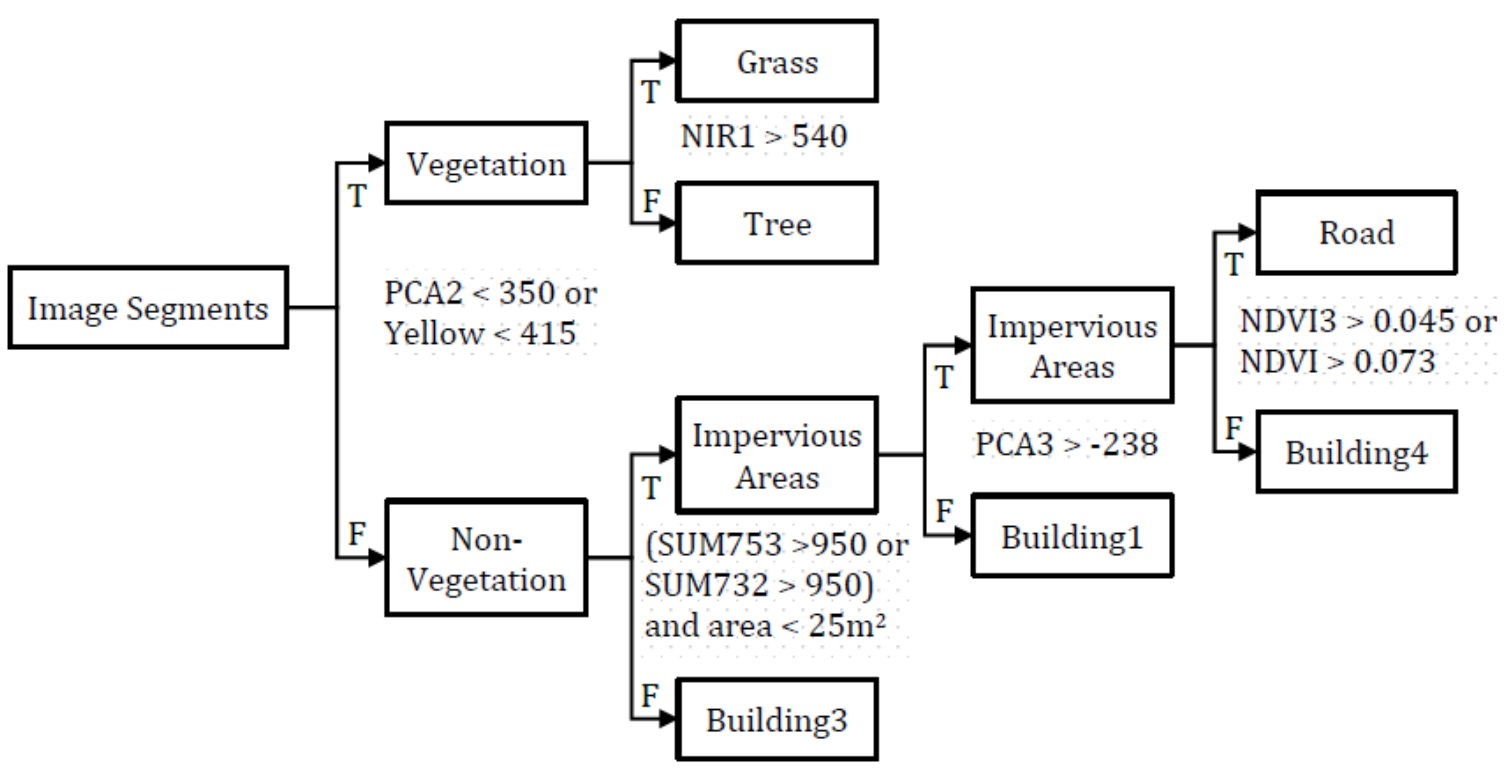

Figure 4-12 Decision Tree for Image1

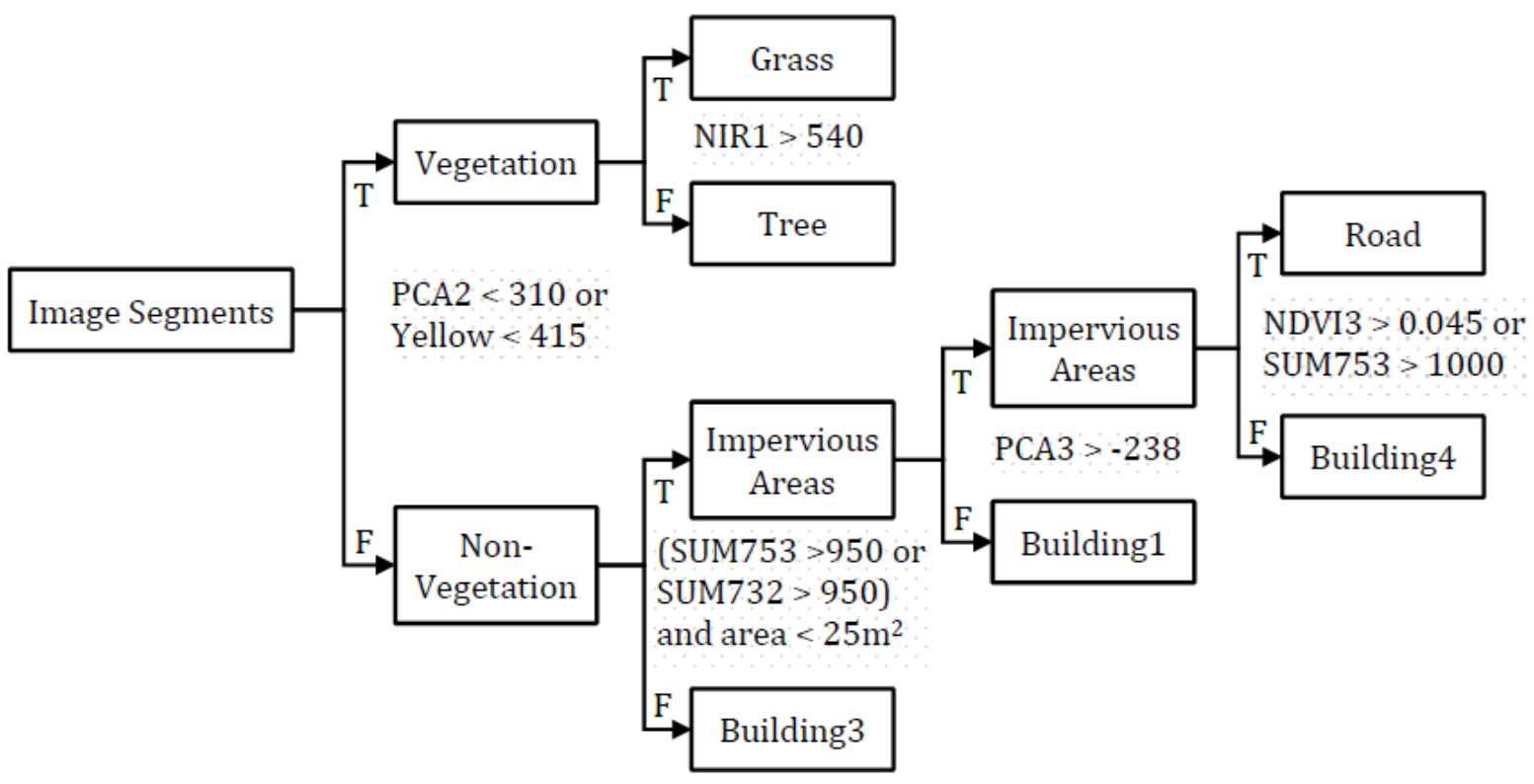

Figure 4-13 Decision Tree for Image2 
Same structure of the decision tree was applied to both Image1 and Image2 with modification of decision rules. With reference to Fig. 4-11, at the point of differentiating between vegetation and non-vegetation, each polygon's brightness values of PCA2 and Yellow bands were examined as shown in Fig. 4-10. If the stated conditions were satisfied, the polygon was classified as vegetation; otherwise, it was assigned into non-vegetation. As noted earlier, due to the existence of a variety of roof colours, buildings were split into different groups. At the end of the decision tree, the images were classified into four land cover types: 1) grass, 2) tree, 3) road, and 4) building. Once each polygon had land cover types assigned, spatial merging was carried out based on the classification result. This process was applied to rectify the over-segmented polygons if they shared the edges and had the same classification result. Fig. 4-15 and Fig. 4-17 display the first-stage classification results of Image 1 and Image2, respectively.

\section{- Second Stage: Post-classification based on Topological Rules}

Land cover classification in urban areas hinders the process due to the existence of unexpected objects. For example, cars either moving on roads or parking at driveways were the problematic in classifying these catchment areas. Cars had a similar reflectance range as rooftops; therefore, many polygons on roads (cars being on roads) were misclassified as buildings as shown in Fig. 4-14. For this reason, the topological rule, derived from a GIS parcel boundary, was applied to enhance the classification accuracy. This parcel boundary restricted the polygons being classified as buildings if the polygons were located on the municipal right-of-way (ROW). Firstly, buffer area of $0.001 \mathrm{~m}$ for buildings on the ROW were generated. Then, in ArcMap 10.2, the condition: 100\% of Boundary of Building intersected 
with the Interior of Road was checked. If the certain buildings satisfied the condition of $B$ (Building) $\cap I($ Road), these misclassified buildings were post-classified as roads.
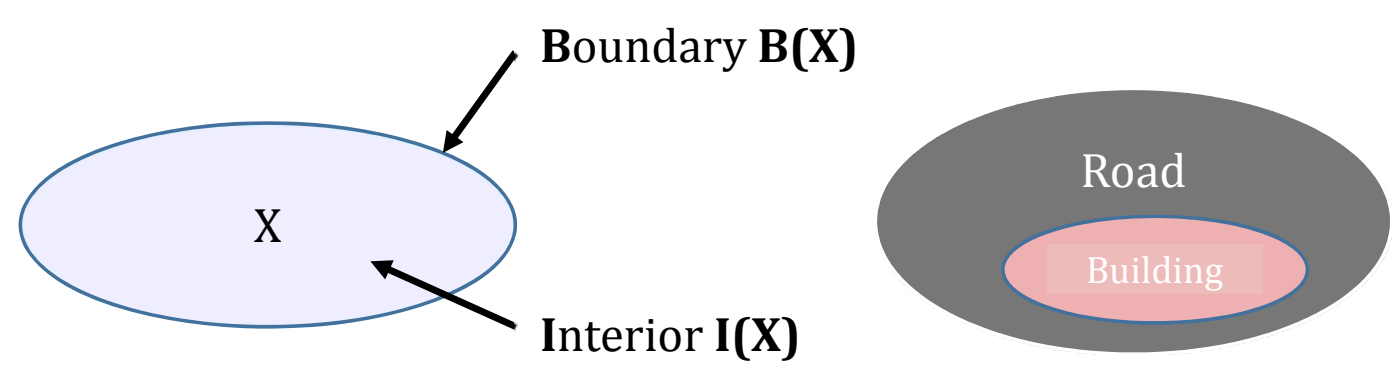

Figure 4-14 A Topological Rule Applied in the Second-stage of the Image Classification

By applying this rule, misclassified buildings were now correctly classified as roads. While using the parcel boundary dealt with some misclassified buildings, this procedure had a drawback. Generally, an overlaying of two or more layers produces sliver polygons, which are small narrow polygons, not representing a real feature. Consequently, the area rule stating that every polygon must be greater than $4.5 \mathrm{~m}^{2}$ to be considered as an object. Otherwise, it was considered as a sliver polygon, and the polygon that shared the longest boundary merged into a sliver polygon. The following Figs. 4-16 and 4-18 were the results of the proposed two-stage classification method of Image1 and Image2, respectively. 


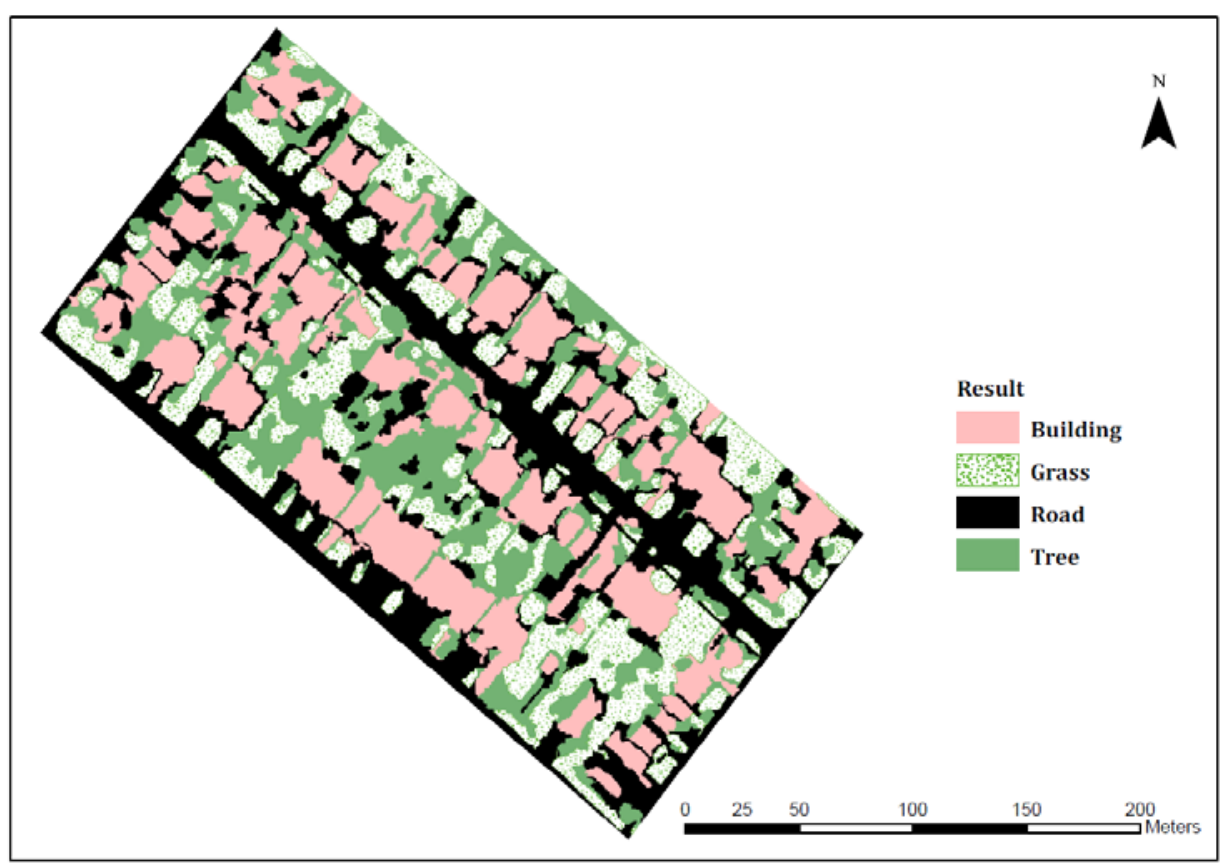

Figure 4-15 First-stage Classification Result -Image1

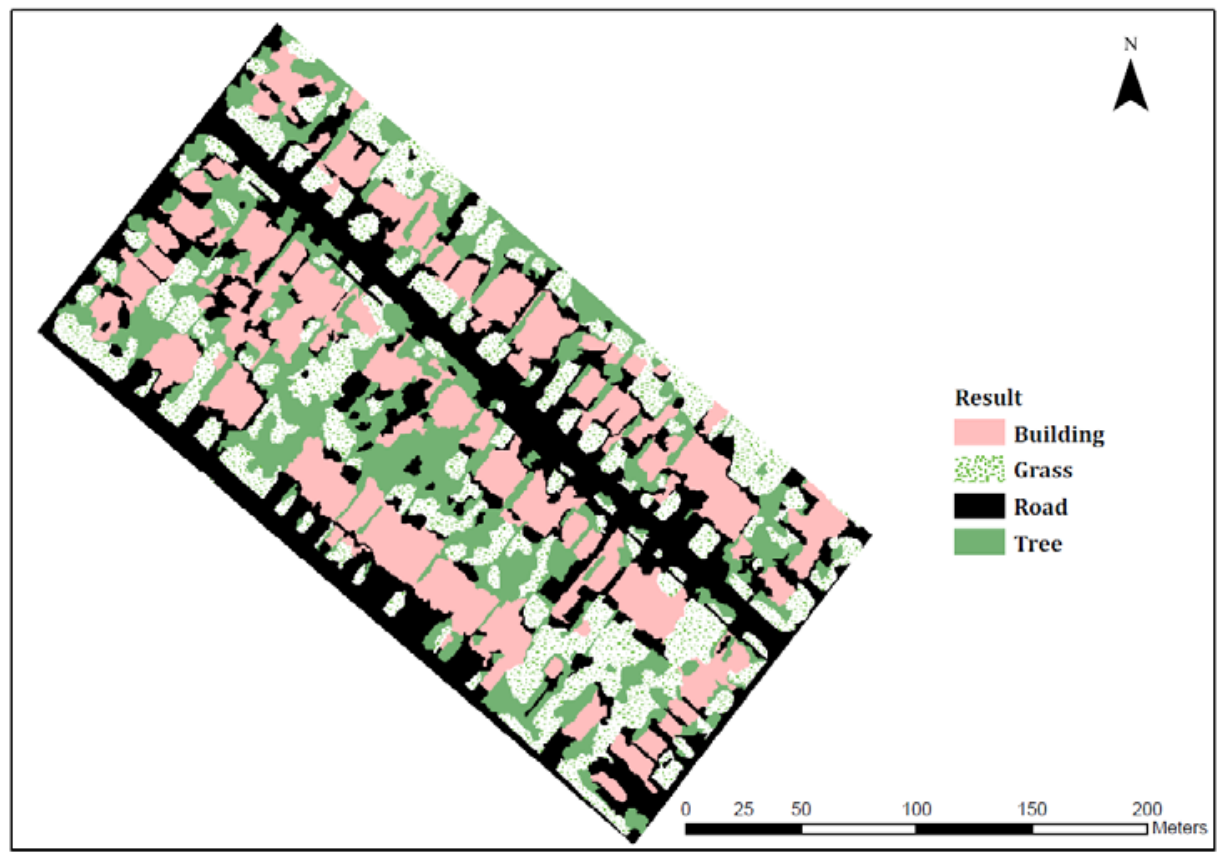

Figure 4-16 Two-stage Classification Result -Image1 


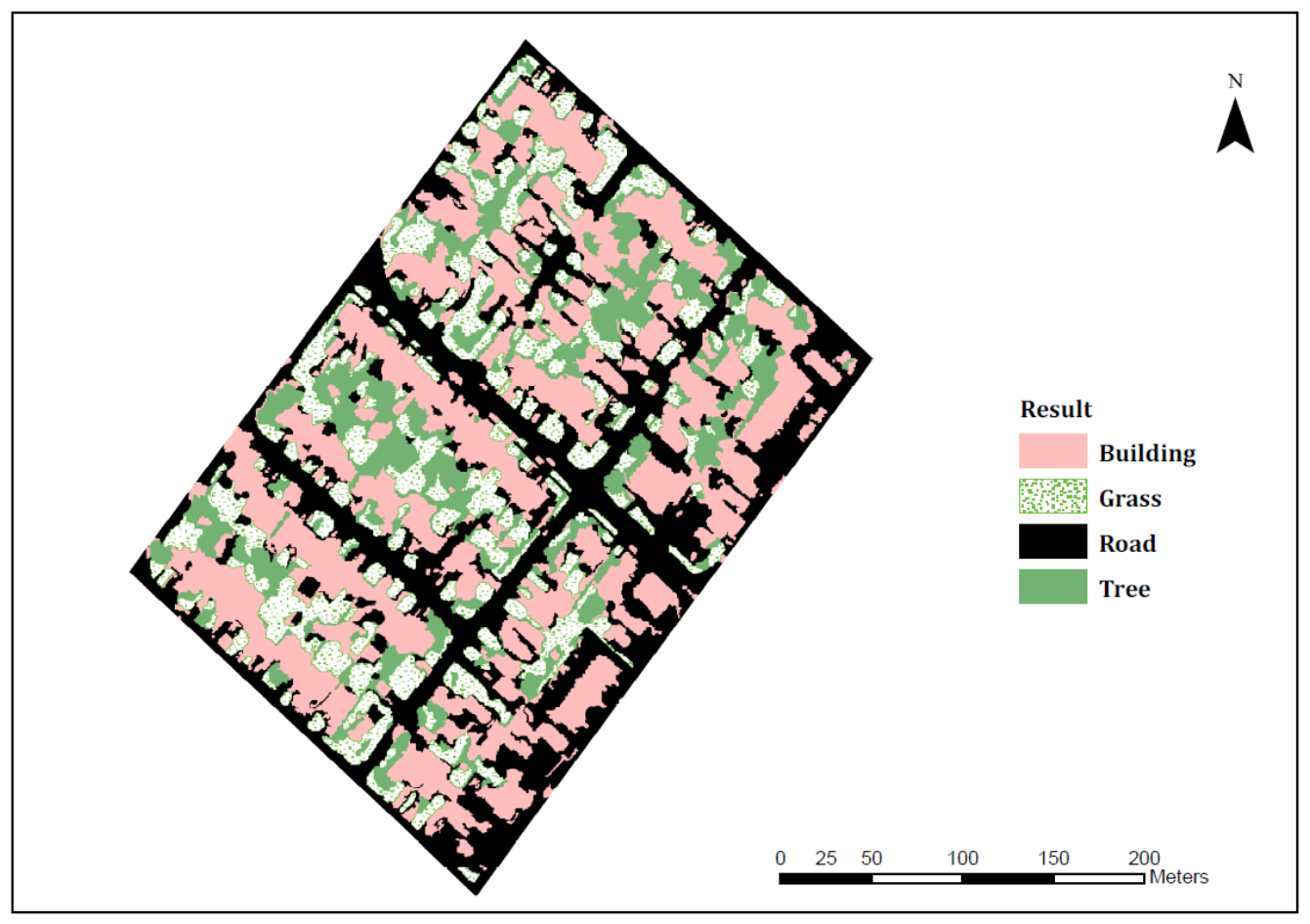

Figure 4-17 First-stage Classification Result -Image2

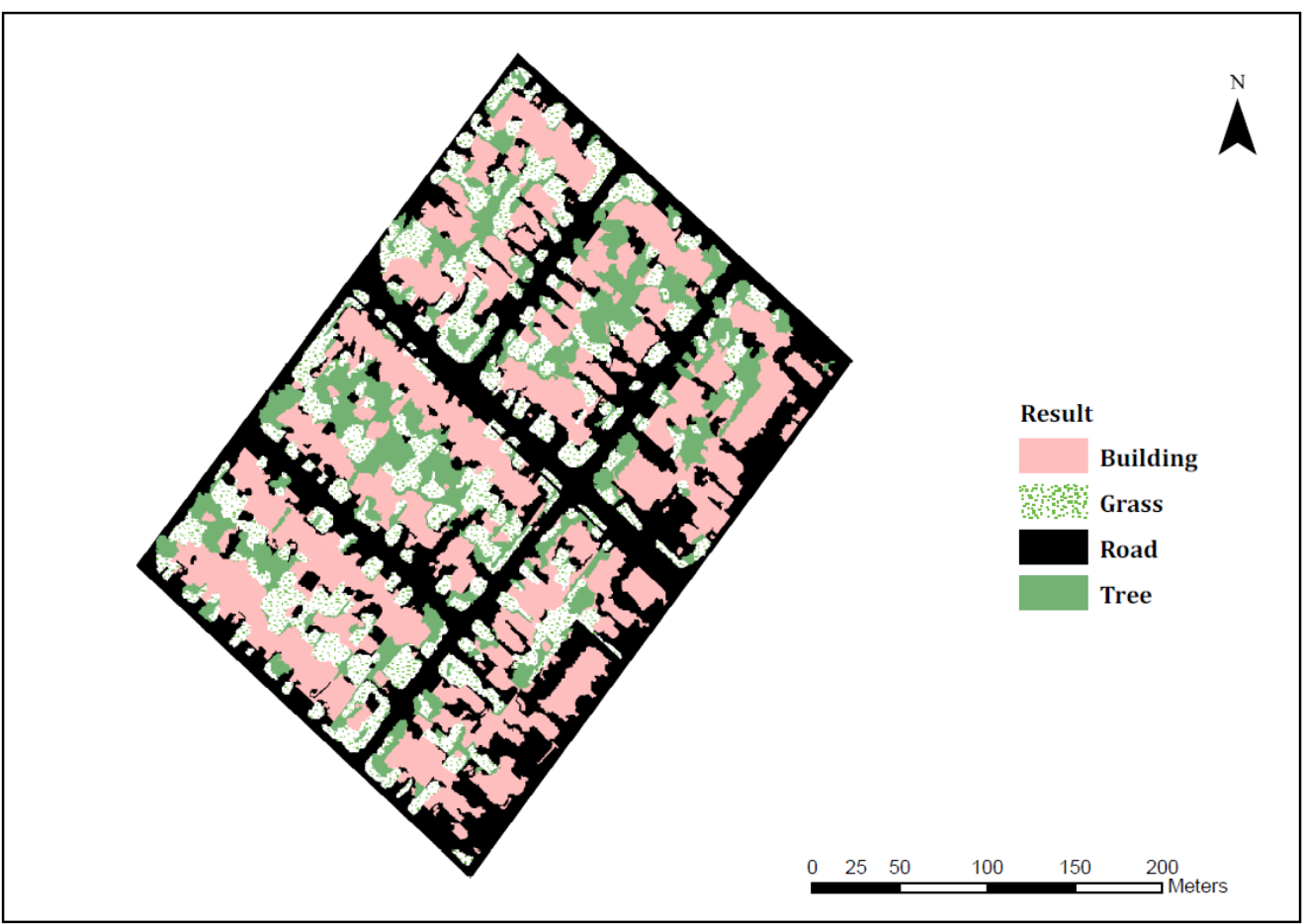

Figure 4-18 Two-stage Classification Result-Image2 


\subsection{Accuracy Assessment}

Accuracy assessment is required to evaluate the accuracy of land cover classification. In this study, the common method using error matrix, overall accuracy, producer's accuracy and user's accuracy were demonstrated with randomly generated 500 reference points for each image. Principally, traditional pixel-based maximum likelihood result is used as a base result to emphasize the improved accuracy of the proposed classification method. Hence, two-stage classification method results were compared with the pixel-based classification result. To perform the comparison, pixel-based classification method using the maximum likelihood algorithm was executed on a WorldView-2 image having the original eight bands.

Moreover, the whole purpose of this study was to classify the study catchment areas and examine how applicable it is to use remote sensing derived land cover information in urban drainage modelling. In order to validate the latter purpose, an assessment with parcelspecific areas distribution, using GIS data of land cover information as reference, was also conducted in addition to the error matrix. This assessment shed light on the effects of land cover data variance on hydrologic simulations. Since in hydrologic sense, the \% imperviousness is more important than the points being classified correctly.

\subsubsection{Assessment with Randomly Generated Points}

To assess the image accuracy, 500 checkpoints were randomly generated for each image in PCI Geomatica, and each point was assigned one of the abovementioned four land cover types based on a visual interpretation of satellite image. As shown in Table. 4-3, there were 
127 checkpoints for grass, while 111 points fell within polygons those were correctly classified as grass, and the remaining 16 points fell within the polygons those were misclassified as followings: seven points of them within tree, none within building, and nine points within road polygons. In this case, 111 out of 127 points were correctly classified; that thus resulted in $87.40 \%$ producer's accuracy for grass.

User's accuracy is associated with how many checkpoints of other land cover types fall within the grass polygons. In row total, 126 of checkpoints fell within the polygons, which were classified as grass; however, nine, two, four of the checkpoints were actually tree, building, and road, respectively. In other words, the polygons having the checkpoints of other land cover types were misclassified as grass. Since 15 of the checkpoints were not grass, only 111 points were correctly classified as grass out of 126 checkpoints. Thus, that resulted in $88.10 \%$ of user's accuracy for grass. The remaining classes can also be interpreted in this way. The overall accuracies achieved were $80.60 \%$ and $83.00 \%$ in Image 1 and Image2, respectively, using the two-stage classification method.

Table 4-3 Error Matrix of the Two-stage Classification Result for Image1

\begin{tabular}{lcccccc}
\hline \hline & \multicolumn{7}{c}{ Known Cover Types } \\
\cline { 2 - 7 } Classified & Grass & Tree & Building & Road & Total & User's \\
\hline Grass & $\mathbf{1 1 1}$ & 9 & 2 & 4 & 126 & $88.10 \%$ \\
Tree & 7 & $\mathbf{5 8}$ & 22 & 10 & 97 & $59.79 \%$ \\
Building & 0 & 2 & $\mathbf{1 2 5}$ & 8 & 135 & $92.59 \%$ \\
Road & 9 & 3 & 18 & $\mathbf{1 0 8}$ & 138 & $78.26 \%$ \\
\hline Total & 127 & 73 & 168 & 132 & 500 & \\
\hline \hline Producer's & $87.40 \%$ & $79.45 \%$ & $74.40 \%$ & $81.82 \%$ & & $\mathbf{8 0 . 6 0 \%}$ \\
\hline \hline
\end{tabular}


Table 4-4 Error Matrix of the Two-stage Classification Result for Image2

\begin{tabular}{lcccccc}
\hline \hline & \multicolumn{7}{c}{ Known Cover Types } \\
\cline { 2 - 7 } Classified & Grass & Tree & Building & Road & Total & User's \\
\hline Grass & $\mathbf{1 1 8}$ & 9 & 0 & 0 & 127 & $92.91 \%$ \\
Tree & 8 & $\mathbf{7 2}$ & 6 & 1 & 87 & $82.76 \%$ \\
Building & 1 & 15 & $\mathbf{1 2 3}$ & 7 & 146 & $84.25 \%$ \\
Road & 6 & 13 & 19 & $\mathbf{1 0 2}$ & 140 & $72.86 \%$ \\
\hline Total & 133 & 109 & 148 & 110 & 500 & \\
\hline Producer's & $88.72 \%$ & $66.06 \%$ & $83.11 \%$ & $92.73 \%$ & & $\mathbf{8 3 . 0 0 \%}$
\end{tabular}

\subsubsection{Assessment with Parcel-specific Areas Distribution}

This assessment was conducted to determine the percent imperviousness at lot-level. The classified image was intersected with the parcel-boundary GIS data to create individual lots. Then, a ratio of the total area of building and driveway/road to the total area of the parcel was taken into consideration to get $\%$ imperviousness at lot-level for both modified GIS and classified images. Modified GIS data was used as a reference data in calculating the percent difference of imperviousness between the modified GIS and remote sensing derived information. As shown in Fig. 4-19, 80\% of the lot's imperviousness difference varies from $+20 \%$ to $-20 \%$. For the remaining $20 \%$ of the lots, imperviousness from remote sensing data overestimated $30 \%$ to $40 \%$ than GIS data.

The overall pervious and impervious areas distribution for the three study catchments at drainage level is as shown in Table 4-5. The classified WorldView-2 image using the two-stage method resulted $7,542 \mathrm{~m}^{2}, 6,469 \mathrm{~m}^{2}, 1,640 \mathrm{~m}^{2}$ of pervious area in LV1, LV2 and LV4, respectively, while the modified GIS data reported $8,272 \mathrm{~m}^{2}, 8,870 \mathrm{~m}^{2}, 2,041 \mathrm{~m}^{2}$ for LV1, LV2 and LV4, respectively. Remote sensing underestimated pervious area than GIS 
data, and the area differences were added onto impervious area. Hence, remote sensing data produced $9,529 \mathrm{~m}^{2}, 10,753 \mathrm{~m}^{2}, 2,209 \mathrm{~m}^{2}$ of impervious area in LV1, LV2 and LV4, respectively; GIS data reported $8,796 \mathrm{~m}^{2}, 8,348 \mathrm{~m}^{2}, 1,635 \mathrm{~m}^{2}$ for $\mathrm{LV} 1, \mathrm{LV} 2$ and LV4, respectively. The reason behind remote sensing data has more impervious area is due to a common problem of high resolution images, which capture shadows (Myint et al., 2011). Shaded areas, which have similar brightness values as dark impervious area, were misclassified as dark impervious area leading to have a higher impervious area in this study.

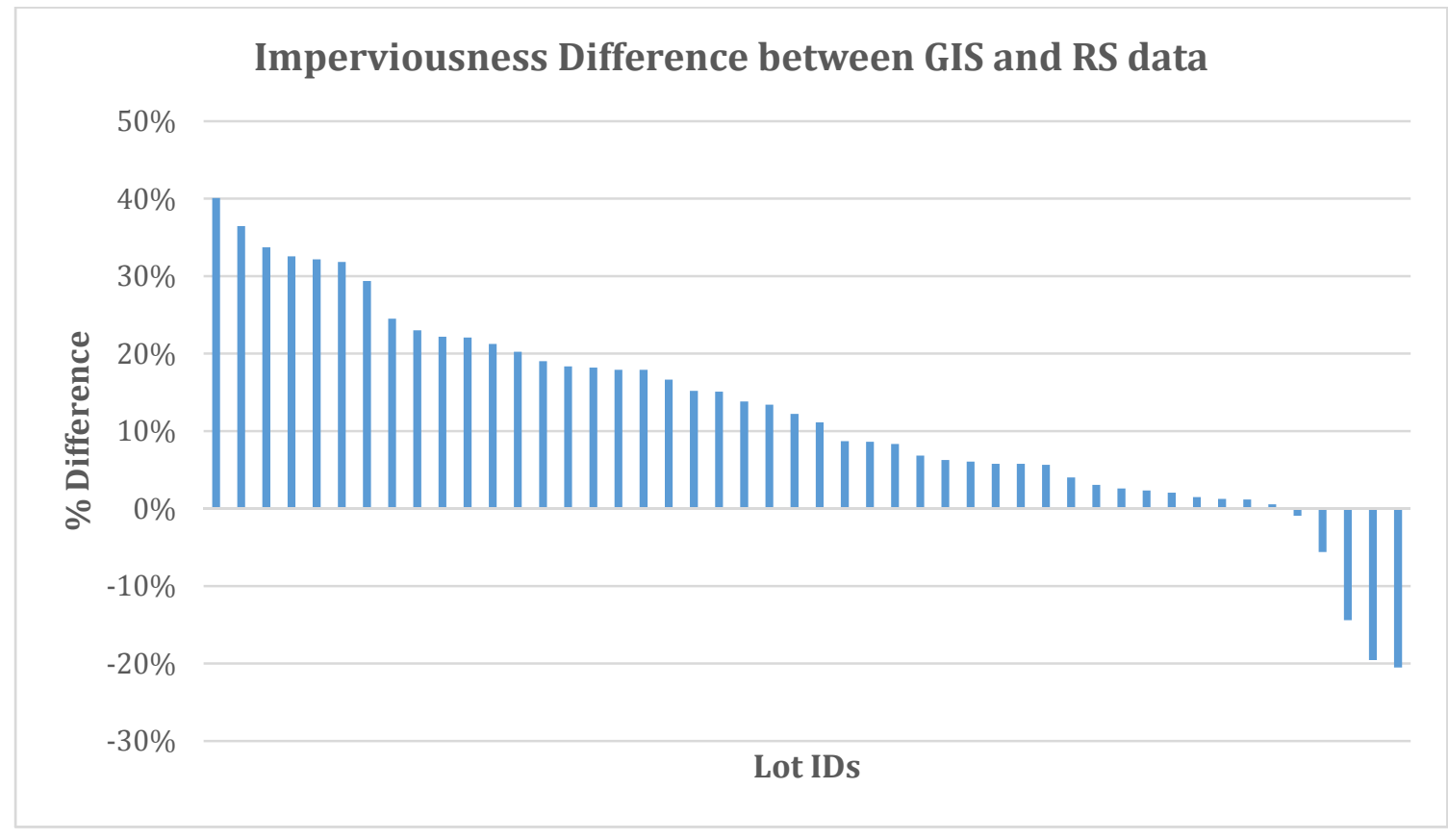

Figure 4-19 Percent Imperviousness Differences between Two Sources of Data

\subsection{Summary}

This chapter demonstrated the image classification on WorldView-2 images using pixelbased and the proposed two-stage classification methods. Four different land cover types that have different hydrological responses were extracted: 1) grass, 2) tree, 3) road and 4) building. 
Table 4-5 Total Area Distribution of Study Catchments

\begin{tabular}{|c|c|c|c|c|c|}
\hline \multicolumn{3}{|c|}{ Remote Sensing Data } & \multicolumn{3}{|c|}{ Reference GIS data } \\
\hline $\begin{array}{l}\text { Catc } \\
\text { hme } \\
\text { nt }\end{array}$ & $\begin{array}{c}\text { Pervious } \\
\text { Area }\left(\mathrm{m}^{2}\right)\end{array}$ & $\begin{array}{c}\text { Impervious } \\
\text { Area }\left(\mathrm{m}^{2}\right)\end{array}$ & $\begin{array}{l}\text { Catch } \\
\text { ment }\end{array}$ & $\begin{array}{c}\text { Pervious } \\
\text { Area }\left(\mathrm{m}^{2}\right)\end{array}$ & $\begin{array}{c}\text { Impervious } \\
\text { Area }\left(\mathrm{m}^{2}\right)\end{array}$ \\
\hline LV1 & 7,542 & 9,529 & LV1 & 8,272 & 8,796 \\
\hline LV2 & 6,469 & 10,753 & LV2 & 8,870 & 8,348 \\
\hline LV4 & 1,640 & 2,209 & LV4 & 2,041 & 1,635 \\
\hline
\end{tabular}

In general, many objects in the residential area are notably small; therefore, a pansharpened image was produced to get a smaller pixel size of 0.5 metre. Despite this visual enhancement, another limitation of urban applications is that many objects may share similar reflectance values because they are made up of the same materials, for example, asphalt driveway vs. asphalt rooftop. Therefore, image segmentation was executed to group pixels that have similar reflectance value to form objects.

Objects' characteristics (e.g. object size and spectral reflectance values) were taken into consideration to develop a rule-based decision tree in the first stage of the classification method. In the second stage of the classification, parcel-boundary was incorporated to produce more accurate classified images. As a part of the post-classification, the area rule of each object must be greater than $4.5 \mathrm{~m}^{2}$ was imposed to eliminate sliver polygons.

The pixel-based method generated an overall accuracy of $63.60 \%$ and $73.00 \%$ in Image1 and Image2. As described in Tables. 4-1and 4-2, maximum likelihood error matrices had high errors of omission and commission resulting in inconsistence of user's and 
producer's accuracy within the class. On the other hand, the proposed two-stage classification method produced a higher overall accuracy of $80.60 \%$ and $83.00 \%$ with a $16.46 \%$ and $10 \%$ improvement. The improvement of the two-stage classification method was evidenced by having more correctly classified points and a visually less pixelated classified images. In the two-stage classification output, the classified image had a lot less speckled pixels since pixels having a similar spectral response were grouped as an object.

The classified images of the two-stage classification method was also examined the $\%$ imperviousness at lot-level as well. The \% imperviousness figure illustrated that remote sensing data resulted in the range of $-20 \%$ to $+20 \%$ imperviousness difference for about $80 \%$ of the total number of lots compared to GIS data. In the extreme case, remote sensing data overestimated the impervious areas of $40 \%$ at lot-level for about $10 \%$ of the total number of lot. Since the employed GIS data were not collected for stormwater management purposes, not all the areas were not presented in closed polygons. For example, driveways were simply described by two parallel polylines and grass areas were excluded in the GIS data collection. Hence, the assumption was made that the un-identified areas in GIS data as grass areas. Regardless of that, the GIS data was used as a reference and compared the \% imperviousness. The next chapter examines the influence of a variation of land cover information by developing urban drainage models with the extracted land cover types from satellite images and GIS land cover data. 


\section{Chapter 5}

\section{Development of Urban Drainage Models}

\subsection{Introduction}

This chapter focuses on the development of drainage models using SWMM for the study catchment areas mentioned in Chapter 3. The aforementioned three catchment areas have three different drainage systems: 1) curb and gutter in LV1, 2) roadside ditches with culvert, and curb and gutter controls in LV2 and 3) LID techniques -porous pavement and bioretention systems in LV4. The land cover information required in SWMM was extracted from two different sources: modified GIS land cover data presented in Chapter 3, and the classified WorldView-2 images that were processed in Chapter 4. Using GIS land cover data each drainage system was modelled in two different resolutions of hydrologic response unit: lumped and detailed models. Therefore, the models developed were: 1) lumped models using GIS data, 2) detailed distributed homogeneous-area models using remote sensing data and 3) detailed distributed homogeneous-area models using GIS data.

CVC conducted detailed survey and found out that some of the downspouts were still directly connected to the stormwater system. The provided list only included roof directly connected area (RDCA) therefore, RDCA were approximately distributed throughout the catchment areas. With this detailed field conditions knowledge, each detailed model had two 
scenarios: downspouts completely disconnected and partially connected, and lumped models had only connected scenario. The latter is a typical approach employed in practice when evaluating LID opportunities or potential to control runoff, while the former would be used if a modeller had access to remote sensing or GIS data as well as detailed field information and took a more detailed approach to modelling the drainage areas with and without LIDs. The below Table 5-1 summarizes the modelled scenarios.

Table 5-1 Modelled Scenarios

\begin{tabular}{|c|c|c|c|}
\hline $\begin{array}{c}\text { Site } \\
\text { Name }\end{array}$ & System & Model & Scenario \\
\hline \multirow{5}{*}{ LV1 } & \multirow{5}{*}{$\begin{array}{l}\text { Curb \& } \\
\text { Gutter }\end{array}$} & Lumped & Partial downspouts connected \\
\hline & & \multirow{2}{*}{ Detailed distributed - RS } & Downspouts disconnected \\
\hline & & & Partial downspouts connected \\
\hline & & \multirow{2}{*}{ Detailed distributed - GIS } & Downspouts disconnected \\
\hline & & & Partial downspouts connected \\
\hline \multirow{5}{*}{ LV2 } & \multirow{5}{*}{$\begin{array}{c}\text { Roadside } \\
\text { Ditches + } \\
\text { Curb \& } \\
\text { Gutter }\end{array}$} & Lumned & Partial downsnouts connected \\
\hline & & \multirow{2}{*}{ Detailed distributed - RS } & Downspouts disconnected \\
\hline & & & Partial downspouts connected \\
\hline & & \multirow{2}{*}{ Detailed distributed - GIS } & Downspouts disconnected \\
\hline & & & Partial downspouts connected \\
\hline & & & \\
\hline \multirow{5}{*}{ LV4 } & \multirow{5}{*}{$\begin{array}{c}\text { Bioretention } \\
\text { \& Porous } \\
\text { Pavement } \\
\text { (After LID) }\end{array}$} & Lumped & Partial downspouts connected \\
\hline & & \multirow{2}{*}{ Detailed distributed - RS } & Downspouts disconnected \\
\hline & & & Partial downspouts connected \\
\hline & & \multirow{2}{*}{ Detailed distributed - GIS } & Downspouts disconnected \\
\hline & & & Partial downspouts connected \\
\hline
\end{tabular}

For lumped models, all of the parameters that affect the hydrologic response of catchments were averaged to create uniform subcatchments, since this is how they are represented in a modelling tool like SWMM (i.e. an inclined rectangular plane with single values used to represent hydrologic losses and calculate the resulting runoff rates) (Johnson 
and Miller, 1997). In distributed homogeneous-area models, on the other hand, a subcatchment was presented by a homogeneous land cover type. Therefore, all the hydrologic parameters explicitly represented a unique hydrologic characteristics of a homogeneous land cover type that, in theory, results in a more representation of the actual runoff process. The two distributed homogeneous-area models used land cover information from two different sources, but the same model structure and subcatchment parameterization. This comparison was made to examine how the land cover variation, as determined from different data sources, influences the hydrologic simulation results.

The development of lumped urban drainage models is discussed in Section. 5.2 and detailed distributed homogeneous-area models is discussed in Section. 5.3. Simulation results of each drainage system from three different models were compared to the observed data based on identified rainfall events that occurred between July 2010 and December 2013. Simulation options are detailed in Section. 5.4. The models performance was analyzed by comparing total simulated vs. observed surface runoff volume, simulated vs. observed peak flow rate, flow duration exceedance and water balance, and is presented in Section. 5.5. The chapter is concluded by providing discussion of the simulation results and the site conditions in Section. 5.6.

\subsubsection{Curb and Gutter Control System}

This model was based on the existing site condition of LV1 that uses traditional curb and gutter and stormwater pipes for runoff conveyance. The location of curb and gutter, minor 
system inflows (catch basin), and properties of storm sewers were obtained from GIS layers (described in Section 3.4) provided by the City of Mississauga.

\subsubsection{Roadside Ditches System}

LV2 drainage area spans over two streets: Eastmount Avenue and First Street. Eastmount Avenue has roadside ditches and First Street is serviced by curb and gutter. SWMM provides two options for modelling of roadside ditches: as a conduit with defined cross-section properties and as an LID - vegetative swales as illustrated in Fig. 5-1. In reality, runoff from ditches drains through culverts that exist beneath each driveway. However, SWMM does not support to discharge runoff from swales (catchment) to an inlet of a culvert system (node). Therefore, outlet of swales was set to be downstream swales. This assumption was reasonable to make since the time taken for runoff to pass through a seven-metre-long culvert system is extremely short. Besides, runoff neither evapotranspirates nor infiltrates while passing through a culvert system. Therefore, this approach is expected to have negligible effects on the model results hydraulically or hydrologically.

Another attempt was also made to model roadside ditches differently by representing ditches' hydrology as a catchment and hydraulics as an open trapezoidal channel with exfiltration. Runoff from a channel was routed to a downstream inlet of a culvert system. This representation in SWMM reflects how roadside ditches convey runoff. However, to let runoff in trapezoidal channel infiltrate, numerical experiments showed that the seepage rate must be set really high, and only an extreme seepage rate seemed to give a reasonable runoff 
in this approach. Therefore, this approach was abandoned in favour of modelling ditches as swales was presented.

When estimating the parameters required for LID - vegetative swales, some uncertainty exists since the true value may not always be known. The most challenging issue was trying to estimate the berm height of swales, which represents a depth of water that can be ponded before draining downstream. The image in Fig 5-1, shows the condition of roadside ditches along Eastmount Avenue. Some of the culverts were almost fully blocked, which restricted the flow of runoff downstream. As a result, runoff was ponded in ditches and local flooding occurred. This is what residents were concerned about the drainage system in this neighbourhood; therefore, a pilot LID project (bioretention and porous pavement) was initiated on the next street to remedy the issue.

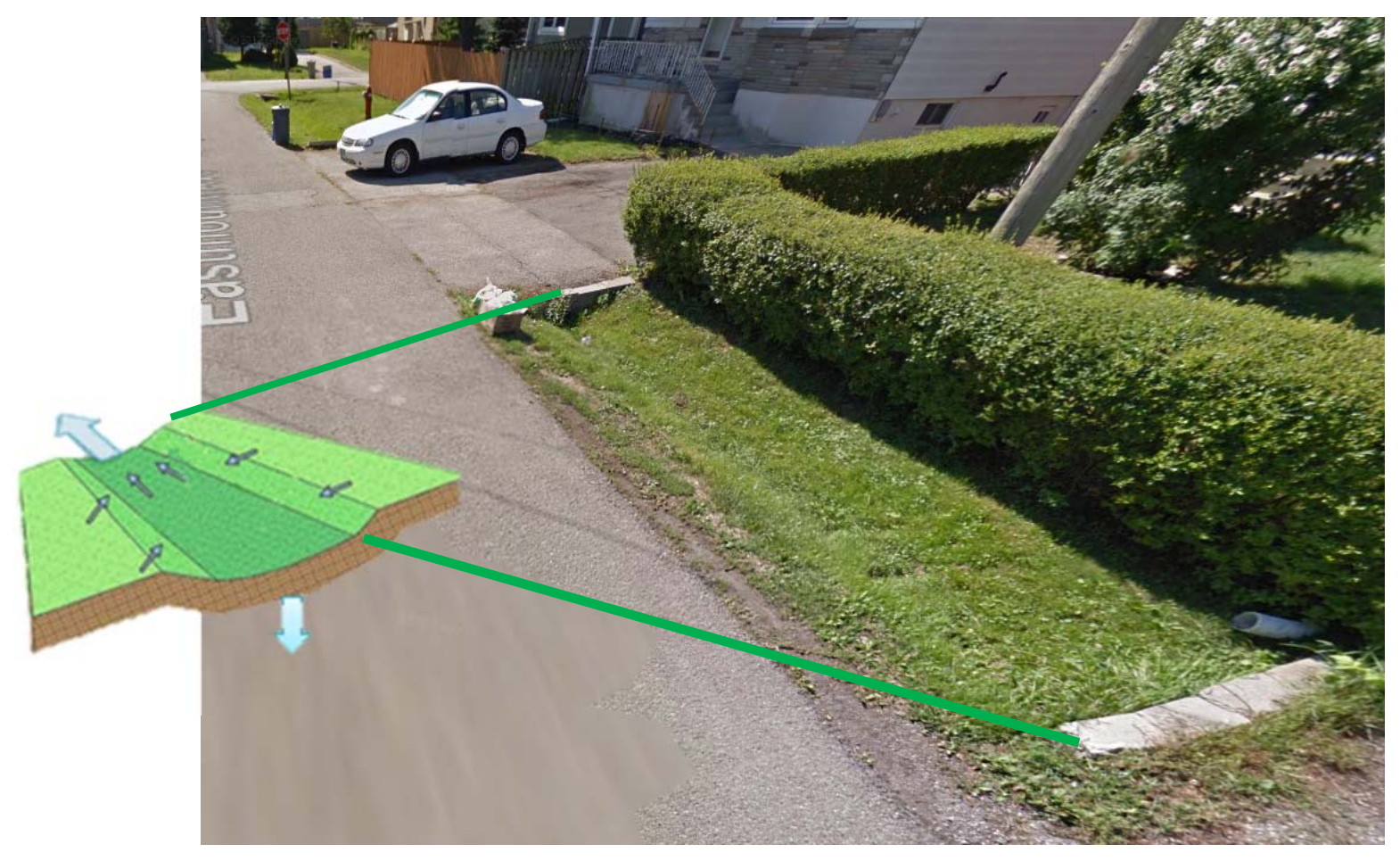

Figure 5-1 A Conceptual Representation of Roadside Ditches as Swales

(Sources: SWMM, Google Streetview) 


\subsubsection{Low Impact Development Systems}

LV4 was transformed from roadside ditches and culvert system to a series of bioretention and porous pavement driveway sections with under-drains as depicted in Fig. 5-2. In nature, runoff from porous pavement flows onto road and underdrain into bioretention. Then, both runon and runoff from road enter biorention through curb cuts. However, in SWMM, both the underdrain flows and the surface runoff are routed to the same downstream outlet without the option to separate the two as illustrated in Fig. 5-3. Therefore, runoff from porous pavement bypassed road and entered directly into bioretention.

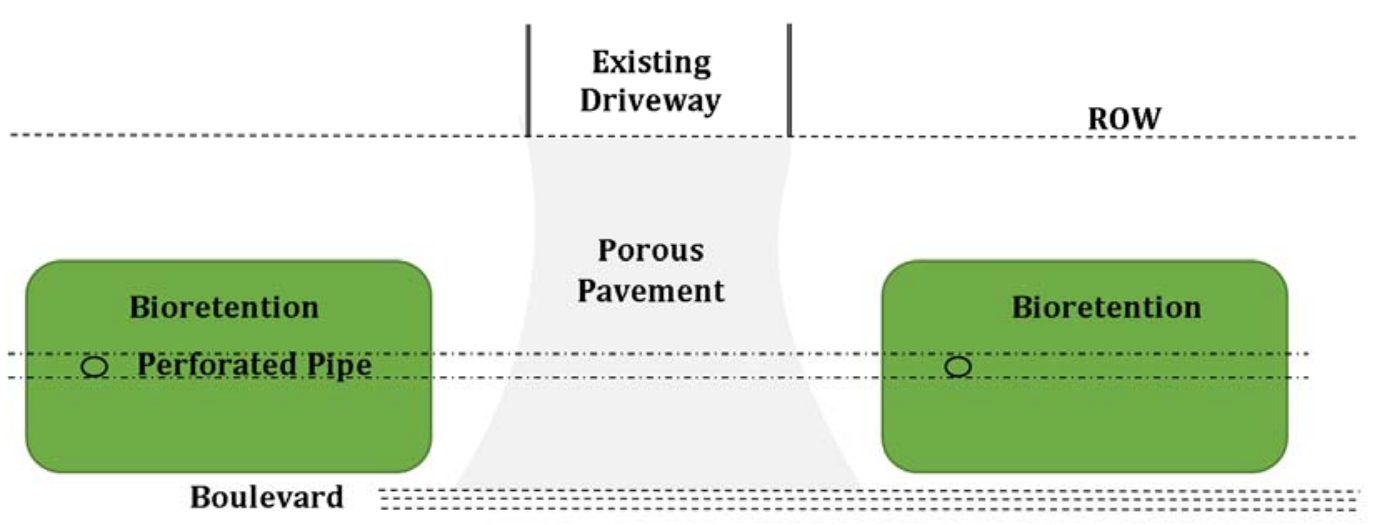

Figure 5-2 A Series of Bioretention and Porous Pavement

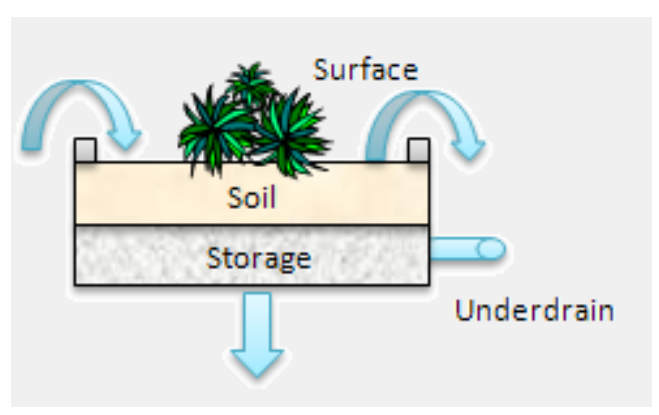

(a)

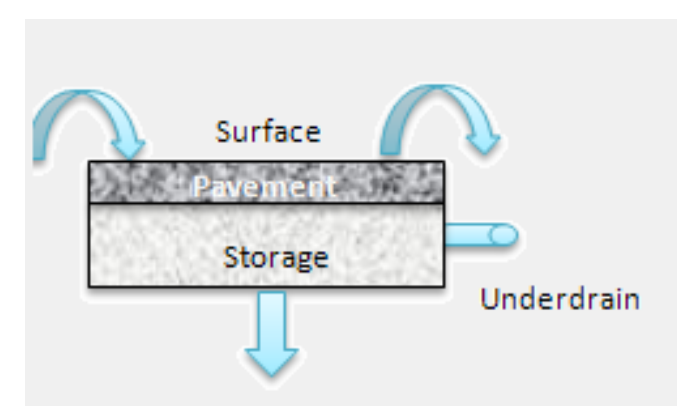

(b)

Figure 5-3 Representation of LIDs in SWMM a) Bioretention b) Porous Pavement (Source: SWMM) 


\subsection{Parameterizing Lumped Models}

Lumped models treat the whole drainage area as a single element; therefore, required parameters were averaged. A shortcoming of lumped models is that their parameters do not represent the true physical characteristics of the catchments (Reed et al., 2004). Table 5-2 describes the parameters used in developing lumped models. To parameterize lumped models, the modified GIS data was used. Since all the parameters have to be lumped together, the following land cover types: road, driveway, sidewalk, building were summed up to get impervious area, and grass and tree areas were summed up to get the overall pervious area.

Area represents the total area of the subcatchment in hectare. The overland flow length is the distance from the hydrologically farthest point to the center line of the road. Therefore, the distance from the back of a lot to the road center line was measured in ArcMap 10.2. As defined in the SWMM Application Manual by Gironás et al. (2009), width was estimated by the subcatchment area divided by the average maximum overland flow length.

Percent Impervious was calculated by taking the ratio of total impervious areas such as building, road, driveway, and sidewalk to the subcatchment total area. Buildings have sloped rooftops; therefore, area of building was considered as impervious area without depression storage. This value represents the \% Zero-Imperv, which is the percent of impervious area with no depression storage. Internal routing of runoff was described as runoff from roof tops flow to front lawn; therefore, IMPERV was chosen for subarea routing.

Then, percent routed determines the portion of runoff from impervious area that flows over the pervious area to the subcatchment outlet. In curb and gutter system, only nonRDCA flow onto pervious area, which is equal to building areas less RDCA. Eq. 5.1 describes 
\%routed in curb and gutter system. In LV2, roadside ditches collect runoff from all the impervious areas. In other words, even for the buildings that were directly connected to the culvert system, runoff was treated at the downstream swales. Hence, only the portion of road and RDCA along curb and gutter system flow onto impervious area. To find out the area from which the flow is from impervious areas to pervious areas, Eq. 5.2 was used for LV2. In LID implemented area, only runoff from RDCA does not flow onto pervious area. Thus, Eq. 5.3 simplifies the percent of impervious routed onto pervious area in LIDs system.

$$
\begin{aligned}
\% \text { routed }(C \& G) & =\left(\frac{\text { Building }-R D C A}{\text { Imperv }}\right) \\
\% \text { routed }(\text { Combined }) & =\left(\frac{\text { Imperv }-(\text { Road }+R D C A \text { along curb \& gutter })}{\text { Imperv }}\right) \\
\% \text { routed }(L I D) & =\left(\frac{\text { Imperv }-R D C A}{\text { Imperv }}\right)
\end{aligned}
$$

where

$$
\begin{aligned}
\text { Building } & =\text { Total area of all the buildings in LV1 } \\
\text { RDCA } & =\text { Total roof area which downspouts are directly connected } \\
\text { Imperv } & =\text { Total Impervious area (building }+ \text { driveway }+ \text { road) } \\
\text { Road } & =\text { Total area of road } \\
\text { RDCA along curb \& } & =\text { Total area of buildings which downspouts are directly } \\
\text { gutter } & \text { connected along the First St. }
\end{aligned}
$$

The remaining parameters were specified using the guidance provided in the Storm Water Management Model's User Manual by Rossman (2010). Manning's n for overland flow over the impervious portion was set as 0.012 , which is a typical value for smooth concrete, and the pervious portion was set as 0.40 , which represents grass and light underbrush. For the developed sites, a typical $2 \%$ slope was used to represent average percent slope of the subcatchment. That concluded the parameterizing for lumped models. However, to prepare 
spatially distributed catchment layers, drainage areas were disaggregated as described in

\section{Section 5.3.}

Table 5-2 Properties of the Subcatchments Used in Lumped Models

\begin{tabular}{|c|c|c|c|c|}
\hline \multicolumn{2}{|c|}{ Subcatchment } & LV1 & LV2 & LV4 \\
\hline \multicolumn{2}{|c|}{ Area (ha) } & 1.707 & 1.722 & 0.367 \\
\hline \multicolumn{2}{|c|}{ Flow Length (m) } & 54 & 50 & 44 \\
\hline \multicolumn{2}{|c|}{ Width (m) } & 316 & 344 & 83 \\
\hline \multicolumn{2}{|c|}{ Percent Impervious (\%) } & 52 & 49 & 45 \\
\hline \multirow{2}{*}{$\begin{array}{l}\text { Building } \\
\left(\mathrm{m}^{2}\right)\end{array}$} & Total Area & 4100 & 3924 & 719 \\
\hline & RDCA & 700 & 1813 & 292 \\
\hline \multicolumn{2}{|c|}{ \% Zero-Imperv } & 46.6 & 47 & 42 \\
\hline \multicolumn{2}{|c|}{$\%$ Routed } & 39 & 84 & 42 \\
\hline
\end{tabular}

\subsection{Constructing Detailed Distributed Homogeneous-area Models}

\subsubsection{Disaggregation of Drainage Areas}

The results of the image classification process on the WorldView-2 images represent four different land cover types:1) grass, 2) tree, 3) road, and 4) building, in irregular-shaped polygons. Similarly, when the available GIS data were combined, the GIS data have six different land cover types: 1) wooded area (tree), 2) building, 3) sidewalk, 4) road, 5) driveway, and 6) grass. As noted earlier, sidewalk, driveway and road were combined as one type in remote sensing data. Apart from this difference, data from both sources were processed in the same way in the forthcoming processes for all three catchment areas. 
To present the catchments in detail at the lot-level, the catchments were first delineated using parcel boundary. That was a requisite step since as a part of image classification, polygons with the same classification result that share the boundary were merged together. Likewise in GIS data, tree was denoted as a large polygon that spans over several lots. Secondly, grass or driveway that fall outside of private properties were treated as right-of-way grass (ROWgrass) and right-of-way driveway (ROWdriveway), respectively. This distinct separation was done in order to describe ROWgrass as swales in road ditches system and bioretention in LID system. In LID system, ROWdriveway was transformed as porous pavement. These fine-scale representations appeared as micro-subcatchments in detailed distributed models at lot-level as shown in the following figures. Roof areas, which are directly connected to the stormwater system are presented as CBuilding. 


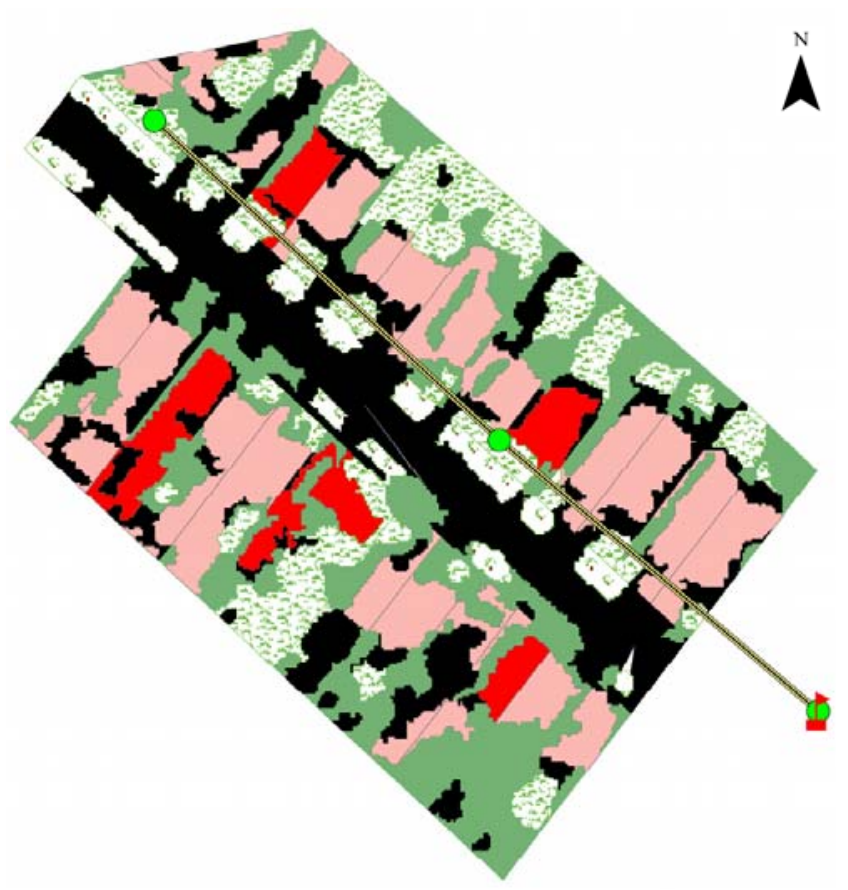

a)

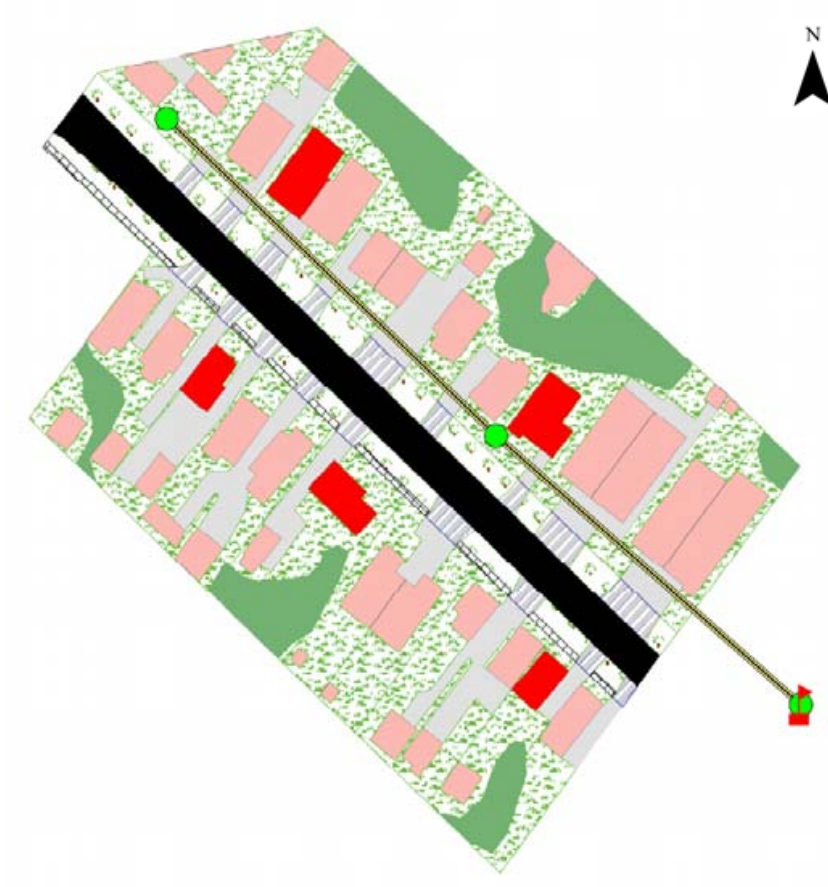

b)
$0 \quad 25 \quad 50$
100
150
200

Figure 5-4 Detailed Distributed Homogeneous-area Models of Curb \& Gutter System

a) Remote Sensing Data

b) GIS Data 


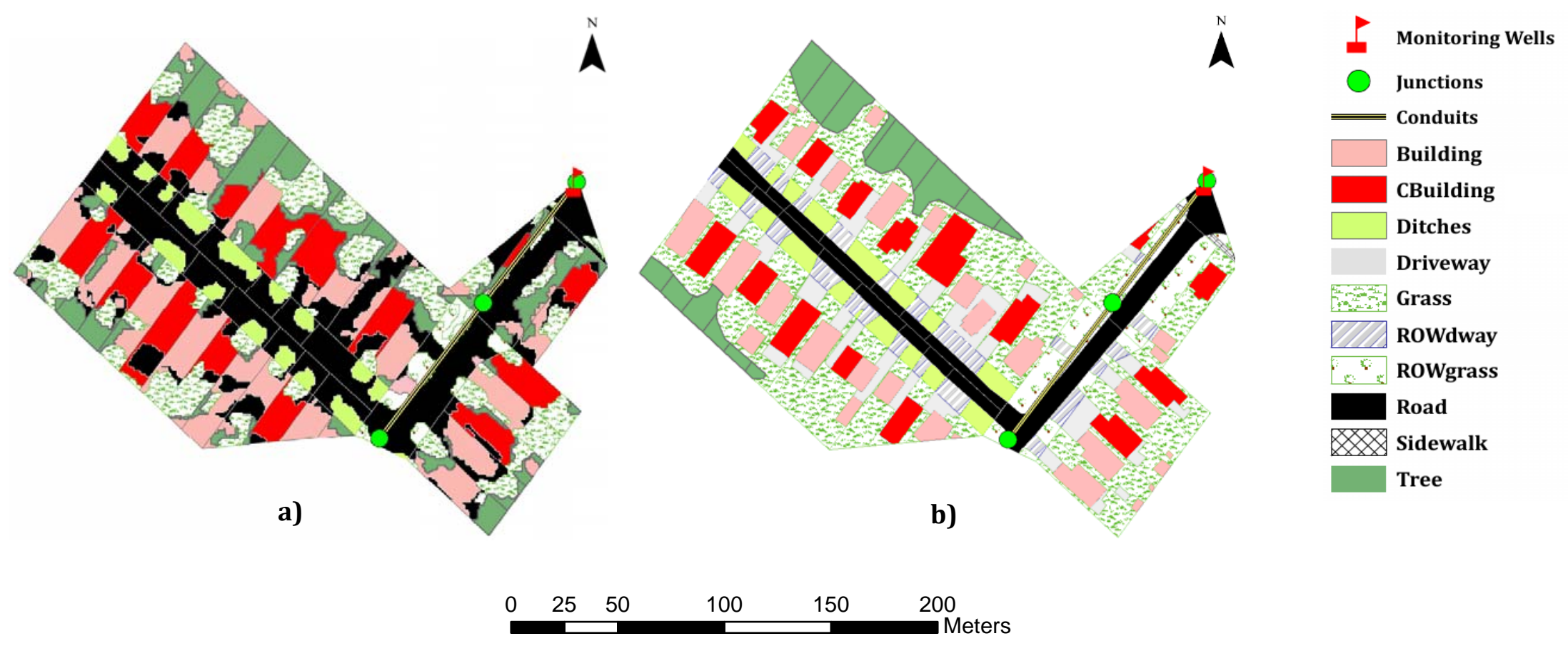

Figure 5-5 Detailed Distributed Homogeneous-area Models of Roadside Ditches and Curb \& Gutter a) Remote Sensing Data b) GIS Data 


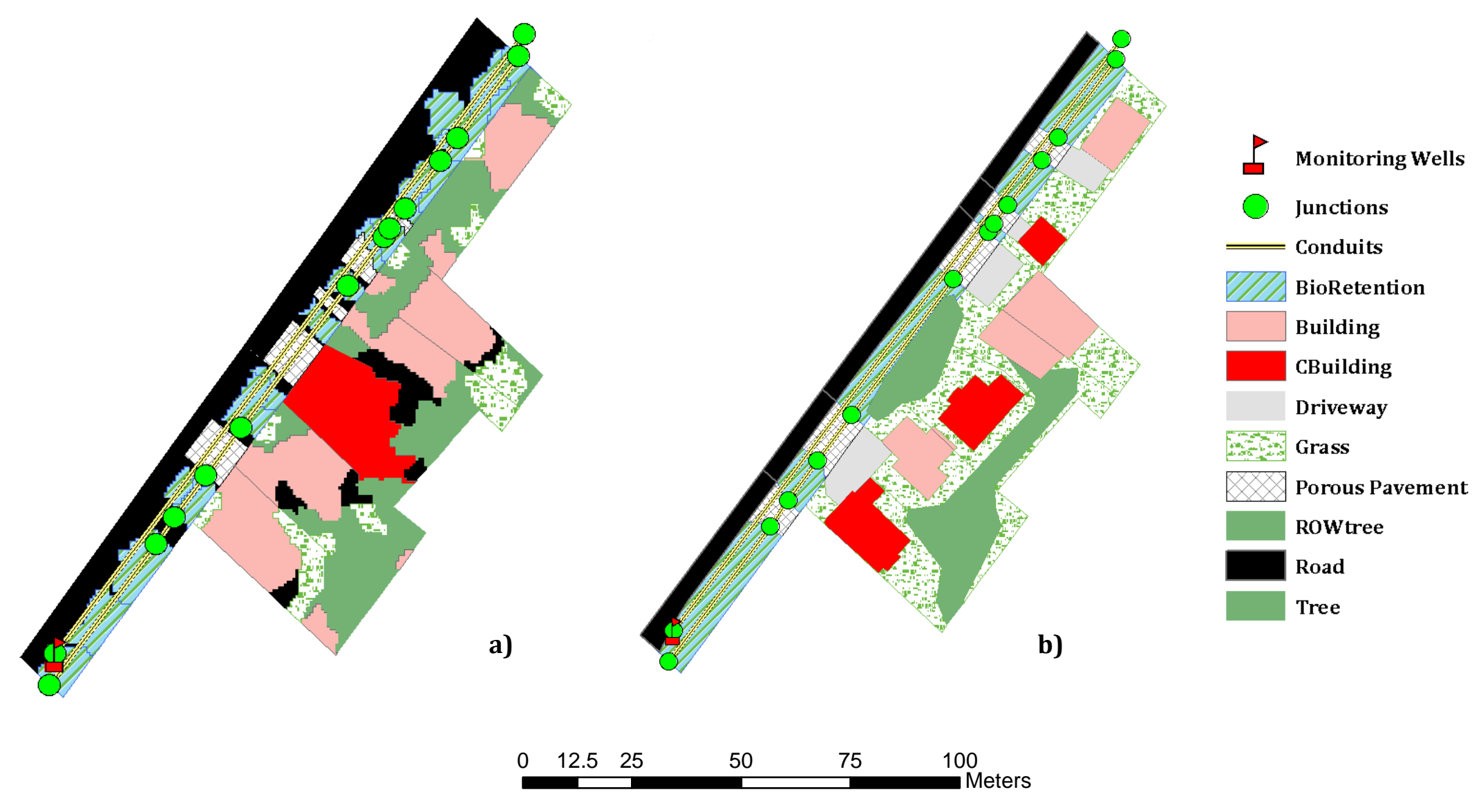

Figure 5-6 Detailed Distributed Homogeneous-area Models of LID Systems

a) Remote Sensing Data

b) GIS Data 


\subsubsection{Subcatchment Parameterization}

\subsubsection{Parameterizing hydrologic/hydraulic parameters}

After the polygon layers representing land cover information was disaggregated as described in Sec.5.3.1, subcatchments were parameterized to prepare SWMM models. Physical characteristics of subcatchment such as $\mathrm{x}, \mathrm{y}$-coordinates and area values were obtained in ArcMap. In contrast, the hydrologic and hydraulic parameters were assigned on the basis of land cover type. Each land cover type had a unique hydrologic response; therefore, with reference to Rossman (2010), the following values were assigned for $\%$ imperviousness, Manning's n value, depression storage (Dstore) and \%zero-impervious as shown in Table.5.3.

Table 5-3 Hydrologic/Hydraulic Parameters Assigned for Each Land Cover Type

\begin{tabular}{|l|c|c|c|c|}
\hline \multirow{2}{*}{ Land cover type } & \multicolumn{4}{|c|}{ Hydrologic/hydraulic parameters } \\
\cline { 2 - 5 } & $\%$ Imperv & Manning's n & Dstore (mm) & \%Zero-Imperv \\
\hline Tree & $0 \%$ & 0.40 & 7.620 & $0 \%$ \\
\hline Building & $100 \%$ & 0.011 & 0.000 & $100 \%$ \\
\hline Sidewalk & $100 \%$ & 0.011 & 1.778 & $0 \%$ \\
\hline Road & $100 \%$ & 0.012 & 1.778 & $0 \%$ \\
\hline Driveway & $100 \%$ & 0.011 & 1.778 & $0 \%$ \\
\hline Grass & $0 \%$ & 0.240 & 3.810 & $0 \%$ \\
\hline
\end{tabular}

The percent imperviousness describes the percentage of impervious area of a subcatchment. As subcatchments were disaggregated to include only one land cover type, 
$0 \%$ was assigned for tree and grass; and $100 \%$ was assigned for the remaining land cover types. Manning's n value refers to the roughness coefficient used to determine the flow velocity, over that certain land cover type. The depression storage value refers to the depth of rainfall that fills surface depressions. With the assumption that building may have a sloped rooftop of 33\%, no depression storage was specified for buildings. On the other hand, road, sidewalk and driveway may have ponding surfaces after being used for some years; therefore, $1.778 \mathrm{~mm}$ was assigned. The last column, \% Zero-Imperv represents the percent of impervious area with no depression storage. Only buildings were considered as the land cover type without depression storage; hence, $100 \%$ was assigned for building and $0 \%$ for the remaining types. This process demonstrates that it is easier to parameterize detailed distributed models compare to lumped models as the assigned parameters are more reasonable for homogeneous surfaces without the need for averaging.

The remaining two parameters, outlet and width, that are required in SWMM involved GIS processing to get rough estimates. Since SWMM allows runoff to be routed as overland flow between catchments in single flow direction, an outlet for each micro-subcatchment was identified as described in Sec. 5.3.2.2.

\subsubsection{Identifying an Outlet}

Several algorithms based on raster DEM to determine the flow path have been used in hydrologic/hydraulic modelling. At a watershed level, DEM is commonly used to delineate the drainage areas, for example, as conducted by Luciani et al. (2011). ArcGIS-based system, ArcHydro, offers the tools to process the watershed level delineation based on the DEM. In 1984, O'Callaghan and Mark introduced the earliest and simplest method called deterministic eight neighbour (D8). 
In D8 algorithm, $3 \times 3$ window of grids were examined to specify one of the eight neighbours that has the steepest downward slope. If all eight neighbours have the same slope, $3 \times 3$ window of grids is expanded to $5 \times 5$ window of grids. At the end, the flow direction will always be rounded to the nearest 45 degrees. This imprecision may not be an issue in modelling at a watershed level. However, in detailed distributed models of heterogeneous urban areas (with irregularly shaped, small subcatchments with abrupt slope changes and engineered drainage systems) using remote sensing data raises some issues. Moreover, the D8 algorithm heavily depends on the quality of DEM; therefore, the horizontal accuracy of DEM should be as fine as the resolution of hydrologic model. For this case study, DEM as fine as micro-subcatchment resolution, was not available. The available DEM as depicted in Fig. 3-8 was not suitable to utilize in flow routing due to its coarse resolution. For these reasons outlets were identified based on the assumption that all the overland flow paths directed were towards the street (i.e. road catchbasins and subsequently the storm sewer), following the standard engineering practice for grading of developed land. As opposed to the ArcHydro tool, this methodology identified the outlet first, then the overland flow path was calculated based on the distance between the catchment and its outlet. Fig.5-7 illustrates the flowchart to identify the outlet. Appendix-B describes the step-by-step with screenshots of this methodology. 


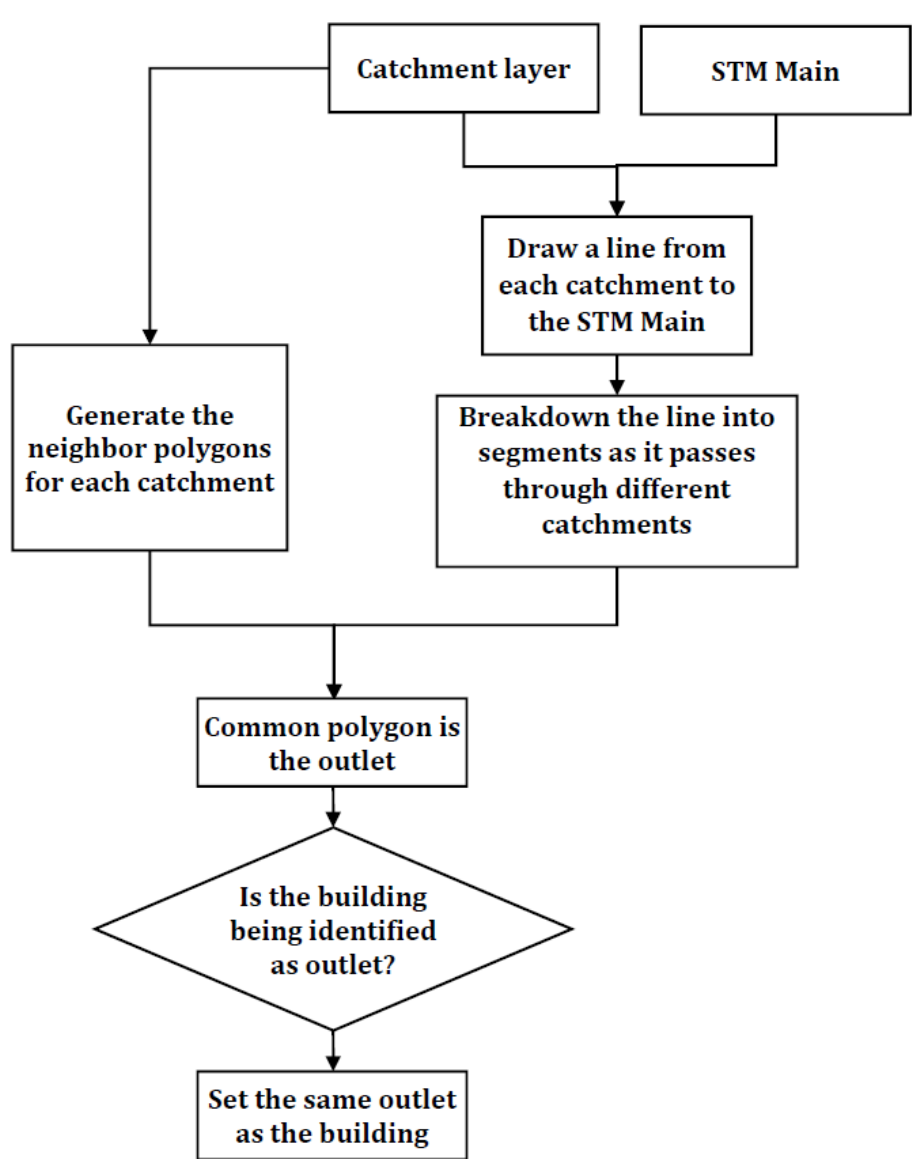

Figure 5-7 Identifying an Outlet

The steps to identify an outlet was conducted in ArcGIS as follows. The first step was to draw a line from the centroid of each catchment to the stormwater main pipe (STM Main). The tool in ArcGIS named, Feature to Point with an option to force the point to be within a polygon, was used to convert polygon to point. So that the line will be drawn from a polygon's centroid point instead of a closest point of the polygon to the STM. Using an arbitrary closest point of a polygon to STM or a centroid of a polygon is not crucial.

Secondly, using the Generate Near Table, the xy coordinates of the closest STM Main from each catchment were identified. The output table reported the catchment ID, STM Main ID, distance between these two features, $\mathrm{x}$ and $\mathrm{y}$ co-ordinates of the STM Main, and angle 
from each centroid point to the x,y co-ordinates of the STM Main. Then the angle had to be converted to the equivalent bearing values, where the origin, 0 degree, starts from vertical axis and rotates in clock-wise as the angle being wider. Using the Bearing Distance to Line function, a line from the centroid point to STM Main was then drawn using the near distance and bearing angle. Finally, this line layer was intersected with the catchment layer using the Intersect (Analysis) tool. By doing that, the line was broken down into smaller segments as it passes through different catchments. This output layer (Bearing Intersected Catchments) consisted of the IDs of subcatchments that where the line passes through until it reaches the STM Main.

Meanwhile, using the Polygon Neighbors function, surrounding polygons of each catchment were identified. The output table was compared with the Bearing Intersected Catchments table using a Visual Basic for Applications (VBA) script to search a common ID between two tables. If there was only one common ID between these two tables, that common ID was the outlet of the catchment. If there were more than one catchments, distance value of each ID were compared, and the ID that had the longest distance was chosen as the outlet. By selecting the catchment that had the longest distance, it is ensured that the runoff was routed to the closest catchment, although, all the catchments were sharing the boundary. Elevation was also taken into account in this case by checking whether the identified outlet was building or not. In the case of the outlet being a building polygon, the outlet was modified to the same outlet as that determined for the building. A manual intervention was necessary to make a modification depending on the drainage system and the catchment morphology as introduced in Sec. 5.1. 
Once the outlet was defined, a line between a centroid of the catchment to a centroid of the outlet was drawn. Then, only the segment of the line that fell within the subcatchment was taken. The length of the line was doubled to represent the overland flow path. After the distance of the overland flow path was obtained, the width was calculated in the same way as described in lumped model by dividing the subcatchment area by the calculated flow length.

\subsection{Simulation Options \& Model Input}

For all the developed models, the following simulation options were chosen as shown in Table. 5-4. The Green-Ampt infiltration model was chosen to represent the infiltration process. For a continuous simulation, the model ran from July 5, 2010 to December 31, 2013. Rainfall data were recorded at 5-min interval; therefore, reporting time was set to 5 minutes. For Evaporation rate, the monthly average values were obtained from Stayer, ON, weather station.

Table 5-4 SWMM Simulation Options

\begin{tabular}{|c|c|}
\hline General & \\
\hline Infiltration Model & Green-Ampt \\
\hline Routing Method & Kinematic Wave \\
\hline Flow Units & Cubic Metre per Second (CMS) \\
\hline Dates & \\
\hline Start analysis on & \begin{tabular}{|l} 
July/5/2010 14:20 \\
\end{tabular} \\
\hline End analysis on & Dec/31/2013 23:55 \\
\hline Time Steps & \\
\hline Reporting & $5 \mathrm{~min}$ \\
\hline Routing & 5seconds \\
\hline
\end{tabular}




\subsubsection{Infiltration Rate}

Scholars GeoPortal reported that a sandy loam covers the study catchment areas. Table 5-5 describes SWMM manual's suggested parameters (Rossman, 2010) for this type of soil to use in Green-Ampt infiltation model.

Table 5-5 Infiltration: Green-Ampt Parameters

\begin{tabular}{|l|l|}
\hline \multicolumn{2}{|l|}{ Infiltration : Green-Ampt Soil type = Sandy Loam } \\
\hline Suction head & $109.982 \mathrm{~mm}$ \\
\hline Conductivity & $10.92 \mathrm{~mm} / \mathrm{hr}$ \\
\hline Initial deficit & 0.190 \\
\hline
\end{tabular}

\subsubsection{Evapotranspiration Rate}

The daily average evapotranspiration rate retrieved from Stayer, ON station is as shown in Table 5-6.

Table 5-6 Evapotranspiration Rate from Stayner, ON

\begin{tabular}{|l|l|l|}
\hline \multicolumn{2}{|l|}{ Climatology } \\
\hline \multicolumn{2}{|l|}{ Evaporation (mm/day) } & Stayner, ON \\
\hline Jan $=0.3$ & May $=3.2$ & Sep $=2.0$ \\
\hline Feb $=0.8$ & Jun $=4.5$ & Oct $=1.1$ \\
\hline Mar $=1.3$ & Jul $=5.3$ & Nov $=1.0$ \\
\hline Apr $=2.5$ & Aug $=3.7$ & Dec $=0.3$ \\
\hline
\end{tabular}




\subsubsection{Rainfall Data}

The monitored rainfall and runoff data were provided by CVC. During the monitoring period, rain gauges from five locations were used as displayed in Fig. 3-10. Rainfall plot in millimetre from July 5, 2010 to December 31, 2013 is as shown in Fig. 5-8.

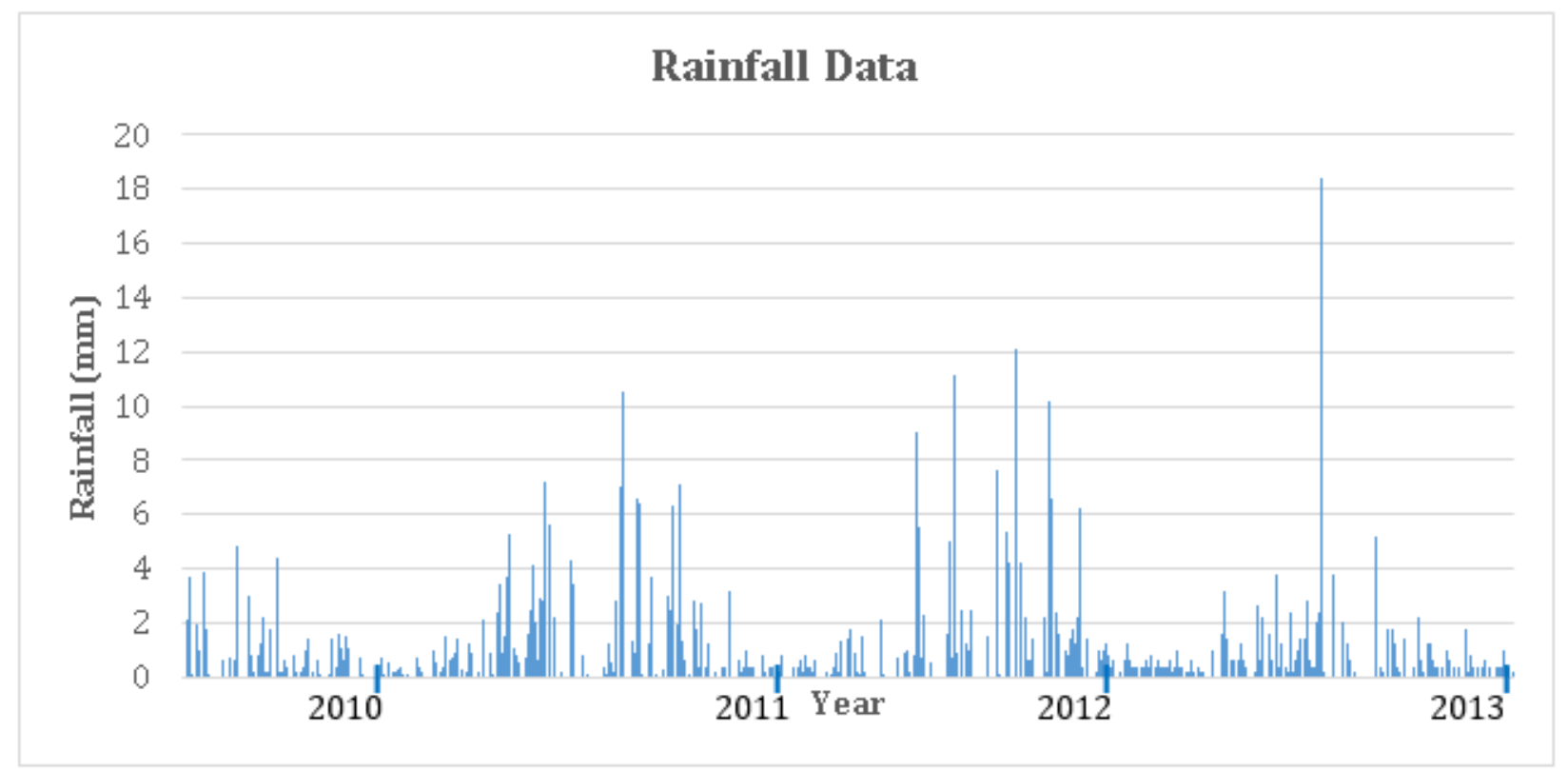

Figure 5-8 Rainfall Data for Study Catchment Areas

\subsubsection{Identifying Rainfall Events}

Using PCSWMM (a graphical user interface that uses SWMM Engine), rainfall events were automatically selected using the following criteria: Minimum interevent time $=12$ hours; event threshold $=0.1 \mathrm{~mm} / \mathrm{hr}$; extend events by $=6$ hours following and 1 hours preceding. If a rainfall intensity was higher than $0.1 \mathrm{~mm} / \mathrm{hr}$, that time period was considered as an event. Events were separated if dry hours between two events was 12 hours. Then event was recorded an hour before and six hours after event. There were 374 events during the monitored period for the LV1 study catchment; although, not every event was applicable 
to validate the models performance, due to the variability of spatial location of some of the rain gauges being at a significant distance from catchment areas where the runoff was monitored. In total, 123 events were identified for which there was recorded rainfall but no observed flow data for the curb and gutter system in LV1. Therefore, such events with no observed flow data were not used in model performance evaluations. Fig. 5-9 to Fig. 5-11 illustrate the observed runoff depth and total rainfall received during the events with different symbols in accordance with different rain gauges used. The circle ones (legend in green texts) are from the rain gauges that located within $1 \mathrm{~km}$ away from the study areas.

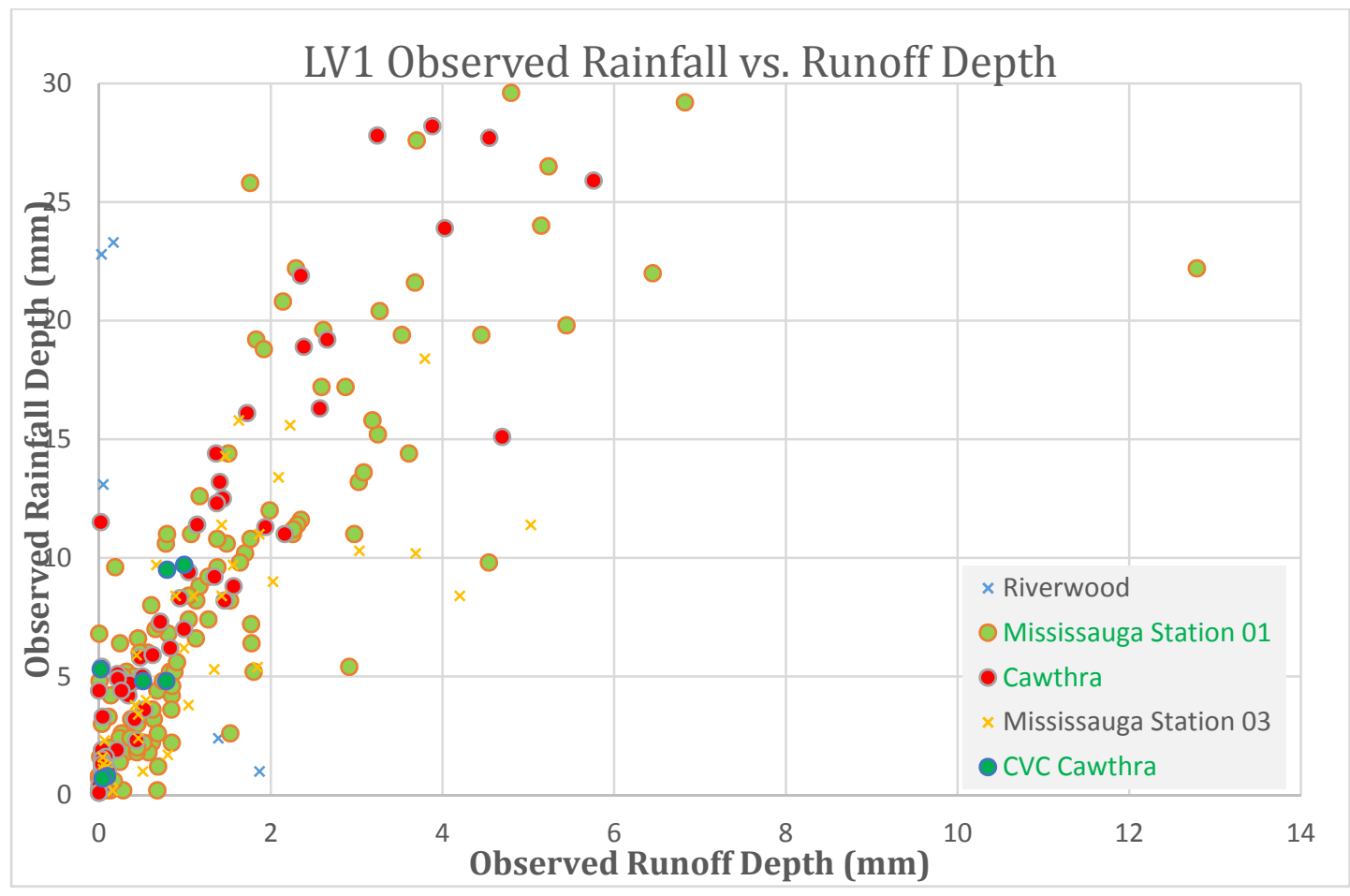

Figure 5-9 Observed Rainfall vs Runoff Depth of a Curb \& Gutter System 


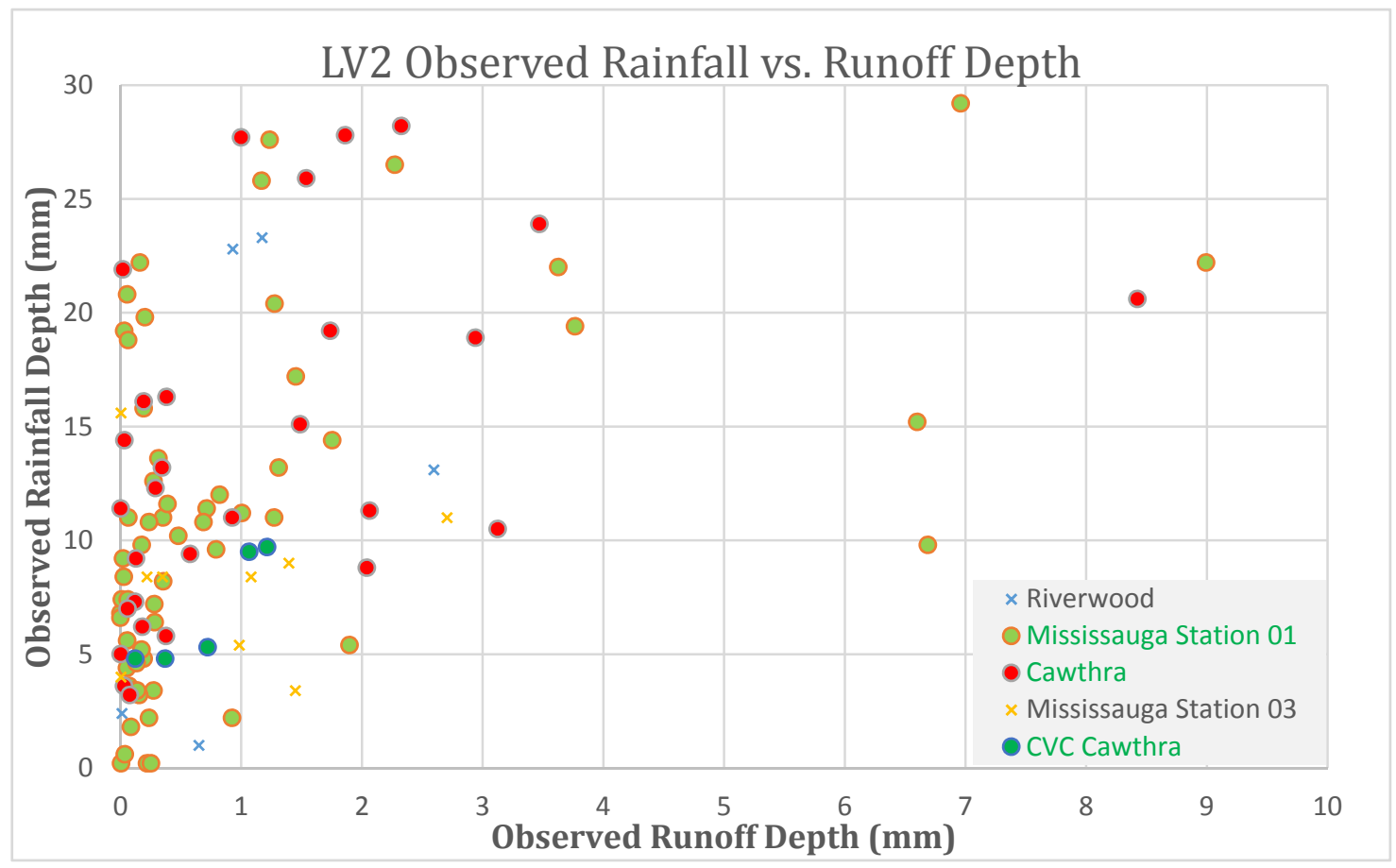

Figure 5-10 Observed Rainfall vs Runoff Depth of a Combined System

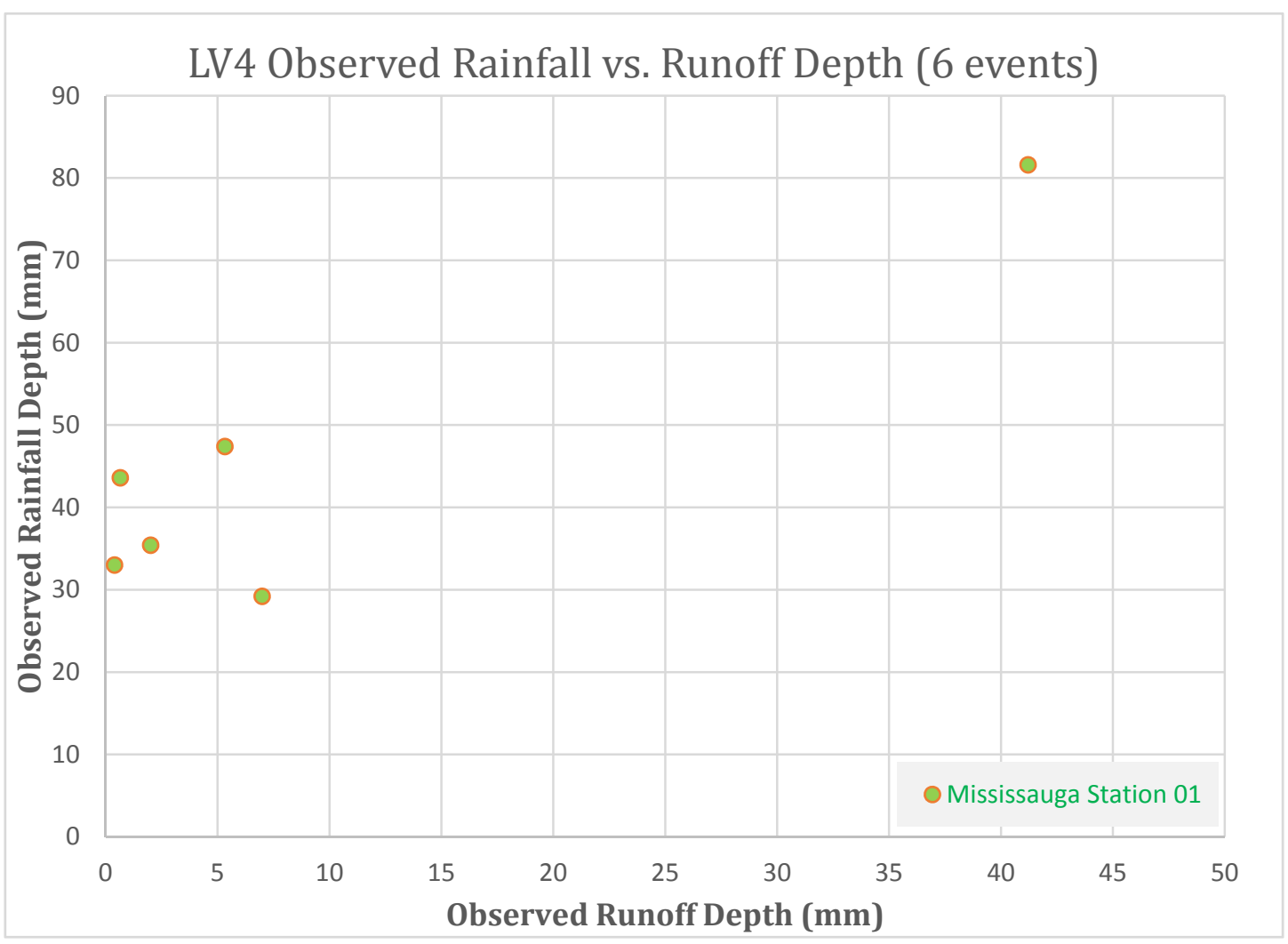

Figure 5-11 Observed Rainfall vs Runoff Depth of a LID System 
In order to visually analyze the data, the upper limit vertical axis (observed rainfall) in the following graphs were set to be $30 \mathrm{~mm}$. A list of the remaining events that received more than $30 \mathrm{~mm}$ rainfall in LV1 and LV2 are provided in Appendix C. Since LID implementation was completed in fall 2012, there was not a long record of observed data available for LV4 site. Moreover, due to the instrumental errors at the monitoring stations and the possibility that the snowmelt was recorded by flow meters, the CVC staff suggested to use only the period from February to December 2013. Since the LIDs on the LV4 site captured all of the runoff generated during small rainfall events, only six of the events had the observed flow that could be used for model evaluations, as shown in Fig. 5-11.

The relationship between the observed depth and rainfall depth depends on the capacity of the infiltration properties of native soils and the characteristics of rainfall event such as intensity and duration. Due to its non-linear relationship, there is no justification to cut down the list of events further. Therefore, even some of the events, seemed outliers in the graphs of total rainfall vs observed depth, were not eliminated.

\subsection{Model Performance Analysis}

\subsubsection{Peak Flow Rate}

Peak flow rate is one of the critical parameters for the design of urban stormwater management systems (Leopold, 1968). Peak flow rate is defined as the maximum rate of surface runoff generated from a specific area during one rain event. Higher flow rates can cause a number of downstream impacts such as flooding, high sediment loading, etc. Figures (Fig. 5-12 to Fig. 5-14) illustrate the simulated peak flow rate using remote sensing data and 
GIS data that fall within $40 \%$ envelope of observed peak flow rate in terms of $\mathrm{L} / \mathrm{s}$, where the green lines represent $+20 \%$ and $-20 \%$ of the observed data. Table $5-7$ summarizes the number of events that fall within $40 \%$ envelope for three study catchment areas from three different models. These results are in conformity with Faurès et al., (1995), who concluded that spatial variability of rain gauges introduce uncertainties, which resultants in large variations in simulated results. Their studies used spatially varied five recording rain gauges and used one rain gauge at a time. From five model runs, they reported peak flow rate varied from 9 to $76 \%$ from the observed flow rate.

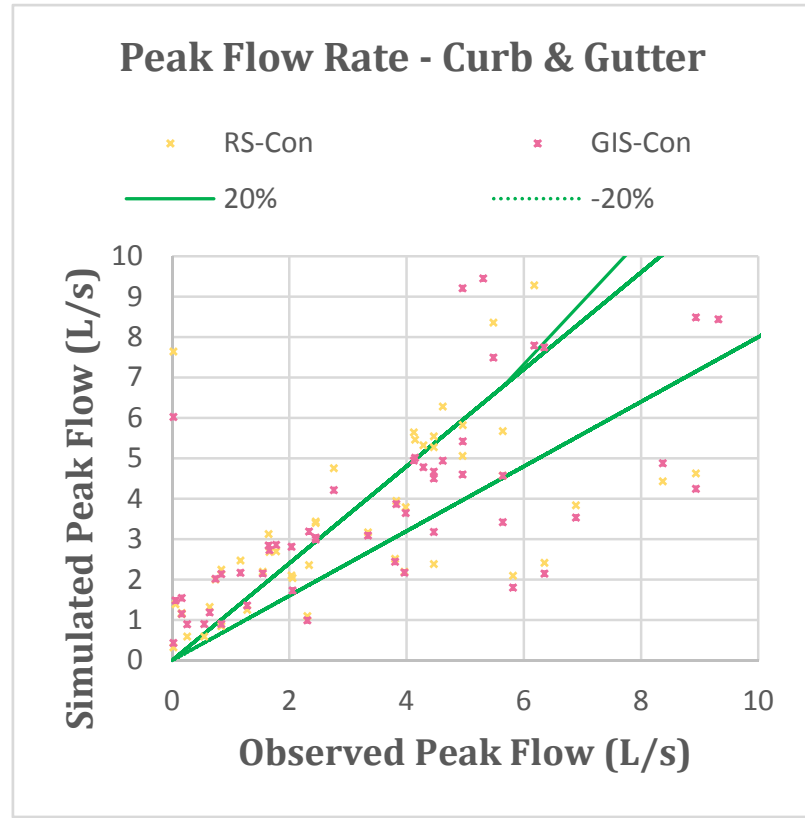

Figure 5-12 Simulated vs. Observed Peak Flow Rate-Curb and Gutter Control (LV1)

\section{Peak Flow Rate - Combined}

RS-Con $\quad$ $\quad$ GIS-Con $-20 \% \ldots \ldots \ldots \ldots . . . .20 \%$

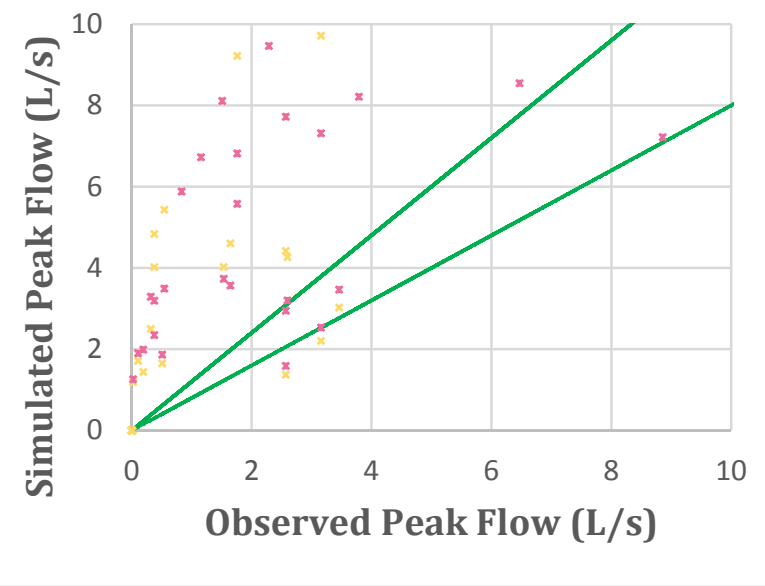

Figure 5-13 Simulated vs. Observed Peak Flow Rate- Combined System (LV2) 


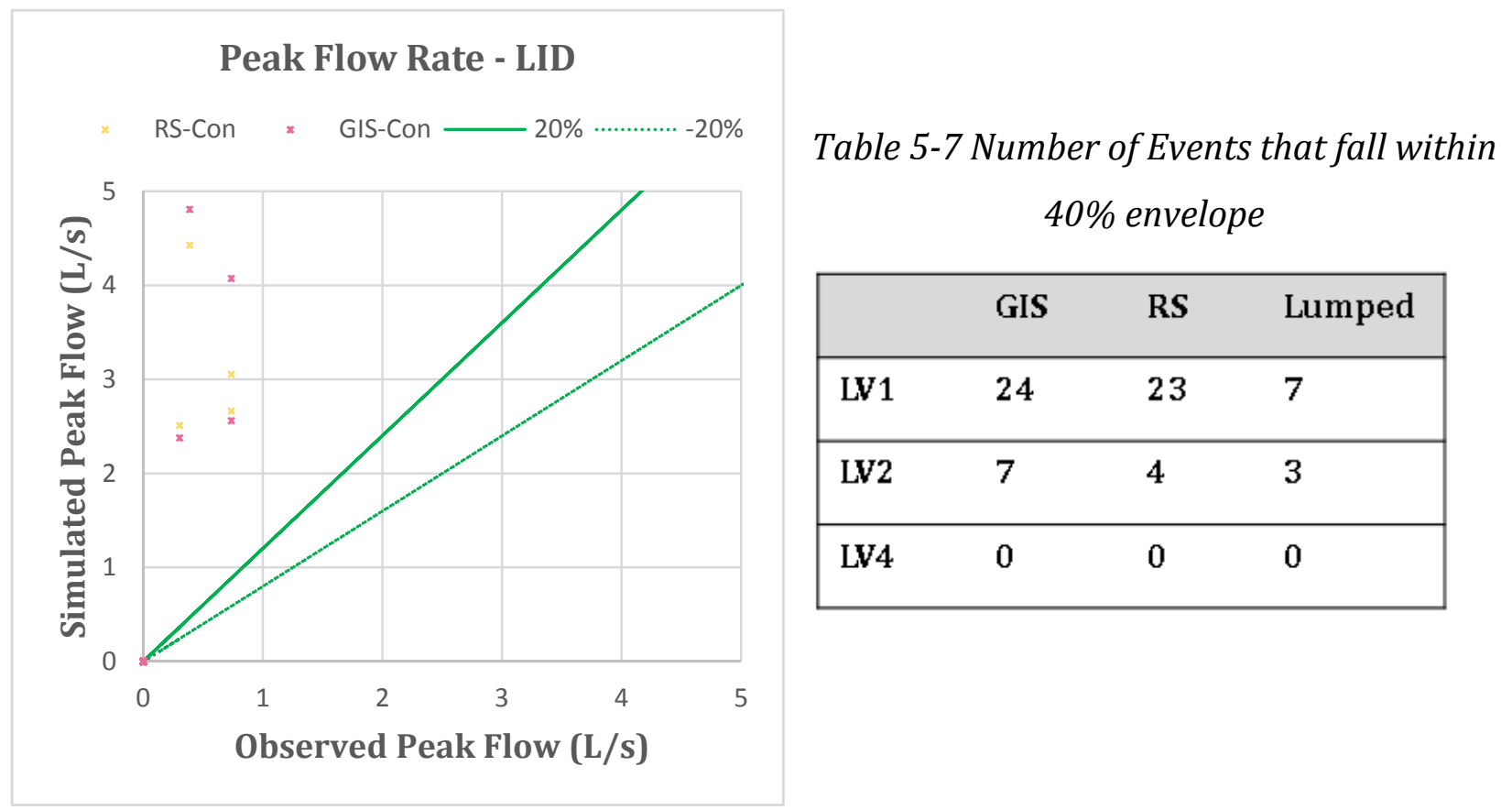

Figure 5-14 Simulated vs. Observed Peak Flow

Rate- LID System (LV4)

\subsubsection{Runoff Volume}

The below table, Table 5-8, summarizes the total surface runoff volume generated from three different drainage systems during the identified events. Please note that number of events varied from sites to sites; hence, total runoff volume should be analyzed only between the different scenarios of the same drainage system. As shown, disconnecting downspouts reduced the runoff significantly. Urban runoff controls such as roadside ditches or LIDs (porous pavement and bioretention) can reduce runoff volume compared to curb and gutter control. A variation of observed and simulated runoff was due to rainfall variability exists at different temporal and spatial resolution. Faurès et al., (1995) studies reported that runoff volume varied from 2 to $65 \%$ over eight observed storm events. 
Table 5-8 Total Surface Runoff Volume

\begin{tabular}{|c|c|c|c|c|c|}
\hline & & & & Total & Volume \\
\hline System & \# of Events & Model & Scenario & Simulated $\left(\mathrm{m}^{3}\right)$ & Observed $\left(\mathrm{m}^{3}\right)$ \\
\hline \multirow{5}{*}{$\begin{array}{l}\text { Curb \& } \\
\text { Gutter } \\
\text { (LV1) }\end{array}$} & \multirow{5}{*}{251} & Lumped & Partial downspouts connected & 14,985 & \multirow{5}{*}{8,976} \\
\hline & & \multirow{2}{*}{ Detailed distributed - RS } & Downspouts disconnected & 12,040 & \\
\hline & & & Partial downspouts connected & 14,635 & \\
\hline & & \multirow{2}{*}{ Detailed distributed - GIS } & Downspouts disconnected & 7,698 & \\
\hline & & & Partial downspouts connected & 9,457 & \\
\hline & & & & & \\
\hline \multirow{5}{*}{$\begin{array}{c}\text { Roadside } \\
\text { ditches + } \\
\text { Curb \& } \\
\text { Gutter } \\
\text { (LV2) }\end{array}$} & \multirow{5}{*}{129} & Lumped & Partial downspouts connected & 4,168 & \multirow{5}{*}{5,007} \\
\hline & & \multirow{2}{*}{ Detailed distributed - RS } & Downspouts disconnected & 8,716 & \\
\hline & & & Partial downspouts connected & 10,235 & \\
\hline & & \multirow{2}{*}{ Detailed distributed - GIS } & Downspouts disconnected & 5,729 & \\
\hline & & & Partial downspouts connected & 7,627 & \\
\hline \multirow{5}{*}{$\begin{array}{l}\text { Bioretention } \\
\text { \& Porous } \\
\text { Pavement } \\
\text { (LV4) }\end{array}$} & \multirow{5}{*}{6} & Lumped & Partial downspouts connected & 261 & \multirow{5}{*}{208} \\
\hline & & \multirow{2}{*}{ Detailed distributed - RS } & Downspouts disconnected & 221 & \\
\hline & & & Partial downspouts connected & 313 & \\
\hline & & \multirow{2}{*}{ Detailed distributed - GIS } & Downspouts disconnected & 225 & \\
\hline & & & Partial downspouts connected & 319 & \\
\hline
\end{tabular}




\subsubsection{Flow Duration Exceedance}

The flow duration exceedance plot shows the exceedance hours of the certain peak flow rate, which occurred during the simulation period. It is used to analyze the probability of the occurrence of the peak flow rate. Magnitude, duration and frequency of the flow rate is particularly important to study hydrologic alteration. Magnitude of the flow rate was relatively high in curb and gutter control system. Since introducing roadside ditches, porous pavement and bioretention altered the catchment hydrology, the magnitude of the flow rate was relatively low as shown in Fig. 5-15 to 5-17. Ghosh et al., (2011) explained that model aggregation reduced peak flows in larger storms due to different in infiltration, soil saturation, and hydraulic conductivity. Whereas in smaller storms, simulated peak flow could be higher than observed flow due to the combined effects of overland flow and conduit routing. These statements applied to the findings of this study as shown in Fig. 5-15 to 5-17.

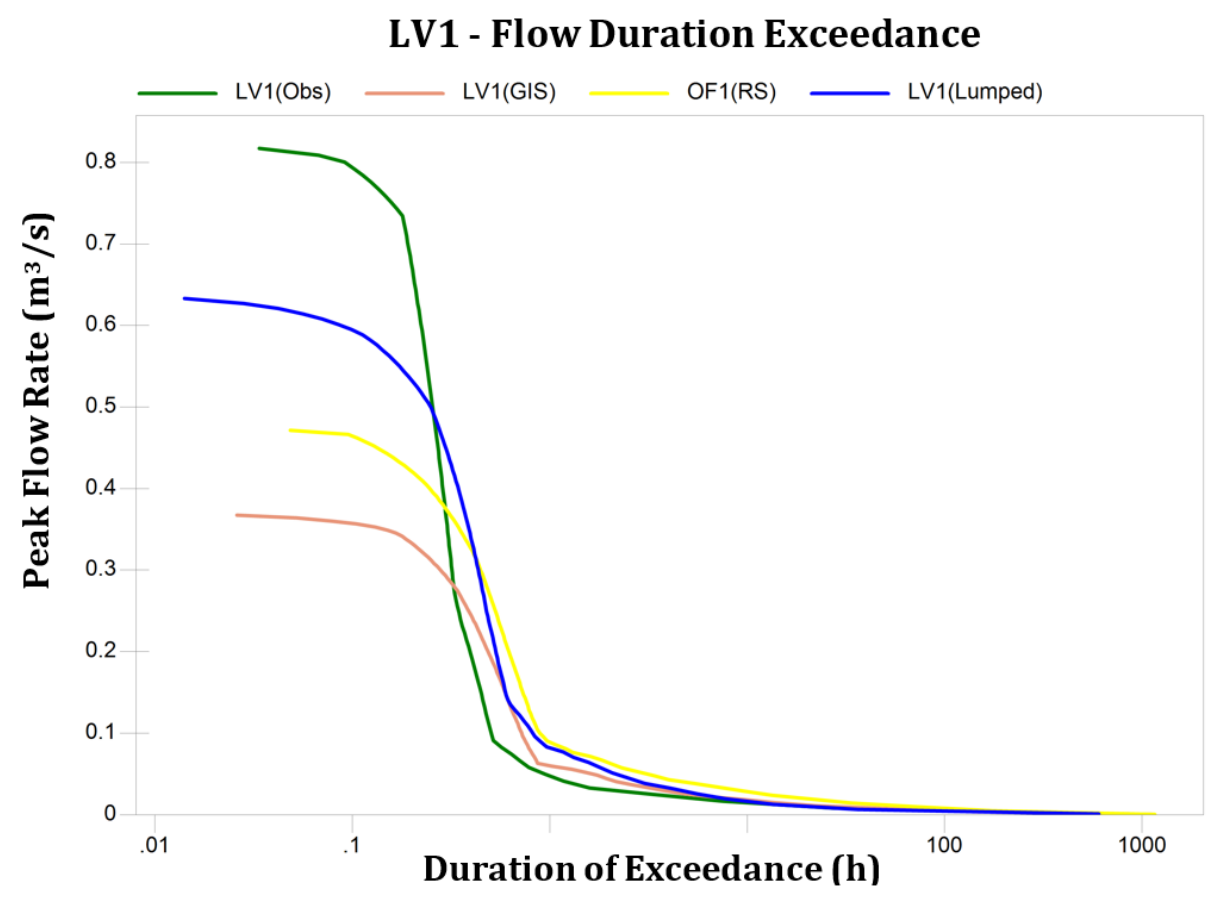

Figure 5-15 Flow Duration Curve for Curb \& Gutter System 


\section{LV2 - Flow Duration Exceedance}

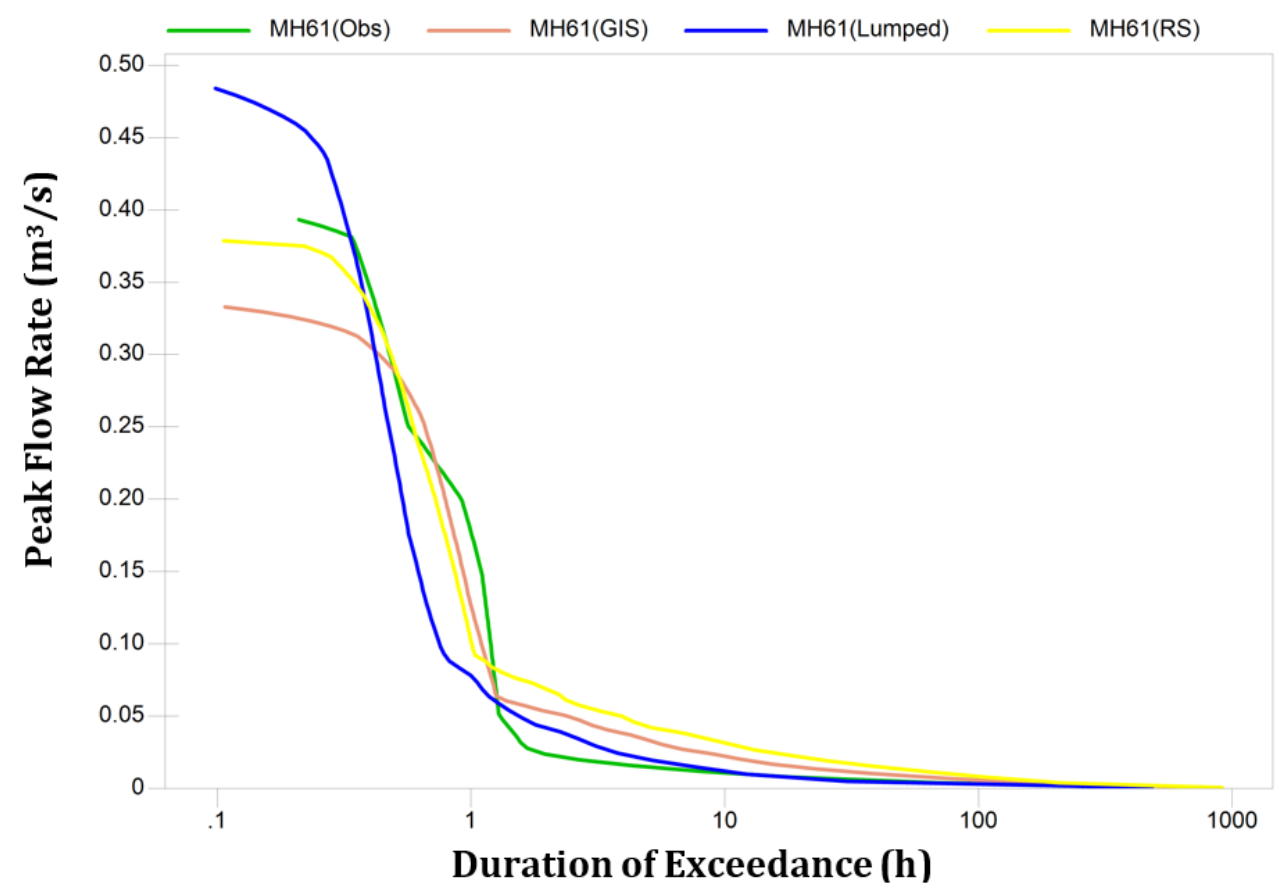

Figure 5-16 Flow Duration Curve for a Combined System

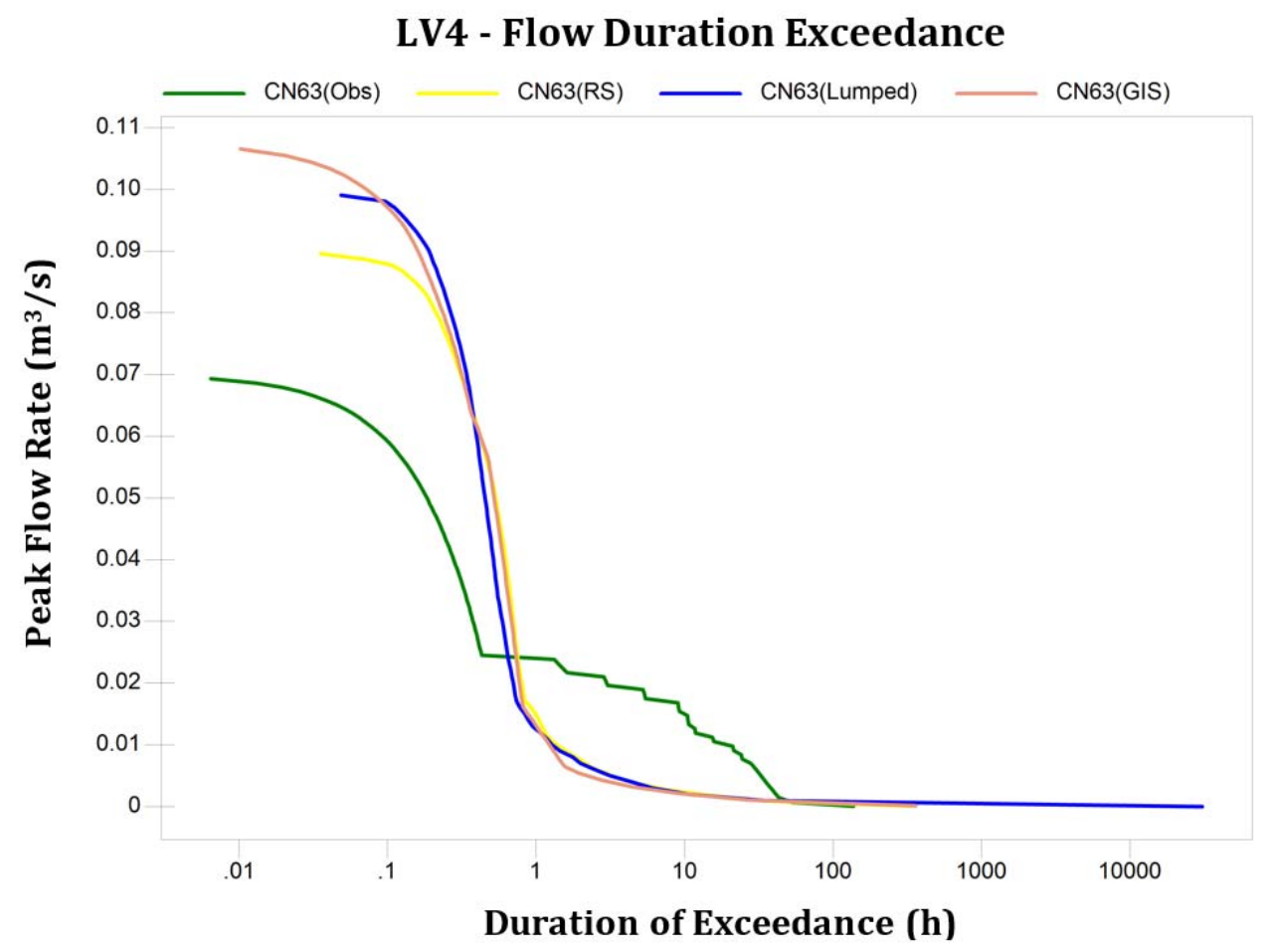

Figure 5-17 Flow Duration Curve for LID system 


\subsubsection{Water Balance}

Water balance pie chart is useful to analyze the percent of runoff, infiltration and evapotranspiration occurring at the catchment. To disregard the continuity error due to a coarse time step, summation of runoff, infiltration and evapotranspiration was used as a base value, instead of precipitation. As LID area promotes infiltration and evapotranspiration, in most of the small rainfall events, $100 \%$ of runoff was captured by a series of bioretention and porous pavement. During the period of February 2013 to December 2013, there were 117 events, and all of the events were considered in order to analyze the water balance restoration after implementing LID.

With reference to Table 5-9, the observed data indicated that runoff constituted 19\%, $14 \%$ and $15 \%$ of the total rainfall in curb \& gutter system, curb \& gutter and roadside ditches system, and LID system, respectively. This indicates that roadside ditches generated less runoff compared to LID system, leading to a question of the credibility of observed data at the roadside ditches site in particular. This could be due to the fact that culvert system might be blocked with debris and ponding water at roadside ditches that is then provided greater opportunity to infiltrate and/or evapotranspire, compared to a newly constructed system that is capable of conveying the flows more efficiently to the monitoring station. If that was the case, observed data could not capture accurate runoff volume in such situation; therefore, simulated results had higher surface runoff percentage compared to the observed data in LV2. In LID sites, the observed data has 15\% runoff, whereas, the simulated Detailed - GIS and RS data gave 19\% and 18\%, respectively. This can be explained by the limitation of SWMM as discussed in Section 5.1.3. 
Table 5-9 Water Balance of Different Drainage Systems

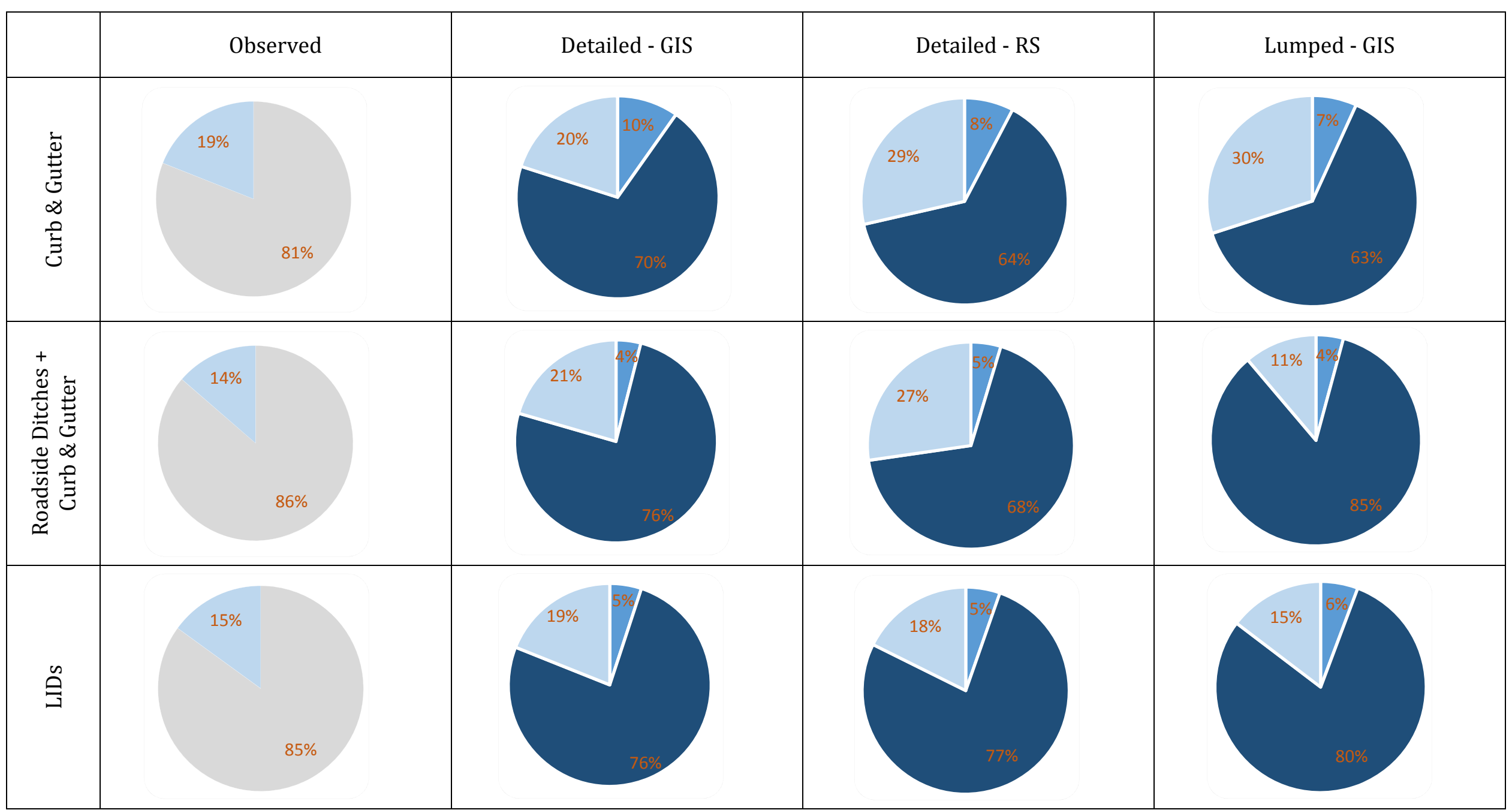

Evapotranspiration $\quad$ Infiltration $\quad$ Surface Runoff $\quad$ Losses 


\subsection{Summary}

This chapter demonstrated the development of detailed distributed and lumped urban drainage models of 1) curb and gutter, 2) roadside ditches, and 3) LIDs (bioretention and porous pavement) in SWMM. Land cover information was retrieved from two sources: GIS data and the classified image from the two-stage classification method presented in Chapter 4. The required hydrologic/hydraulic and physical parameters of each subcatchment, such as area, width, overland flow path, \% imperviousness, Manning's n value and depression storage value were determined using procedures developed in ArcMap 10.2. The performance of the detailed models utilizing WorldView-2 image was compared with the models that replicated the model structures and connectivity between subcatchment, but using the GIS data and lumped models. All of the developed models were then compared against the observed flow data.

The comparison of the simulation results between lumped models and detailed distributed homogeneous-area models using GIS data highlighted which approach (lumped vs detailed) to model study catchment areas. The important thing to note is the spatial resolution of rain gauges. Rain gauge located within $1 \mathrm{~km}$ from the study sites introduce uncertainties in rainfall, which is the main driven factor of runoff generation. Faurès et al., (1995) suggested that a very small catchment less than five ha should have on-site rain gauge at a temporal resolution of 5-minute. After analyzing peak flow rate, total runoff volume, water balance and flow duration curve for three different drainage systems, mixed results were observed with respect to different models' ability to simulate runoff closest to the observed data. 
In this regard, the measurement uncertainty of observed data was not taken into account when comparing the simulated and observed data; although, measurement errors could exist in the monitored data. For example, deteriorated roadside ditches allow runoff to be ponded, evapotranspirated and infiltrated at an intermediate area, instead of conveying runoff unrestrictedly to the outlet. In this situation, observed runoff volume at an outlet did not reflect the total runoff volume generated from a study drainage area. This is consistent with the results shown in Table 5-8, where the observed runoff volume is less than simulated results.

A comparison of the simulation results between two detailed distributed models showed the impact of a variation of land use information from two sources of data on the performance of urban drainage models. As discussed earlier, image classification results overestimated the impervious areas; therefore, the net results of the model with remote sensing data indicated higher runoff volume and peak flow rate than GIS data, as expected. This results provided a better understanding of impervious land cover contribution in urban settings to hydrologic/hydraulic system.

The intent of this study was accomplished by demonstrating a way to develop detailed distributed (up to date) models assuming little to no GIS data available. This modelling approach would assist the modellers in the development and application of uncalibrated models, particularly useful in retrofit situations, where monitored data is unavailable or green field developments, where it is unable to collect such data. Utilizing remote sensing is more attractive in the process of implementing large scale retrofits, which would significantly reduce the associated costs in collecting detailed land cover information. 
Overall, detailed distributed models explored the best way to conceptually represent natural hydrologic/hydraulic components in models. Some of the lessons learned included a proper way to disaggregate roads, especially in roadside ditches and LID system. So that a smaller segment of roads route to the intermediate ditches or bioretention without overwhelming the most downstream impervious areas. Sensitivity analysis of each parameter in detailed distributed models revealed that they are quite robust, in the sense that the developed models were quite insensitive to moderate changes in input parameters. 


\section{Chapter 6}

\section{Conclusions and Recommendations}

\subsection{Summary}

Stormwater issues are increasingly being solved by implementing LIDs in urban areas, which in turn requires detailed distributed urban drainage models to accurately estimate the benefits of LIDs. The benefits of detailed drainage models were discussed in Chapter 2, including more realistic parameterizing that is less reliant on modellers' experience, accessing the performance of individual BMPs, LIDs etc., along with the cost of requiring detailed land cover information and complex models. Chapter 3 demonstrated the work methodology used to develop an image classification approach for WorldView-2 satellite image. This chapter introduced the key data used and parameters extracted for the hydrological modelling. Chapter 4 demonstrated process and the results of the two-stage image classification method that improved the classification accuracy, which dealt with shadow problems and existence of unexpected objects within the study areas. Chapter 5 utilized the image classification results from Chapter 4, GIS data from the City of Mississauga and, monitored rainfall and runoff data from CVC to model three types of drainage systems: 1) curb and gutter, 2) roadside ditches, and 3) LIDs (a series of porous pavement and 
bioretention cells) using both in lumped and detailed distributed. The contributions, limitations, and recommendations of this thesis are as summarized in the following sections.

\subsection{Accomplishments}

The main accomplishment of this thesis comes from integrating the processing of remote sensing data and applying the processed data in detailed urban drainage modellings, an application that is hardly found in the image classification studies. The advanced image analysis methods have been well-established since high resolution imagery has bloomed in the 1990's. While keeping the objectives of the study in mind, image analysis is conducted on the available data type. Number of research works have addressed the extraction of impervious surfaces in the urban areas using satellite images. However, previous work has been conducted differently by many researchers, but not with the resolution of data and the modelling approach presented here.

The two-stage image classification method was developed: this classification method was demonstrated on WorldView-2 image that covers a residential area. The first stage of the two-stage image classification method used both spectral reflectance values and objects' area to segment and classify the image of an old residential neighbourhood into four different land cover classes: 1) grass, 2) tree, 3) road, and 4) building. Then, in the second stage, post-classification was conducted by imposing the topological rules to further improve the classification accuracy. Combining the spectral, size and topological information increased the overall accuracy to $80 \%$ and $83 \%$ from $64 \%$ and $73 \%$ accuracy using pixelbased classification technique. The overall accuracy of the two-stage classification method demonstrated a great improvement over a traditional pixel-based classification method. 
With the aid of auxiliary bands such as NDVIs, PCA and SUM bands, this proposed method improved the image accuracy by $16 \%$ and $10 \%$ for two different areas, compared to a traditional pixel-based classification method. This classification method results resolved a challenging issue of inputting detailed land cover information in hydrologic/hydraulic modelling.

Detailed distributed urban drainage models were developed in this research work. These detailed models bring advantages over lumped models, such as being able to identify local flooding and, evaluate performance of individual LIDs etc. By disaggregating catchments into homogeneous area, every natural hydrologic/hydraulic components (e.g: roadside ditches, LIDs) effects were being considered while these effects might be suppressed in lumped models. On the one hand, fine resolution of catchments make the models more complex and requires more development effort if overland flow routing has to be done manually. Hence, an approach to identify outlets automatically for each catchment at lot-level was presented using ArcMap 10.2.

\subsection{Limitations}

The limitations of the work can be described in terms of available input data such as: a single WorldView-2 image to extract land cover information, 5-metre resolution DEM to identify the connectivity between micro-subcatchment, rain gauge data at distances greater than the size of the modelled drainage areas, and the limitations of SWMM ability to model LIDs. Also the condition of deteriorated drainage systems in the study areas also contributed uncertainties in the observed runoff data. 
The image classification process was limited to use only a single WorldView-2 image to classify a residential area, where small heterogeneous land cover types were common. The result of the image classification was then used in urban drainage modelling, where the quality of input imperviousness is related to the model performance. Again, in identifying the most sensitive parameter, a connectivity between catchments, was defined based on an assumption that all water flow towards roads. This assumption was made since a 5-metre resolution DEM was too coarse to utilize in identifying outlets for each subcatchment. The limitation of presented method of outlet identifications is morphology of the study area has a significant impact on this approach of defining the outlet for each subcatchment. For example, in the case of having a front lawn and disconnected-downspout, runoff from building get an opportunity to infiltrate and evapotranspirate; however, a building with a side lawn did not get this benefits of having pervious area within a lot.

Another main driving parameter for rainfall-runoff process, rainfall records, also had some uncertainties since the rain monitoring stations were not located within the catchments. The rainfall records used in this study were recorded by the rain gauge stations located off-site, as far as eight kilometres away from the study catchment areas. Patchy rain or drizzle might have recorded on the rain gauge, but it could be totally dry at the study catchment areas or the vice versa. A comprehensive study of the impact of spatial and temporal resolutions of rain gauge and the effects on the modelling results can be found in Faurès et al. (1995). The current condition of the roadside ditches also contributed to suspicious observed data. Due to these reason, when the models performance was validated with the rainfall events, these situations led to inconsistencies in the observed data. 


\subsection{Recommendations and Future Work}

- The credibility of the observed data should be increased in order to confidently use the observed data in validating the developed models performance. With the more accurate observed data, a meaningful comparison can be made between the observed data and the simulated results from developed models.

- This research and similar studies (Faurès et al., 1995; Beven, 2001; Gilroy and McCuen, 2009; Ghosh and Hellweger, 2011) recommend to use an on-site rain gauge especially for a very small catchment (less than 5 ha). A better delineation of drainage area is associated with a lot of costs, for instance: detailed land cover information, a complex model that requires outlets to be defined for micro-subcatchments, etc. It is meaningful to develop detailed distributed models only if observed data is well representative of site conditions, and the purpose of the study indeed requires detailed models. For example, detailed models would be more valuable to be used in designing LIDs than analyzing urban drainage systems.

- Further studies should consider modelling water quality as well since CVC has collected water quality sampling. With the awareness of water quality issues, the evaluation of LIDs performance should also consist of water quality aspects.

- Utilization of remote sensing data would be more attractive to a large scale projects, where on-screen digitization and field surveying are not practical approaches. As described in this thesis, even if GIS data is available, some manual modifications may require on existing GIS data. In this regard, remote sensing technique would be a better source to obtain land cover information. Remote sensing data, which requires a specialty skillset, can automatically extract the land cover information for a large 
extent. To further improve the image classification accuracy, the following data should be considered in future studies:

o a stereo-pair of very high resolution satellite images should be considered (e.g. WorldView-2 image or more recently launched WorldView-3). From a stereopair images, Digital Surface Model (DSM) in the same resolution as pansharpened image can be generated. That DSM would reduce the confusion between shaded area vs. dark impervious area, which could lead to a higher accuracy in defining imperviousness. Moreover, DSM could be used to produce more precise overland flow paths.

0 an alternative to a pair of satellite image that could be used is Light Detection and Ranging (LiDAR) data to aid in urban land cover classification. LiDAR data is used widely to generate high-quality $3 \mathrm{D}$ topographic surface data. 


\section{Appendices}

\section{A. Training Areas Statistics}

\section{1) Vegetation vs NonVegetation}

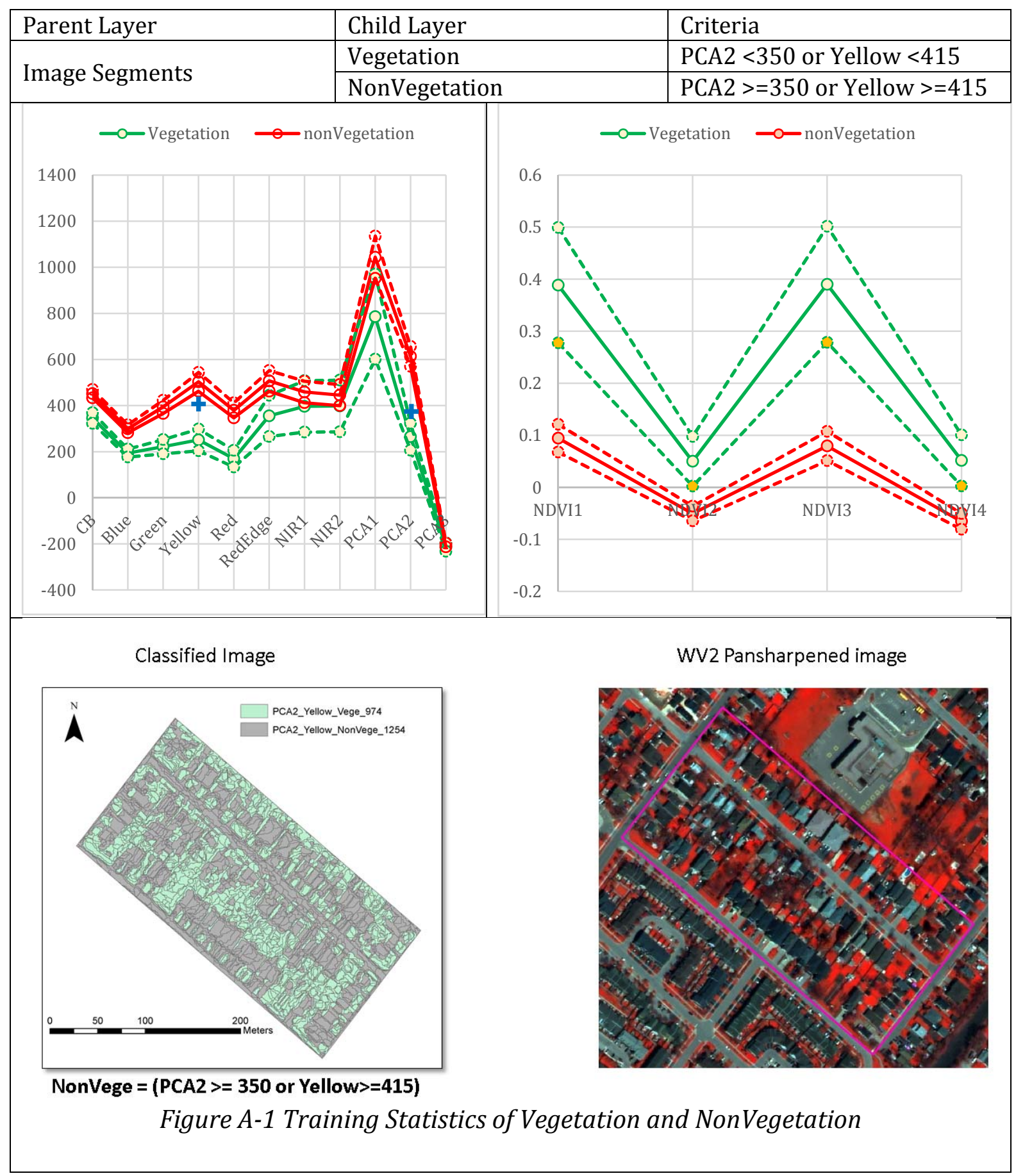




\section{2) Grass vs Tree}

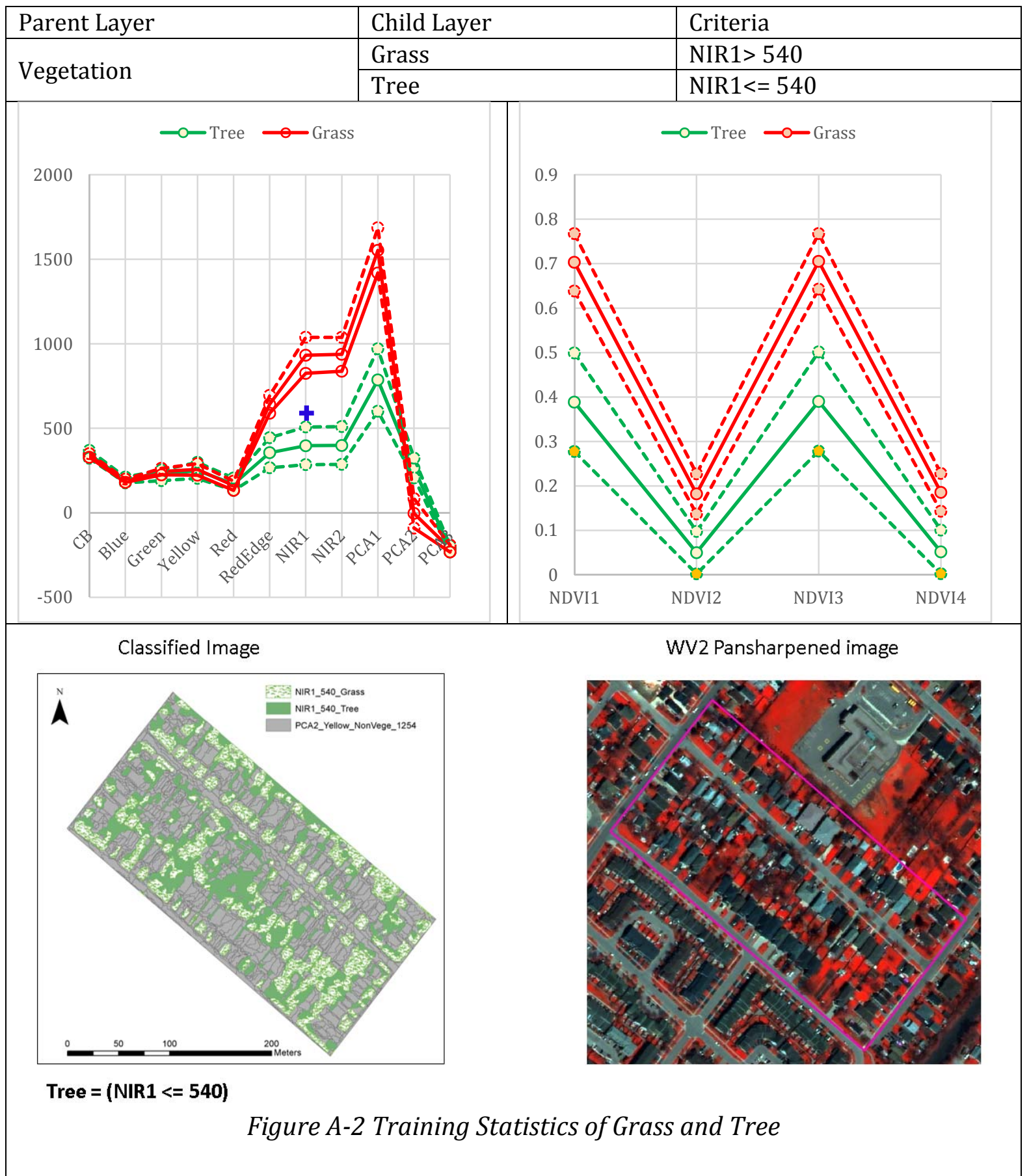




\section{3) Extracting Building 3}

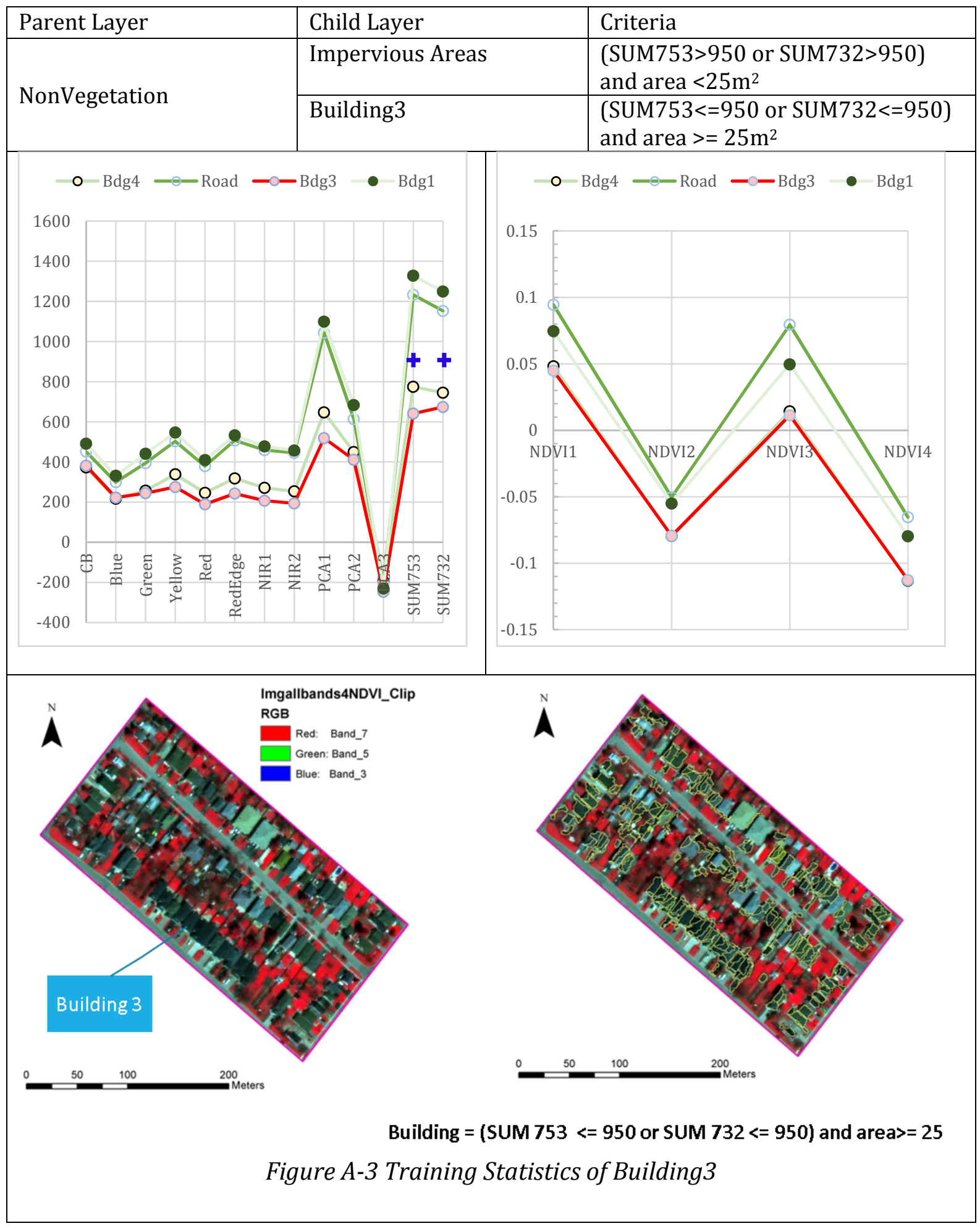




\section{4) Extracting Building 1}
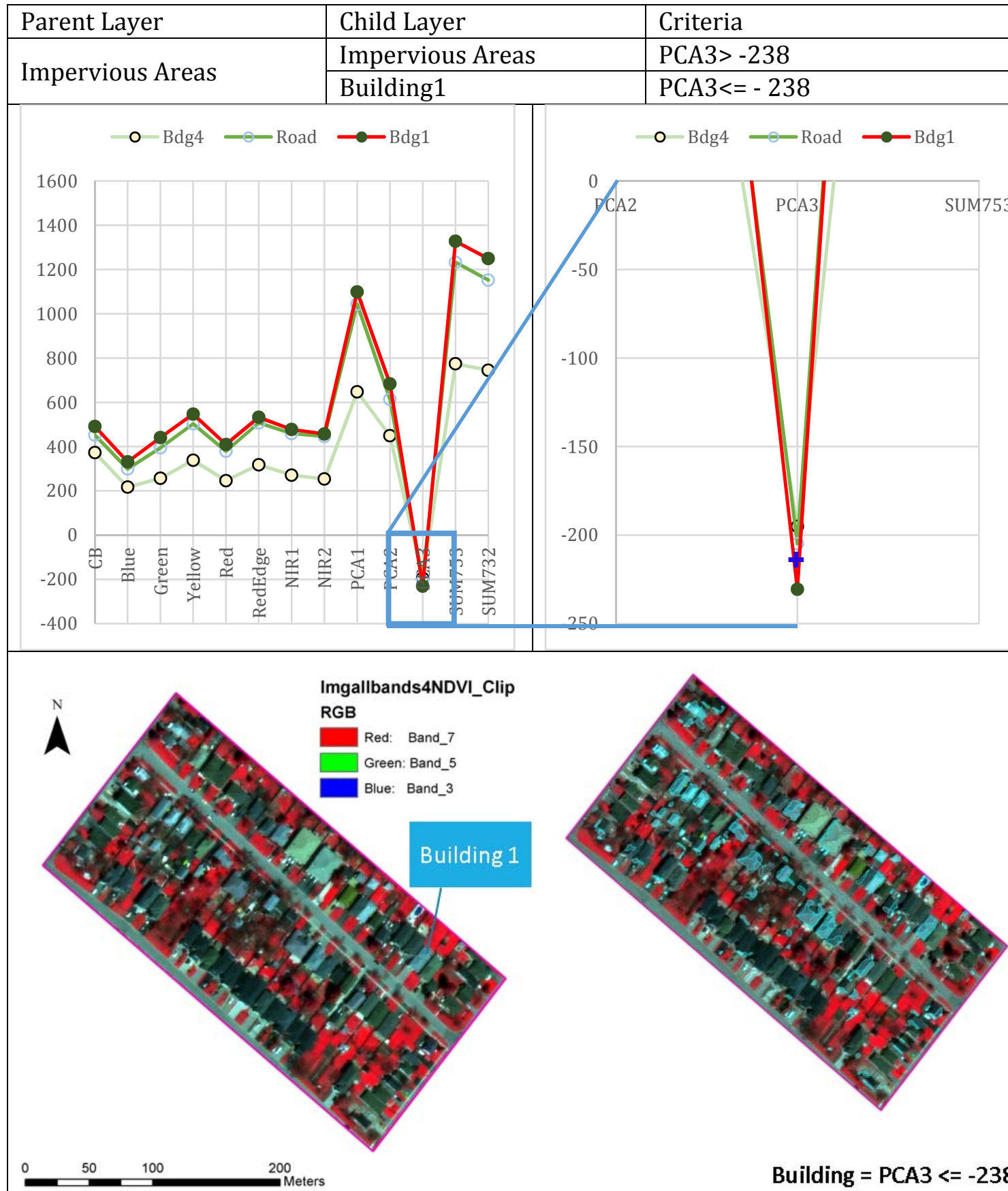

Building $=$ PCA $3<=-238$

Figure A-4 Training Statistics of Building 1 


\section{5) Extracting Building 4}

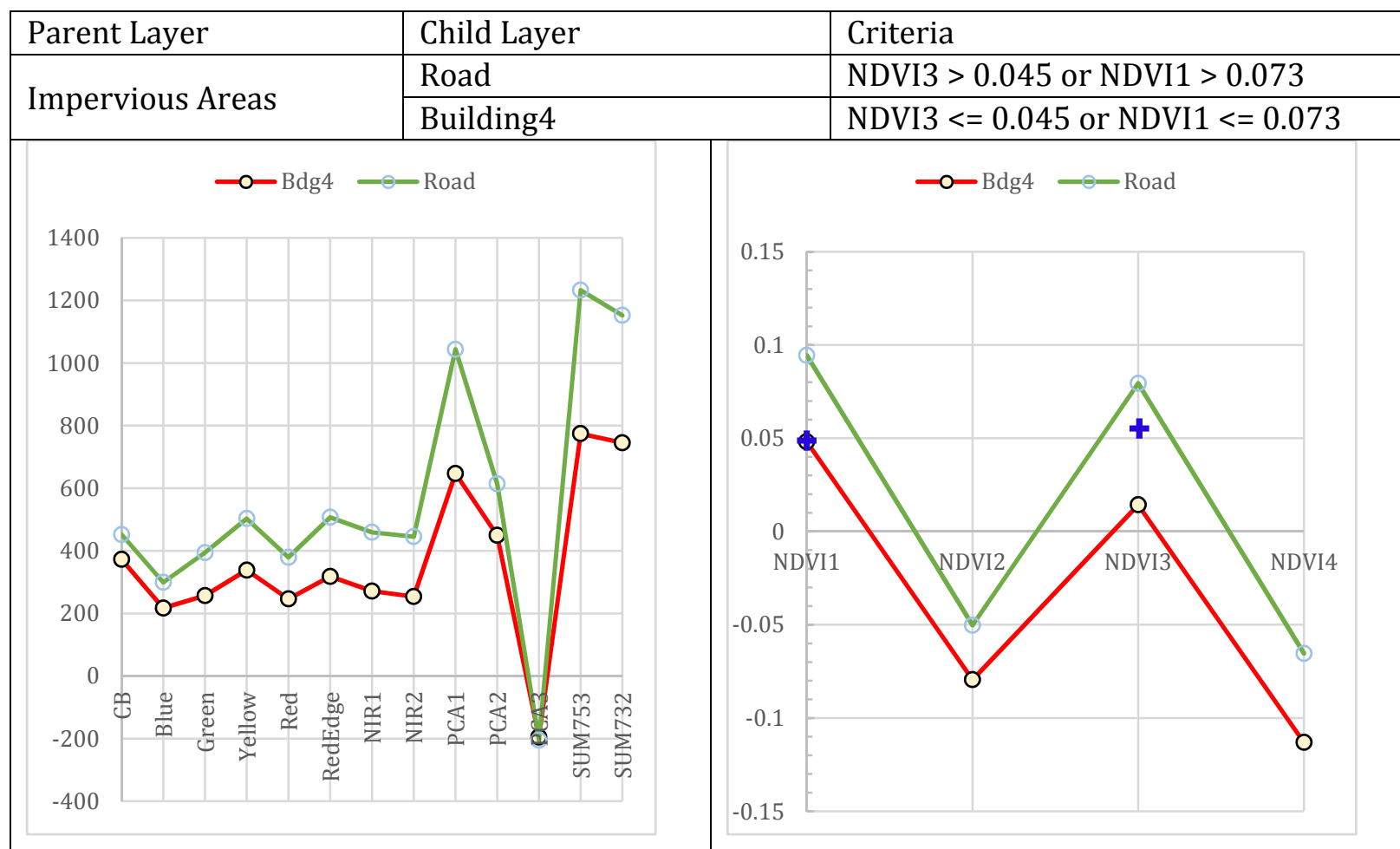
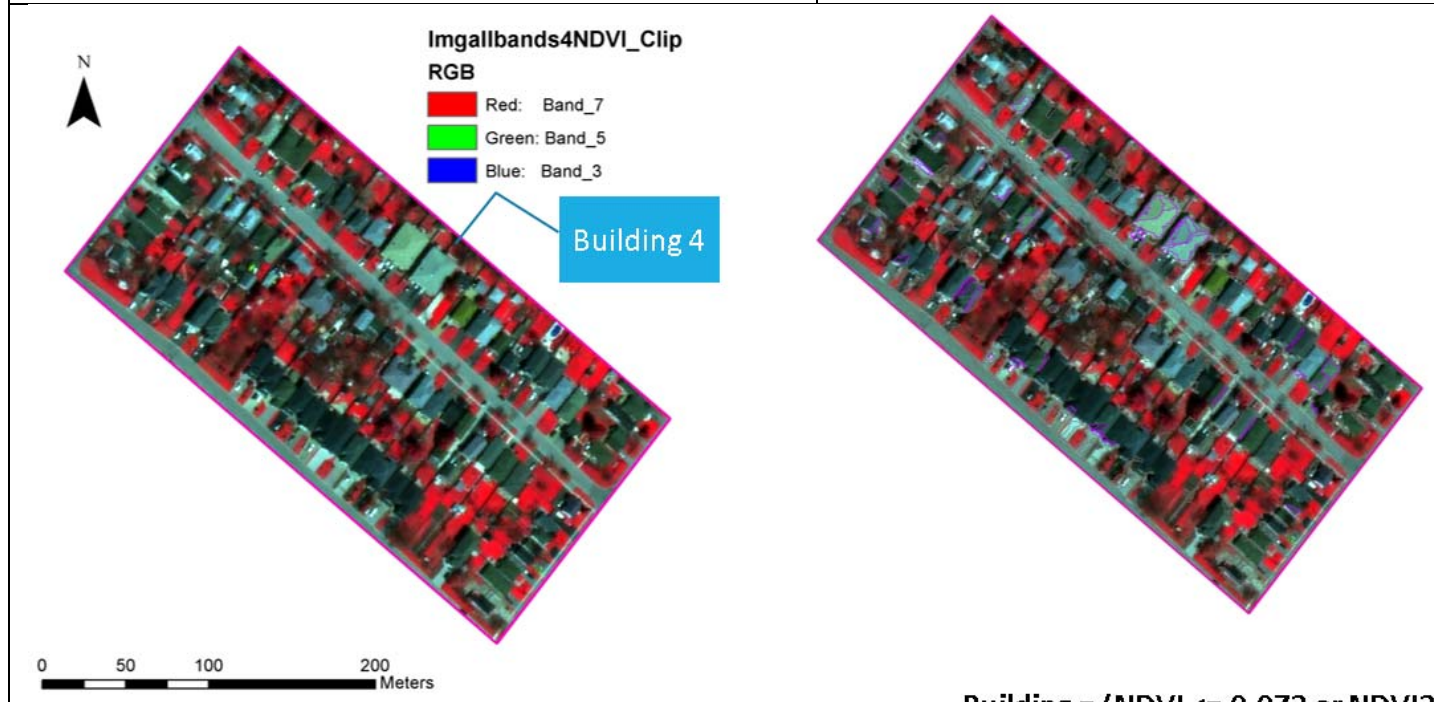

Building $=(\mathrm{NDV} I<=0.073$ or NDVI $3<=0.045)$

Figure A-5 Training Statistics of Building 4 


\section{6) Classified Image}

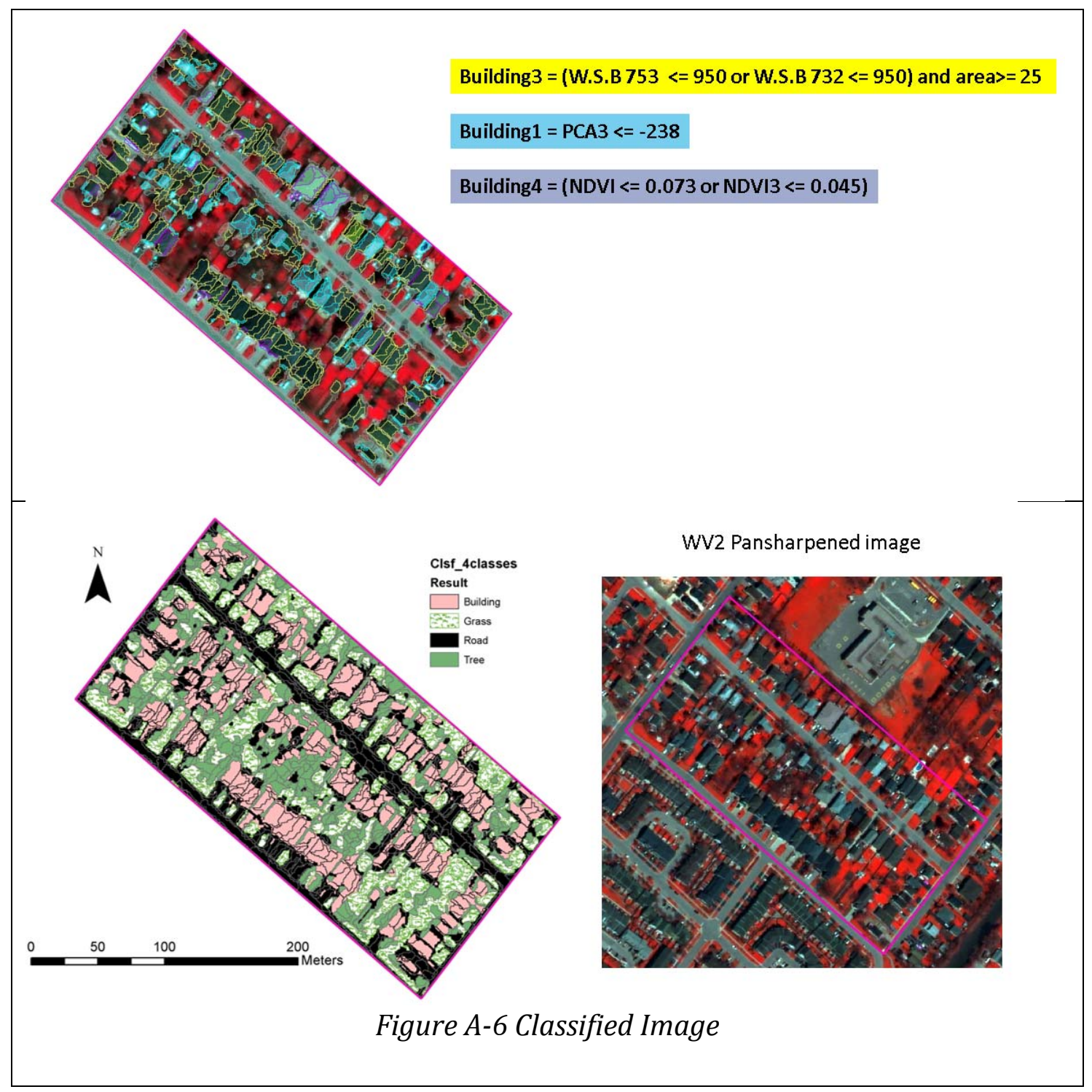


Rules for Identifying a Subcatchment Outlet

Appendix. B

\section{B. Rules for Identifying a Subcatchment Outlet}

Draw a line from each catchment to STM Main

If the STM Main is not at the center of the Road, need to temporarily move it to the center of the Road.

1) Use the "Generate Near Table (Analysis)" Function to generate the Near X, Near Y, Distance, Angle parameters from each polygon to the STM main.

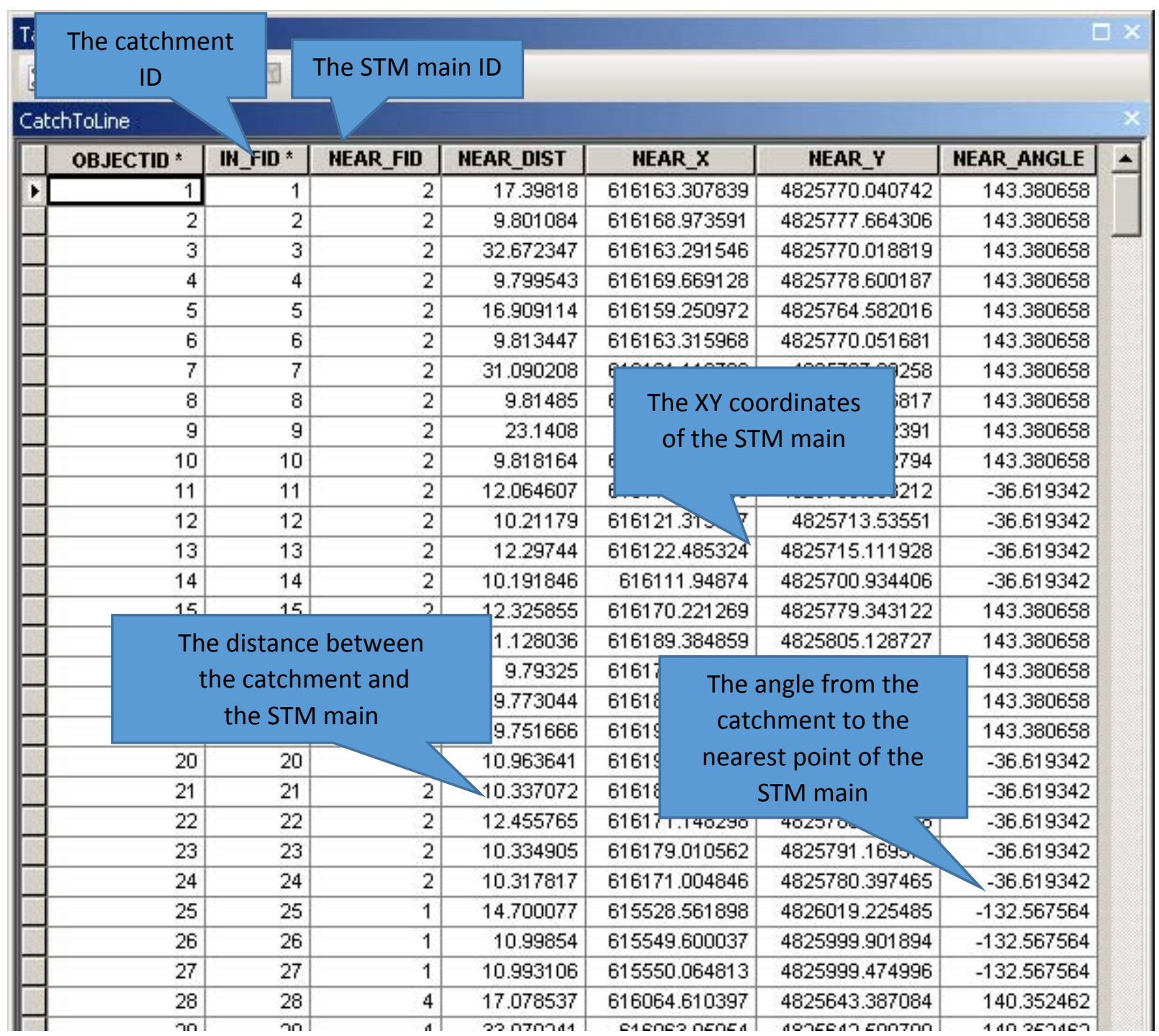

Figure B-1 Output of the Generate Near Table Analysis 
Convert the NEAR_ANGLE column to the equivalent Bearing

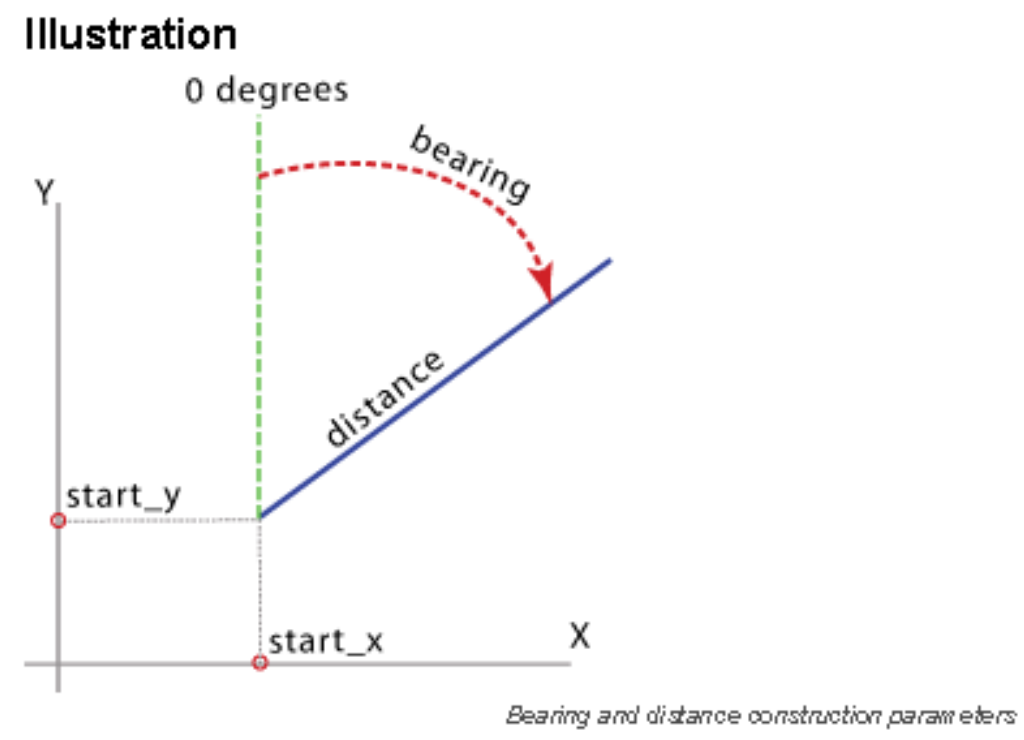

Figure B-2 Conversion of Near Angle to Bearing

http://resources.arcgis.com/en/help/main/10.1/index.html\#//0017000000ts000000 
Breakdown the line into smaller segments with the boundary of the catchment

1) Use the "Intersect (Analysis)" function.

2) The output layer will consist of the intersected portions of the line until it reaches the STM main.

The route to get the STM main for CatchmentID $=184$, it has to pass through these polygons ID $=184,186,398$ and 410.

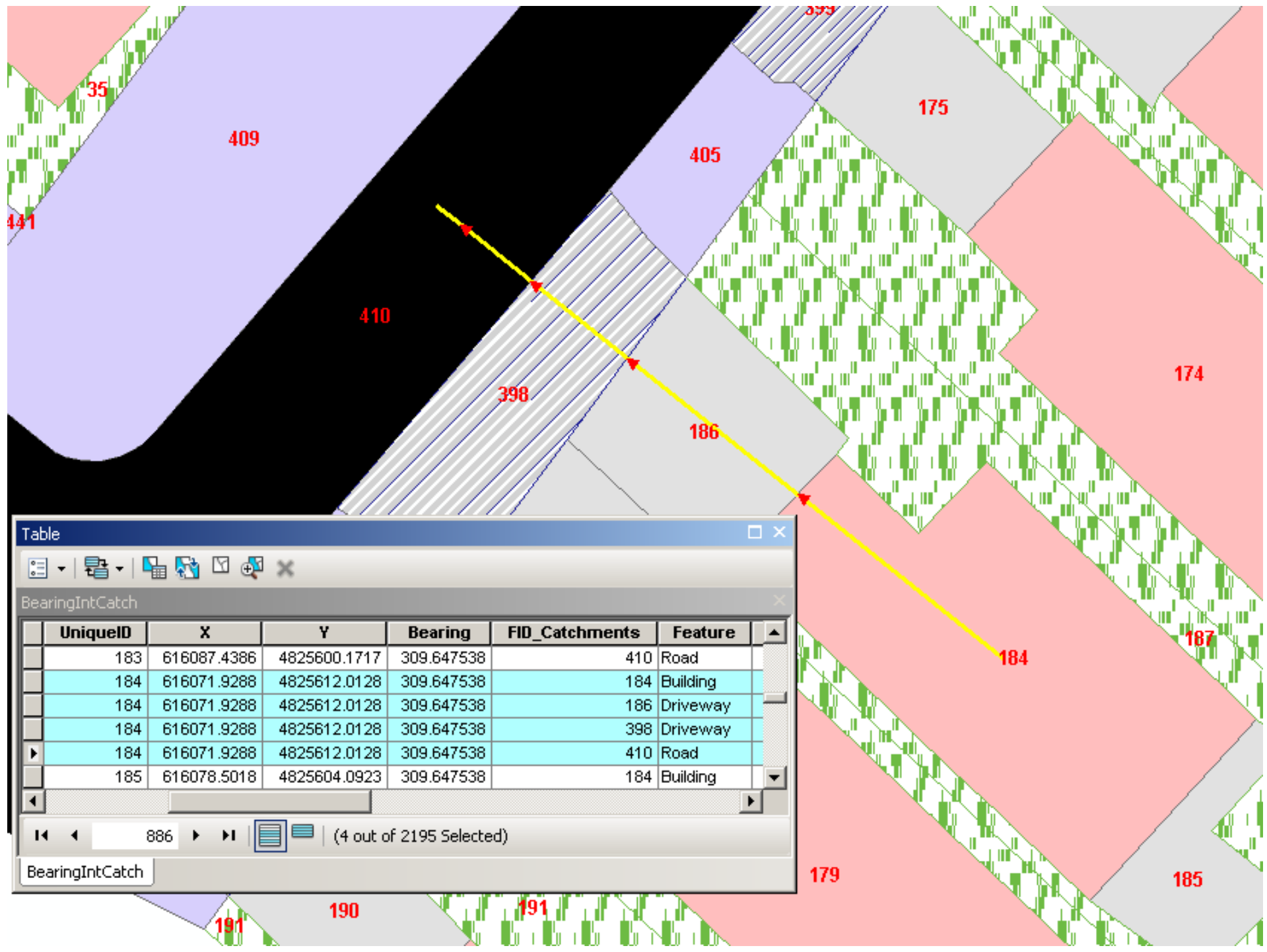

Figure B-3 Output of Intersect (Analysis) function 
Generate the neighbor polygons for each catchment

1) Use the "Polygon Neighbors" function to generate the surrounding polygons of each catchment.

Catchment ID = 184 is surrounded by the following catchments: 185, 186, and 187 .

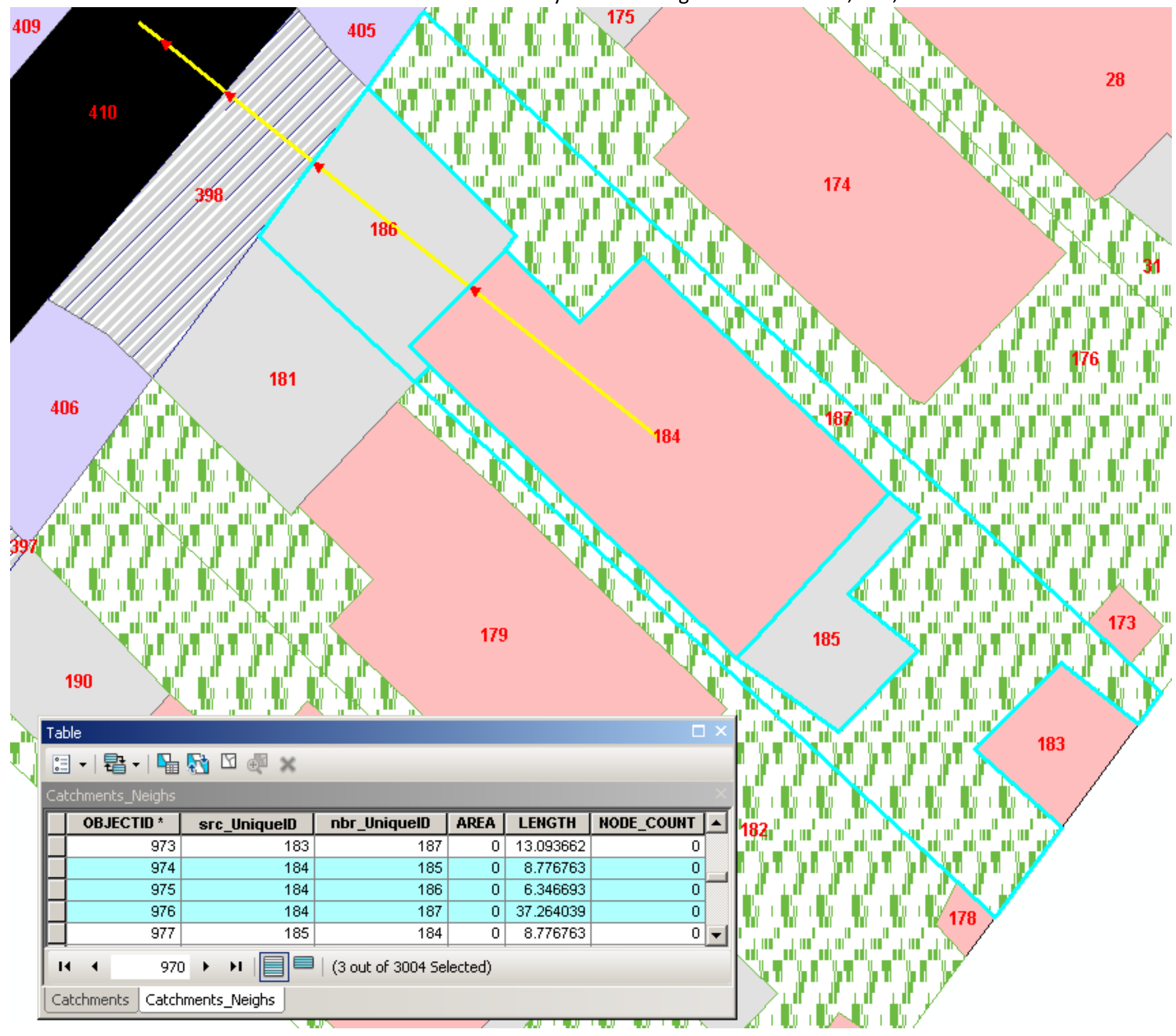

Figure B-4 Output of the Polygon Neighbors Function 


\section{Appendix. C}

\section{Summary of Monitored Rainfall Events in Excess of 30mm}

Site = LV1

\begin{tabular}{|c|c|c|c|c|c|}
\hline Event & Gauge & Date & $\begin{array}{c}\text { Duration } \\
\text { (h) }\end{array}$ & $\begin{array}{c}\text { Total Rainfall } \\
(\mathrm{mm})\end{array}$ & $\begin{array}{c}\text { Observed Flow } \\
\text { Depth }(\mathrm{mm})\end{array}$ \\
\hline 6 & Riverwood & $8 / 21 / 201012: 50$ & 42.25 & 30.1 & 4.717324 \\
\hline 10 & Mississauga Station 01 & $9 / 16 / 20107: 45$ & 13.17 & 32.6 & 3.709063 \\
\hline 26 & Cawthra & $11 / 30 / 20104: 30$ & 37.42 & 32.7 & 5.375242 \\
\hline 40 & Cawthra & $3 / 9 / 2011$ 10:10 & 59.83 & 50.2 & 14.63472 \\
\hline 55 & Cawthra & $5 / 13 / 201118: 20$ & 136.83 & 81.4 & 13.56846 \\
\hline 59 & Cawthra & $5 / 25 / 201118: 20$ & 42.33 & 32.3 & 5.058293 \\
\hline 68 & Cawthra & $8 / 9 / 20114: 50$ & 27.33 & 39.3 & 6.872107 \\
\hline 79 & Cawthra & 9/23/2011 9:20 & 15.33 & 34.9 & 5.186596 \\
\hline 83 & Cawthra & $10 / 12 / 20119: 50$ & 19.33 & 32.9 & 3.798114 \\
\hline 85 & Cawthra & $10 / 18 / 201122: 20$ & 45.58 & 44.3 & 5.794716 \\
\hline 93 & Mississauga Station 03 & $11 / 27 / 20118: 10$ & 82.33 & 52.2 & 9.848263 \\
\hline 127 & Mississauga Station 03 & $6 / 1 / 2012$ 2:45 & 25.08 & 41.3 & 5.54807 \\
\hline 138 & Mississauga Station 03 & $7 / 31 / 201211: 15$ & 13.58 & 34.7 & 4.261527 \\
\hline 146 & Mississauga Station 01 & 9/7/2012 23:30 & 21.42 & 38.4 & 7.539985 \\
\hline 157 & Mississauga Station 01 & $10 / 28 / 20128: 20$ & 114.08 & 51.2 & 8.430488 \\
\hline 169 & Mississauga Station 01 & $1 / 13 / 20132: 00$ & 34.67 & 35.6 & 10.72705 \\
\hline 181 & Mississauga Station 01 & $2 / 26 / 201318: 20$ & 41 & 47.4 & 17.95653 \\
\hline 191 & Mississauga Station 01 & 4/9/2013 14:10 & 30.17 & 35.4 & 7.000996 \\
\hline 206 & Mississauga Station 01 & $5 / 28 / 20134: 55$ & 38 & 31.4 & 6.620189 \\
\hline 209 & Mississauga Station 01 & $6 / 10 / 20136: 50$ & 26.58 & 33 & 6.831097 \\
\hline 221 & Mississauga Station 01 & $7 / 8 / 201315: 15$ & 21.42 & 81.6 & 64.20997 \\
\hline 232 & Mississauga Station 01 & 9/20/2013 21:05 & 25.33 & 34 & 8.418771 \\
\hline 251 & Mississauga Station 01 & $12 / 19 / 201322: 45$ & 65.92 & 43.6 & 4.919445 \\
\hline
\end{tabular}




\section{Summary of Monitored Rainfall Events in Excess of 30mm}

\begin{tabular}{|c|c|c|c|c|c|}
\hline Event\# & Rain Gauge & Date Time & $\begin{array}{l}\text { Duration } \\
\text { (h) }\end{array}$ & $\begin{array}{l}\text { Total Rainfall } \\
(\mathrm{mm})\end{array}$ & $\begin{array}{c}\text { Observed } \\
\text { FlowDepth }(\mathrm{mm})\end{array}$ \\
\hline 6 & Riverwood & $8 / 21 / 201012: 50$ & 42.25 & 30.1 & 0.92550659 \\
\hline 8 & Mississauga Station 01 & $9 / 16 / 20107: 45$ & 13.17 & 32.6 & 1.95494397 \\
\hline 15 & Cawthra & $11 / 30 / 20104: 30$ & 37.42 & 32.7 & 0.814027754 \\
\hline 18 & Cawthra & $3 / 9 / 2011$ 10:10 & 59.83 & 50.2 & 7.339023399 \\
\hline 29 & Cawthra & $5 / 13 / 2011$ 18:20 & 136.83 & 81.4 & 16.62312025 \\
\hline 31 & Cawthra & $5 / 25 / 201118: 20$ & 42.33 & 32.3 & 4.113685188 \\
\hline 39 & Cawthra & $8 / 9 / 20114: 50$ & 27.33 & 39.3 & 3.676479127 \\
\hline 46 & Cawthra & 9/23/2011 9:20 & 15.33 & 34.9 & 3.484294258 \\
\hline 48 & Cawthra & 10/12/2011 9:50 & 19.33 & 32.9 & 0.412181385 \\
\hline 49 & Cawthra & $10 / 18 / 201122: 20$ & 45.58 & 44.3 & 0.544214132 \\
\hline 53 & Mississauga Station 03 & $11 / 27 / 20118: 10$ & 82.33 & 52.2 & 5.022353829 \\
\hline 68 & Mississauga Station 01 & 9/7/2012 23:30 & 21.42 & 38.4 & 0.986471579 \\
\hline 70 & Mississauga Station 01 & $10 / 28 / 20128: 20$ & 114.08 & 51.2 & 3.905823608 \\
\hline 78 & Mississauga Station 01 & $1 / 13 / 20132: 00$ & 34.67 & 35.6 & 10.05632004 \\
\hline 87 & Mississauga Station 01 & $2 / 26 / 201318: 20$ & 41 & 47.4 & 16.20507461 \\
\hline 93 & Mississauga Station 01 & 4/9/2013 14:10 & 30.17 & 35.4 & 6.410033095 \\
\hline 102 & Mississauga Station 01 & $5 / 28 / 20134: 55$ & 38 & 31.4 & 6.473901179 \\
\hline 105 & Mississauga Station 01 & $6 / 10 / 20136: 50$ & 26.58 & 33 & 5.404401092 \\
\hline 115 & Mississauga Station 01 & $7 / 8 / 201315: 15$ & 21.42 & 81.6 & 81.40277536 \\
\hline 122 & Mississauga Station 01 & 9/20/2013 21:05 & 25.33 & 34 & 0.161702375 \\
\hline 129 & Mississauga Station 01 & $12 / 19 / 201322: 45$ & 65.92 & 43.6 & 0.417581141 \\
\hline
\end{tabular}




\section{Bibliography}

Abbott, M. B., Bathurst, J. C., Cunge, J. A., O'Connell, P. E., and Rasmussen, J.,1986. An introduction to the European Hydrological System-Systeme Hydrologique Europeen, "SHE", 2: Structure of a physically-based, distributed modelling system. Journal of Hydrology, 87(1), 61-77.

Abida, H. and Ellouze, M., 2006. Hydrological delineation of homogeneous regions in Tunisia. Water Resources Management, 20 (6), 961-977.

Ahmad, S., Kalra, A., and Stephen, H., 2010. Estimating soil moisture using remote sensing data: a machine learning approach. Advances in Water Resources, 33 (1), 69-80.

Alam, Z 2014, Utilizing GIS in the development of detailed distribution urban drainage models. MASc thesis, Ryerson University.

Alig, R.J., Kline, J.D., and Lichtenstein, M., 2004. Urbanization on the US landscape: looking ahead in the 21st century. Landscape and Urban Planning, 69 (2), 219-234.

Belgiu, M., Drgu,t, L., and Strobl, J., 2014. Quantitative evaluation of variations in rule-based classifications of land cover in urban neighbourhoods using WorldView-2 imagery. ISPRS Journal of Photogrammetry \& Remote Sensing, 87, 205-215.

Bellal, M., Sillen, X., and Zech, Y., 1996. Coupling GIS with a distributed hydrological model for studying the effect of various urban planning options on rainfall-runoff relationship in urbanized watersheds. IAHS Publications-Series of Proceedings and Reports-Intern Assoc Hydrological Sciences, 235, 99-106.

Beven, K., 2001. Dalton Medal Lecture: How far can we go in distributed hydrological modelling? Hydrology and Earth System Sciences, 5 (1), 1-12.

Beven, K.J., 2011. Rainfall-runoff modelling: the primer. John Wiley \& Sons.

Blaschke, T., 2010. Object based image analysis for remote sensing. ISPRS Journal of Photogrammetry \& Remote Sensing, 65 (1), 2-16.

Canters, F., Batelaan, O., de Voorde, T. V., Chormański, J., and Verbeiren, B., 2011. Use of impervious surface data obtained from remote sensing in distributed hydrological modeling of urban areas. Urban Remote Sensing: Monitoring, Synthesis and Modeling in the Urban Environment, 255-273.

Carlson, T.N. and Ripley, D.A., 1997. On the relation between NDVI, fractional vegetation cover, and leaf area index. Remote sensing of Enviornment, 62 (3), 241-252.

Chen, D. and Stow, D., 2002. The effect of training strategies on supervised classification at different spatial resolutions. Photogrammetric Engineering and Remote Sensing, 68 (11), 1155-1162. 
Coppin, P.R. and Bauer, M.E., 1996. Digital change detection in forest ecosystems with remote sensing imagery. Remote Sensing Reviews, 13 (3-4), 207-234.

D'Arcy, B. and Frost, A., 2001. The role of best management practices in alleviating water quality problems associated with diffuse pollution. Science of the Total Environment, 265 (1), 359-367.

Dare, P.M., 2005. Shadow analysis in high-resolution satellite imagery of urban areas. Photogrammetric Engineering \& Remote Sensing, 71 (2), 169-177.

Davis, A.P., 2008. Field performance of bioretention: Hydrology impacts. Journal of Hydrologic Engineering, 13 (2), 90-95.

Dietz, M.E., 2007. Low impact development practices: A review of current research and recommendations for future directions. Water, Air, and Soil Pollution, 186 (1-4), 351363.

Eckert, S., 2012. Improved forest biomass and carbon estimations using texture measures from WorldView-2 satellite data. Remote Sensing, 4 (4), 810-829.

Elgy, J., 2001. Airborne remote sensing for urban drainage. Urban Water, 3 (4), 287-297.

Elliott, A. and Trowsdale, S., 2007. A review of models for low impact urban stormwater drainage. Environmental Modelling \& Software, 22 (3), 394-405.

Everitt, J. H., Yang, C., Fletcher, R., and Deloach, C. J., 2008. Comparison of QuickBird and SPOT 5 satellite imagery for mapping giant reed. Journal of Aquatic Plant Management, 46, 77.

Faurès, J. M., Goodrich, D. C., Woolhiser, D. A., and Sorooshian, S., 1995. Impact of small-scale spatial rainfall variability on runoff modeling. Journal of Hydrology, 173(1), 309-326.

Foley, J. A., DeFries, R., Asner, G. P., Barford, C., Bonan, G., Carpenter, S. R., Chapin, F.S., Coe, M.T., Daily, G.C., Gibbs, H.K., Helkowski, J.H., Holloway, T., Howard, E.A., Kucharik.C.J., Monfreda, C., Patz, J.A., Prentice, I.C., Ramankutty, N and Snyder, P. K., 2005. Global consequences of land cover. Science, 309 (5734), 570-574.

Ghosh, I., and Hellweger, F. L., 2011. Effects of spatial resolution in urban hydrologic simulations. Journal of Hydrologic Engineering, 17(1), 129-137.

Gilroy, K. L., and McCuen, R. H., 2009. Spatio-temporal effects of low impact development practices. Journal of Hydrology, 367(3), 228-236.

Gironás, J., Roesner, L. A., Davis, J., and Rossman, L. A., 2009. Storm water management model applications manual. National Risk Management Research Laboratory, Office of Research and Development, US Environmental Protection Agency.

Goldstein, A.E 2011, Comparison of a high and low spatial resolution model for an urban block and implications for depicting low impact development. MSc Thesis, Drexel University 
Guo, Q., Kelly, M., Gong, P., and Liu, D., 2007. An object-based classification approach in mapping tree mortality using high spatial resolution imagery. GIScience \& Remote Sensing, 44(1), 24-47.

Ha, S., Park, S., and Park, D., 2003. Estimation of urban runoff and water quality using remote sensing and artificial intelligence. Water Science \& Technology, 47 (7-8), 319-325.

Hatt, B. E., Fletcher, T. D., Walsh, C. J., and Taylor, S. L., 2004. The influence of urban density and drainage infrastructure on the concentrations and loads of pollutants in small streams. Environmental Management, 34 (1), 112-124.

Hood, M.J., Clausen, J.C., and Warner, G.S., 2007. Comparison of Stormwater Lag Times for Low Impact and Traditional Residential Development. Journal of the American Water Resources Association, 43 (4).

Huang, C., Davis, L., and Townshend, J., 2002. An assessment of support vector machines for land cover classification. International Journal of Remote Sensing, 23 (4), 725-749.

Jacobson, C.R., 2011. Identification and quantification of the hydrological impacts of imperviousness in urban catchments: A review. Journal of Environmental Management, 92 (6), 1438-1448.

Jawak, S.D. and Luis, A.J., 2013. Improved land cover mapping using high resolution multiangle 8-band WorldView-2 satellite remote sensing data. Journal of Applied Remote Sensing, 7 (1).

Jensen, C.A., Quinn, R.J., and Davis, T.H., 2010. Urban watershed management: using remote sensing to implement low impact development. Infrastructure Systems and Services: Next Generation Infrastructure Systems for Eco-Cities (INFRA), 2010 Third International Conference 1-6.

Jensen, J.R., 2005. Introductory Digital Image Processing: A Remote Sensing Perspective. Ed. 3 Prentice-Hall Inc.

Jia, X. and Richards, J.A., 1999. Segmented principal components transformation for efficient hyperspectral remote-sensing image display and classification. IEEE Transactions on Geoscience and Remote Sensing, 37 (1), 538-542.

Krebs, G., Kokkonen, T., Valtanen, M., Koivusalo, H., and Setälä, H., 2013. A high resolution application of a stormwater management model (SWMM) using genetic parameter optimization. Urban Water Journal, 10(6), 394-410.

Lee, M., Park, G., Park, M., Park, J., Lee, J., and Kim, S., 2010. Evaluation of non-point source pollution reduction by applying Best Management Practices using a SWAT model and QuickBird high resolution satellite imagery. Journal of Environmental Sciences, 22 (6), 826-833.

Leopold,L.B., 1968. Hydrology for urban land planning: A guidebook on the hydrologic effects of urban land cover. 
Li, J., Orland, R., and Hogenbirk, T., 1998. Environmental road and lot drainage designs: alternatives to the curb-gutter-sewer system. Canadian Journal of Civil Engineering, 25(1), 26-39.

Liu, Y., Guo, Q., and Kelly, M., 2008. A framework of region-based spatial relations for nonoverlapping features and its application in object based image analysis. ISPRS Journal of Photogrammetry and Remote Sensing, 63(4), 461-475.

Lu, D. and Weng, Q., 2009. Extraction of urban impervious surfaces from an IKONOS image. International Journal of Remote Sensing, 30 (5), 1297-1311.

Luciani, P.D., Li, J.Y., and Banting, D., 2011. Distributed urban storm water modeling within GIS integrating analytical probabilistic hydrologic models and remote sensing image analyses. Water Quality Research Journal of Canada, 46 (3), 183-199.

Montalto, F., Behr, C., Alfredo, K., Wolf, M., Arye, M., and Walsh, M., 2007. Rapid assessment of the cost-effectiveness of low impact development for CSO control. Landscape and Urban Planning, 82 (3), 117-131.

Montgomery, D.R. and Foufoula-Georgiou, E., 1993. Channel network source representation using digital elevation models. Water Resources Research, 29 (12), 3925-3934.

Moore, I.D., Grayson, R., and Ladson, A., 1991. Digital terrain modelling: a review of hydrological, geomorphological, and biological applications. Hydrological Processes, 5 (1), 3-30.

Myint, S. W., Gober, P., Brazel, A., Grossman-Clarke, S., and Weng, Q. ., 2011. Per-pixel vs. object-based classification of urban land cover extraction using high spatial resolution imagery. Remote Sensing of Environment, 115 (5), 1145-1161.

Nosetto, M. D., Jobbágy, E. G., Brizuela, A. B., and Jackson, R. B., 2012. The hydrologic consequences of land cover change in Central Argentina. Agriculture, Ecosystems \& Environment, 154, 2-11.

O'Callaghan, J.F. and Mark, D.M., 1984. The extraction of drainage networks from digital elevation data. Computer Vision, Graphics, and Image Processing, 28 (3), 323-344.

Ontario Ministry of the Environment (MOE). 2003. Stormwater Management Planning and Design Manual.

Ontario Ministry of the Environment and Ministry of Natural Resources (MOE-MNR). 1991. Interim Stormwater Quality Guidelines for New Development. Prepared by Water Resources Branch and both Central Regions of MOE and MNR.

Owens, P.N. and Walling, D.E., 2002. The phosphorus content of fluvial sediment in rural and industrialized river basins. Water Research, 36 (3), 685-701.

Padwick, C., Deskevich, M., Pacifici, F., and Smallwood, S., 2010. WorldView-2 pansharpening. Proc. American Society for Photogrammetry \& Remote Sensing, p. 13. 
Paudel, M., 2010. An examination of distributed hydrologic modeling methods as compared with traditional lumped parameter approaches. Ph.D dissertation, Brigham Young University.

$\mathrm{Pu}, \mathrm{R}$. and Landry, S., 2012. A comparative analysis of high spatial resolution IKONOS and WorldView-2 imagery for mapping urban tree species. Remote Sensing of Environment, 124, 516-533.

Pullar, D. and Springer, D., 2000. Towards integrating GIS and catchment models. Environmental Modelling \& Software, 15 (5), 451-459.

Reed, S., Koren, V., Smith, M., Zhang, Z., Moreda, F., Seo, D. J., and DMIP Participants. 2004. Overall distributed model intercomparison project results. Journal of Hydrology, 298 (1), 27-60.

Refsgaard, J.C., 1997. Parameterisation, calibration and validation of distributed hydrological models. Journal of Hydrology, 198 (1-4), 69-97.

Rossman, L.A., 2010. Storm Water Management Model User's Manual, Version 5.0. National Risk Management Research Laboratory, Office of Research and Development, US Environmental Protection Agency.

Rushton, B.T., 2001. Low-impact parking lot design reduces runoff and pollutant loads. Journal of Water Resources Planning and Management, 127 (3), 172-179.

Salehi, B., Zhang, Y., and Zhong, M., 2012. Automatic moving vehicles information extraction from single-pass WorldView-2 imagery. IEEE Journal of Selected Topics in Applied Earth Observations and Remote Sensing, 5 (1), 135-145.

Shackelford, A.K. and Davis, C.H., 2003. A hierarchical fuzzy classification approach for highresolution multispectral data over urban areas. IEEE Transactions on Geoscience \& Remote Sensing, 41 (9), 1920-1932.

Smith, D., Li, J., and Banting, D., 2005. A PCSWMM/GIS-based water balance model for the Reesor Creek watershed. Atmospheric Research, 77 (1), 388-406.

Song, Y., Wang, J., Yang, K., Ma, M., Li, X., Zhang, Z., and Wang, X., 2012. A revised surface resistance parameterisation for estimating latent heat flux from remotely sensed data. International Journal of Applied Earth Observation and Geoinformation, 17, 7684.

Stow, D. A., Hope, A., McGuire, D., Verbyla, D., Gamon, J., Huemmrich, F., Houston, S., Racine, C., Sturm, M., Tape, K., Hinzman, L., Yoshikawa, K., Tweedie, C., Noyle, B., Silapaswan, C., Douglas, D., Griffith, B., Jia, G., Epstein, H., Walker, D., Daeschner, S., Petersen, A., Zhou, L., and Myneni, R., 2004. Remote sensing of vegetation and land-cover change in Arctic Tundra Ecosystems. Remote Sensing of Environment, 89 (3), 281-308.

Sugumaran, R., Pavuluri, M.K., and Zerr, D., 2003. The use of high-resolution imagery for identification of urban climax forest species using traditional and rule-based classification approach. IEEE Transactions on Geoscience \& Remote Sensing, 41 (9), 1933-1939. 
Sui, D. and Maggio, R., 1999. Integrating GIS with hydrological modeling: practices, problems, and prospects. Computers, Environment and Urban Systems, 23 (1), 33-51.

Thanapura, P., Helder, D. L., Burckhard, S., Warmath, E., O’Neill, M., and Galster, D., 2007. Mapping urban land cover using QuickBird NDVI and GIS spatial modeling for runoff coefficient determination. Photogrammetric Engineering \& Remote Sensing, 73 (1), 57.

Tong, X., Liu, S., and Weng, Q. 2010. Bias-corrected rational polynomial coefficients for high accuracy geo-positioning of QuickBird stereo imagery. ISPRS Journal of Photogrammetry and Remote Sensing, 65(2), 218-226.

Turcotte, R., Fortin, J. P., Rousseau, A. N., Massicotte, S., and Villeneuve, J. P., 2001. Determination of the drainage structure of a watershed using a digital elevation model and a digital river and lake network. Journal of Hydrology, 240 (3), 225-242.

Walter, V., 2004. Object-based classification of remote sensing data for change detection. ISPRS Journal of Photogrammetry \& Remote Sensing, 58 (3), 225-238.

Weng, Q., 2009. Thermal infrared remote sensing for urban climate and environmental studies: Methods, applications, and trends. ISPRS Journal of Photogrammetry \& Remote Sensing, 64 (4), 335-344.

Weng, Q., 2012. Remote sensing of impervious surfaces in the urban areas: Requirements, methods, and trends. Remote Sensing of Environment, 117, 34-49.

White, M.D. and Greer, K.A., 2006. The effects of watershed urbanization on the stream hydrology and riparian vegetation of Los Penasquitos Creek, California. Landscape and Urban Planning, 74 (2), 125-138.

Wilson, C.B., Valdes, J.B., and Rodriguez-Iturbe, I., 1979. On the influence of the spatial distribution of rainfall on storm runoff. Water Resources Research, 15 (2), 321-328.

Xiao, Q., McPherson, E. G., Simpson, J. R., and Ustin, S. L., 2007. Hydrologic processes at the urban residential scale. Hydrological processes, 21 (16), 2174-2188.

Yan, W.Y. and Shaker, A., 2011. The effects of combining classifiers with the same training statistics using Bayesian decision rules. International Journal of Remote Sensing, 32 (13), 3729-3745.

Yang, L., Xian, G., Klaver, J. M., and Deal, B., 2003. Urban land-cover change detection through sub-pixel imperviousness mapping using remotely sensed data. Photogrammetric Engineering \& Remote Sensing, 69 (9), 1003-1010.

Zhang, W. and Montgomery, D.R., 1994. Digital elevation model grid size, landscape representation, and hydrologic simulations. Water Resources Research, 30 (4), 10191028.

Zhang, Y., Odeh, I.O., and Han, C., 2009. Bi-temporal characterization of land surface temperature in relation to impervious surface area, NDVI and NDBI, using a sub-pixel image analysis. International Journal of Applied Earth Observation and Geoinformation, 11 (4). 256-264. 
Zhang, Y., 2004. Understanding image fusion. Photogrammetric Engineering and Remote Sensing, 70 (6), 657-661. 